\title{
The Relationship Amongst Faith, Perceived Discrimination, Sexuality Acceptance, and Psychological Well-Being in Black Sexual Minority Individuals
}

\author{
Sandra Fanning \\ scf0008@mix.wvu.edu
}

Follow this and additional works at: https://researchrepository.wvu.edu/etd

Part of the Counseling Psychology Commons

\footnotetext{
Recommended Citation

Fanning, Sandra, "The Relationship Amongst Faith, Perceived Discrimination, Sexuality Acceptance, and Psychological Well-Being in Black Sexual Minority Individuals" (2021). Graduate Theses, Dissertations, and Problem Reports. 8319.

https://researchrepository.wvu.edu/etd/8319

This Dissertation is protected by copyright and/or related rights. It has been brought to you by the The Research Repository @ WVU with permission from the rights-holder(s). You are free to use this Dissertation in any way that is permitted by the copyright and related rights legislation that applies to your use. For other uses you must obtain permission from the rights-holder(s) directly, unless additional rights are indicated by a Creative Commons license in the record and/ or on the work itself. This Dissertation has been accepted for inclusion in WVU Graduate Theses, Dissertations, and Problem Reports collection by an authorized administrator of The Research Repository @ WVU. For more information, please contact researchrepository@mail.wvu.edu.
} 
The Relationship Amongst Faith, Perceived Discrimination, Sexuality Acceptance, and Psychological Well-Being in Black Sexual Minority Individuals

Sandra Fanning 
The Relationship Amongst Faith, Perceived Discrimination, Sexuality Acceptance, and Psychological Well-Being in Black Sexual Minority Individuals Sandy C. Fanning M.S.

Dissertation submitted

To the College of Education and Human Services

At West Virginia University

\author{
In partial fulfillment of the requirements for the degree of \\ Doctor of Philosophy in \\ Counseling Psychology \\ Lisa F. Platt, Ph.D., Chair \\ Jeffrey Daniels, Ph.D. \\ Jonathan Hall, Ph.D. \\ Abhik Roy, Ph.D.
}

Department of Counseling and Learning Sciences

Morgantown, West Virginia

2021

Keywords: psychological well-being, sexual minority individuals, Black/African American Copyright: 2021 Sandy C. Fanning 


\begin{abstract}
The Relationship Amongst Faith, Perceived Discrimination, Sexuality Acceptance, and Psychological Well-Being in Black Sexual Minority Individuals Sandy C. Fanning M.S.
\end{abstract}

The present study explored the relationship amongst faith, internalized homophobia, outness, perceived discrimination, and psychological well-being in Black sexual minorities (BSM). BSM participants $(N=211)$ completed an online survey assessing these variables. The result of this study indicate that faith is not related to internalized homophobia, outness, perceived discrimination, or psychological well-being in BSM individuals. However, internalized homophobia, outness, and perceived discrimination all independently predict psychological wellbeing. Explicitly, greater reports of internalized homophobia, outness, and perceived discrimination predicted worse psychological well-being in participants. However, the effects of internalized homophobia and outness were no longer present when accounting for perceived discrimination, suggesting the perceived discrimination mediates the relationship between internalized homophobia, outness, and psychological well-being. Exploratory analyses revealed gender differences in psychological well-being, discrimination within the Black community, and outness. 


\section{DEDICATION}

\section{B R E O N N A T A Y L O R}

ERIC GARNER - JOHN CRAWFORD III - MICHAEL BROWN - EZELL FORD DANTE PARKER - MICHELLE CUSSEAUX - LAQUAN MCDONALD - TANISHA ANDERSON - AKAI GURLEY - TAMIR RICE - RUMAIN BRISBON - JERAME REID - GEORGE MANN - MATTHEW AJIBADE - FRANK SMART - NATASHA MCKENNA - TONY ROBINSON - ANTHONY HILL - MYA HALL - PHILLIP WHITE - ERIC HARRIS - WALTER SCOTT - WILLIAM CHAPMAN II - ALEXIA CHRISTIAN - BRENDON GLENN - VICTOR MANUEL LAROSA - JONATHAN SANDERS - FREDDIE BLUE - JOSEPH MANN - SALVADO ELLSWOOD SANDRA BLAND - ALBERT JOSEPH DAVIS - DARRIUS STEWART - BILLY RAY DAVIS - SAMUEL DUBOSE DAY CHRISTIAN TAYLOR PHAROAH MANLEY - FELIX MCLEOD - JUNIOR JONES - PATERSON HUTCHINSON ALONZO SMITH MICHAEL SABBIE - BRIAN KEITH TROY ROBINSON ASSHAMS KUMI - KEITH HARRISON PROSPER LAMONTEZ BROWN - DOMINIC ANTHONY ASHFORD TYREE CRAWFORD - INDIA KAGER - MICHAEL LEE JAMAR CLARK PERKINS PICKETT - BENNI LEE ESPINAL - MICHAEL MATTHEWS BETTIE JONES KEITH CHILDRESS JR. JANET ANTRONIE SCOTT - WENDELL LA'VANTE BIGGS MARSHALL RICHARD NATHANIEL HARRIS MATTER CALIN ROQUEMORE - DYZHAWN

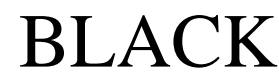
LIVES MARCO LOUD - PETER GAINES TORREY ROBINSON - DARIUS ROBINSON KEVIN HICKS - MARY TRUXILLO - DEMARCUS SEMER - WILLIE TILLMAN TERRILL THOMAS - SYLVILLE SMITH - ALTON STERLING - PHILANDO CASTILE - TERENCE CRUTCHER - PAUL O'NEAL - ALTERIA WOODS JORDAN EDWARDS - AARON BAILEY - RONELL FOSTER STEPHON CLARK - ANTWON ROSE II - BOTHAM JEAN - PAMELA TURNER - DOMINIQUE CLAYTON TATIANA JEFFERSON CHRISTOPHER WHITFIELD - CHRISTOPHER MCCORVEY - ERIC REASON - MICHAEL LORENZO DEAN

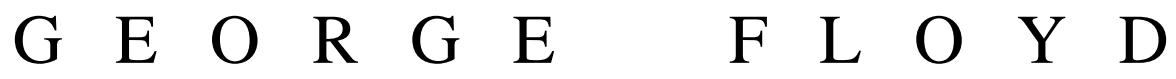




\section{ACKNOWLEDGMENTS}

First and foremost, I would like to thank Jesus Christ, my lord and savior for bring me through this trattorias time that is grad school. Through you, all things are possible.

To my foster mom, Lenora Hines, for showing me the true meaning of unconditional love, for introducing me to Christ, and for being a true angel. Your presence is truly missed and I will hold you in my heart every day for the rest of my life.

To my advisor and chair, Lisa Platt, for providing support and encouragement throughout my doctorate. You said it would all be worth it. I'm not sure if that is true at the moment but I will let you know in 5 years or so. Either way, thank you for pushing me to continue.

To my committee members Jeffery Daniels and Abhik Roy for your patience and support throughout my academic career and dissertation. I know I can be a wild card. I pride myself on that.

To Jonathan Hall for being a source of light during dark times, a mentor and providing guidance, and for listening to me during my many rants. I appreciate you.

To Southern Regional Education Board (SREB) for support throughout my doctorate.

To my best friend Winnie for helping me through life and sticking by my side since high school. For being an all-around decent human. Words could never convey my gratitude for the love and support you have extended me over the years and so I shall pay you back, every day of my life by getting on your last nerve, respectfully.

To my close friends Devlyn, Janine, and Natty, thank you for always believing in me even when I did not believe in myself. Thank you for the laughs that helped brighten my days.

To my loved ones, family and friends, who have helped along the way, thank you.

To Nabisco for the best cookie formally known as double stuffed Oreos. The world may never know how many family sized packs I consumed throughout this process and is like to keep it that way.

To my turtle, Flash, who had survived countless temper tantrums, 5 apartments, three degrees, three institutions, 3 cities, 2 states, and at $23 \mathrm{hr}$ drive. I would love to give you a pond to live out the rest of your days but I do not trust you to stay there so in a tank in my home is where you shall remain for as long as we both shall live.

To my internship cohort, Baanu and Vy, for helping me survive a global panarama, on the extraterrestrial planet that is called Texas, I appreciate you both.

And finally, in the words of the wise Snoop Dog, I'd like to thank myself for doing what I do best, panicking and questioning myself every step of the way. I didn't think I would make but I 
am happy to say that I proved myself wrong, yet again. And I hope to continue to do so through the rest of my life. 


\section{Table of Contents}

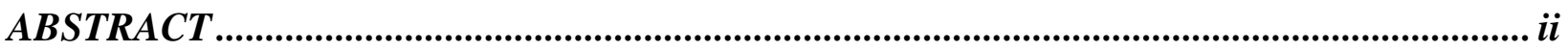

DEDICATION ......................................................................................................................................

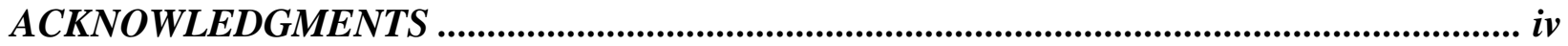

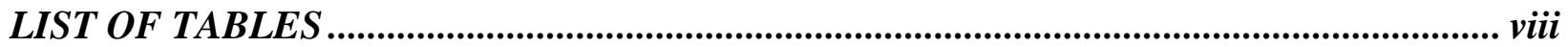

LIST OF FIGURES........................................................................................................................... ix

CHAPTER 1: INTRODUCTION AND LITERATURE REVIEW.......................................... 1

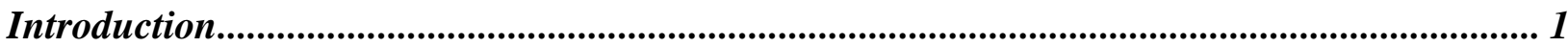

Perceived Discrimination ........................................................................................................................ 2

Racial Discrimination .............................................................................................. 5

Sexual Minority Discrimination .......................................................................... 8

Internalized Sexuality Discrimination .................................................................................................. 10

Sexual Identity Disclosure: “Outness” ............................................................................ 13

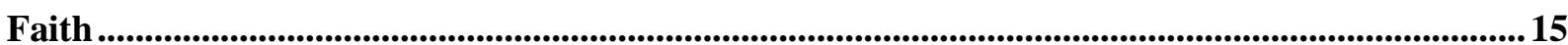

Faith in Black Individuals..................................................................................... 17

Faith in Sexual Minorities....................................................................................... 19

Intersectionality \& BSM Individuals ......................................................................................................... 22

Current Study ............................................................................................................................................. 25

Research Question and Hypotheses ................................................................................. 26

CHAPTER 2: METHOD ................................................................................................................... 27

Participants ...................................................................................................................................... 27

Measures............................................................................................................................................. 31

Procedure .........................................................................................................................................

Research Design ................................................................................................................................ 39

Data Analysis Plan ..............................................................................................................................4 40

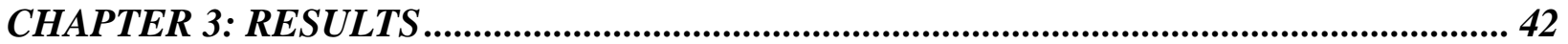

Preliminary Analysis ..........................................................................................................4 42

Measure Descriptive Statistics ..................................................................................... 42

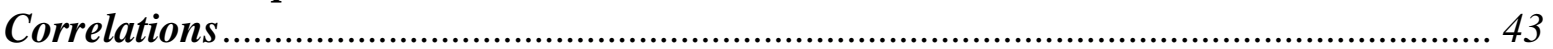

Multiple Regression Assumptions and Testing............................................................... 44

Primary Analysis .......................................................................................................................................... 47

Hypotheses 2 and 3 ................................................................................................................................ 51

Exploratory Analysis........................................................................................................................... 53

Chapter 4: Discussion................................................................................................................ 57

Summary of the Findings........................................................................................................................ 58

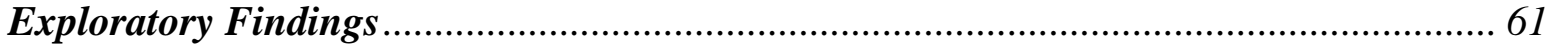




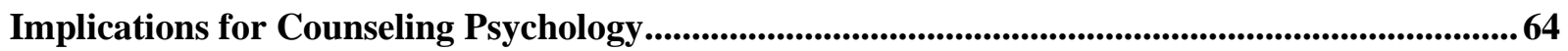

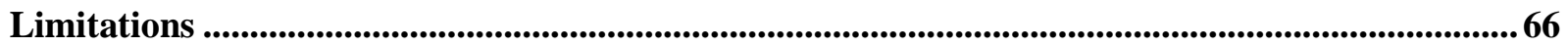

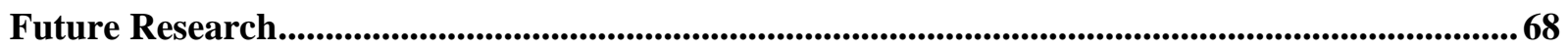

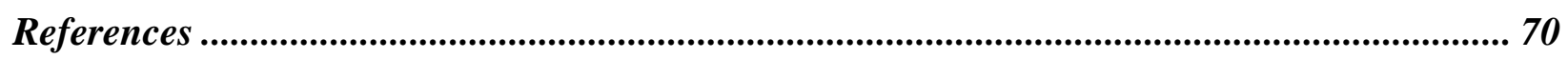

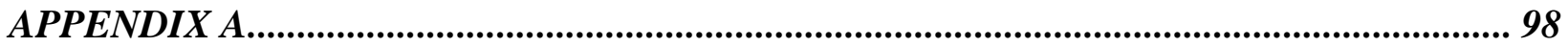

Kessler Psychological Distress Scale (K6).............................................................. 98

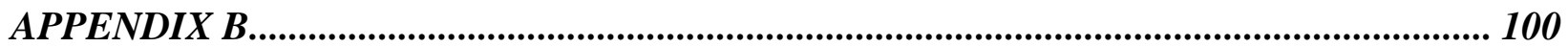

LGBT People of Color Microaggressions Scale ............................................................ 100

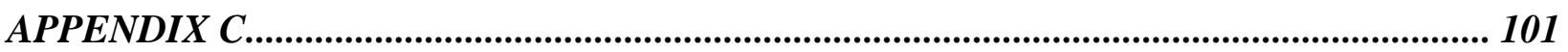

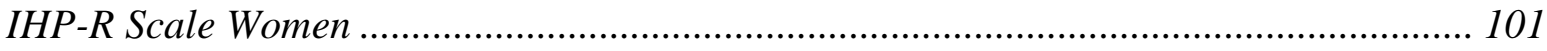

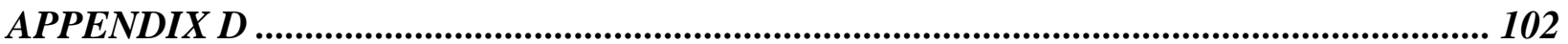

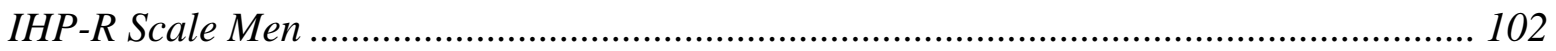

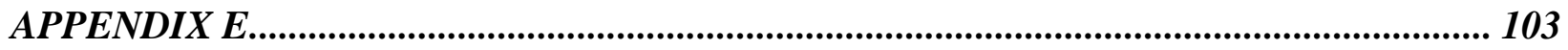

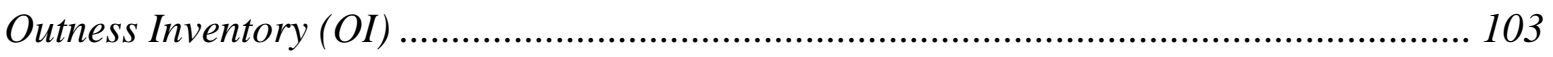

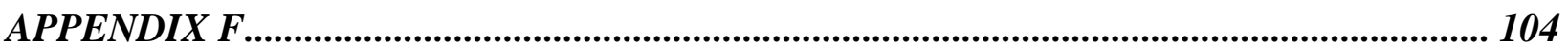

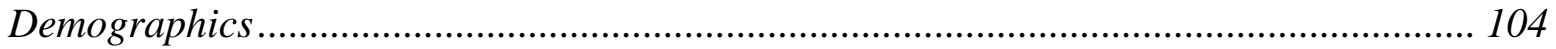

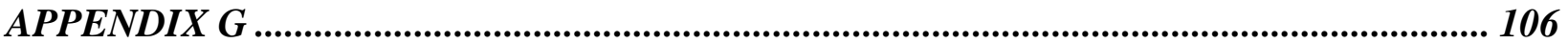

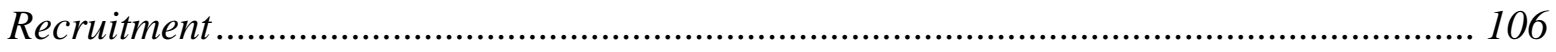

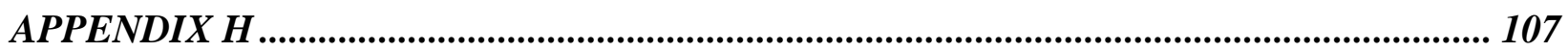

Example Images of Facebook Pages ......................................................................... 107

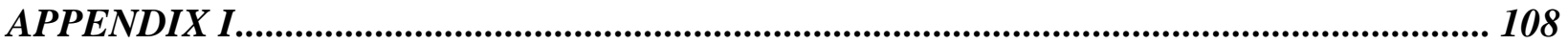

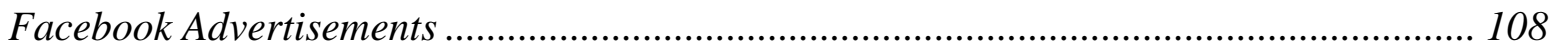




\section{LIST OF TABLES}

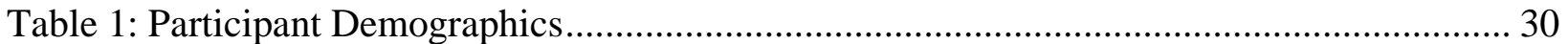

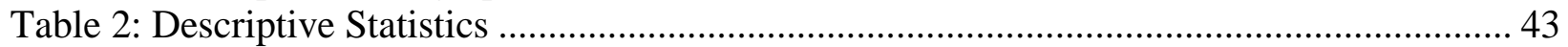

Table 3: Frequency Statistics of Faith Variable................................................................. 43

Table 4: Bivariate Correlation Analysis for Predictor Variables .............................................. 44

Table 6: Summary of Multiple Regression Analyses for Variables Predicting Psychological

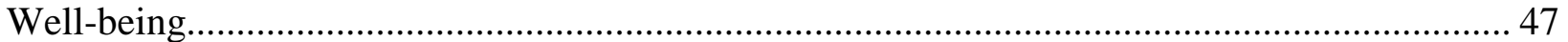

Table 7: Summary of Multiple Regression Analyses for Variables Predicting Psychological

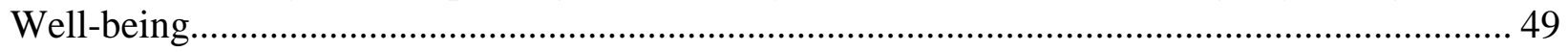

Table 8: Summary of Linear Regression Analyses for Faith Independently Predicting Outness 51 Table 9: Summary of Linear Regression Analyses for Faith Independently Predicting

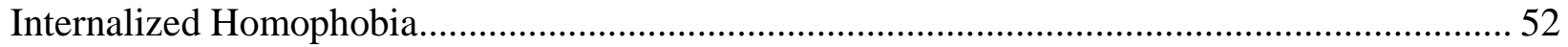
Table 10: Summary of t-tests and Descriptive Statistics LGBT-PCMS, OI, IHP-R, and K6 by Gender. 54

Table 11: Summary of t-tests and Descriptive Statistics LGBT-PCMS and OI Subscales by Gender..... 54 Table 12: Summary of Linear Regression Analyses for LGBT-PCMS Subscales Independently Predicting Psychological Well-being. 


\section{LIST OF FIGURES}

Figure 1: Line Graph of The Relationship Between K6 And IHP-R, LGBT-PCM, And OI Scores.

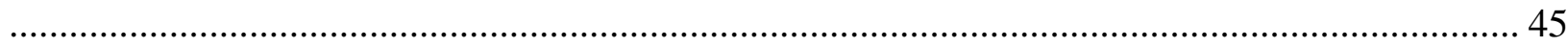

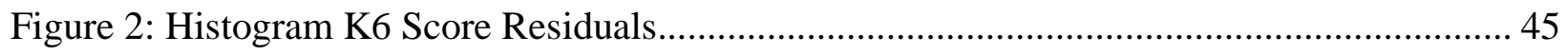

Figure 3: Scatterplot of K6 Scores and Predictor Variable Error Terms................................... 46

Figure 4: Indirect effects of internalized homophobia and outness on psychological well-being

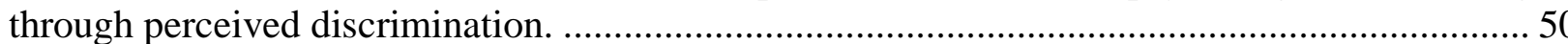




\section{CHAPTER 1: INTRODUCTION AND LITERATURE REVIEW}

\section{Introduction}

For Black sexual minority (BSM) individuals, the intersection of race and sexuality uniquely impacts daily lived experiences. These experiences include sexuality discrimination within their racial group, racial discrimination within lesbian, gay, bisexual, transgender, and queer or questioning (LGBTQ) community, and implications for their sociopolitical standing in the U.S. Additionally, Black individuals are more religious than any other ethnic/racial minority group (Lassiter et al., 2017; Pew, 2015; Wilkerson et al., 2012); which may also be associated with the well-being of BSM individuals.

Although well researched, many studies often assess psychological well-being related to a single demographic factor or social identity. However, with the growing support for studying intersecting identities, researchers have begun to examine the relationship between psychological well-being, multiple identities, and social factors (Balsam et al., 2011). Psychological well-being is defined as both the presence of positive affect and the absence of negative affect and living a life that is authentic and subjectively meaningful (Deci \& Ryan, 2006). Psychological well-being has been studied regarding specific groups such as ethnic minorities (Molix \& Bettencourt, 2010) and sexual minorities in the U.S. (Diamond \& Lucas, 2004; Meyer, 2003) and in various countries across the world (de Freitas et al., 2018; Gisladottir et al., 2018). Additionally, psychological well-being is associated with perceived discrimination (Garofalo et al., 1999; Kessler et al., 2010), sexuality acceptance (Rostosky et al., 2018), sexual orientation outness (Riggle et al., 2017), and faith (Moreira-Almeida et al., 2014).

However, few studies have examined each of these factors in BSM individuals. Using a cross-sectional, correlational, quantitative survey research design, the current study aimed to 
assess the relationships among faith, internalized homophobia, outness, perceived discrimination, and psychological well-being in BSM individuals.

\section{Literature Review}

Several factors may contribute to the psychological well-being of BSM individuals. These factors include perceived discrimination (related to race and sexuality), internalized sexuality discrimination, outness, and faith. Although many studies have assessed each of these factors and their relationship with psychological well-being (Frost \& Meyer, 2009; Meyer, 2003; Mohr \& Fassinger, 2000), perceived discrimination is often assessed through a single identity and has consisted of predominantly White samples. Even with more diverse samples, more studies individually assessing BSM individuals' experiences with perceived discrimination will provide a more nuanced explanation of how their intersecting identities, race, and sexuality uniquely and jointly impact their psychological well-being.

The literature review will introduce the key factors that are related to the psychological well-being of BSM individuals. A conceptual background will then be provided on the various factors to provide foundation information, definitions, and review of previous research conducted. Previous research will include those exploring perceptions of racial discrimination, internal and external views of same-sex attraction, and the intersections in identity regarding race and sexuality. This chapter will be concluded with a description of the current study, research question, and hypotheses.

\section{Perceived Discrimination}

Researchers have defined perceived discrimination as a behavioral manifestation of subjective negative judgments, attitudes, or the unfair treatment of a specific group or identity (Pascoe \& Richman, 2009). In a meta-analysis of 134 articles, researchers noted that increased 
perceived discrimination was significantly related to more negative mental health outcomes such as mood disturbances, post-traumatic stress symptoms, psychosis or paranoia indicators, psychological distress, perceived stress, and anger (Pascoe \& Richman, 2009). Researchers have also linked experiences of discrimination to reductions in self-esteem, as marginalized individuals and groups often internalize the discriminatory messages (Crocker \& Major, 1989; Israel et al., 2019; Marquet et al., 2019; Mason et al., 2015; Molero et al., 2019; Sosoo et al., 2020). For BSM individuals, their racial identity and sexual minority identity are essential when considering their perceived discrimination experiences.

Similarly, a second, more recent meta-analysis of 328 independent studies found that perceived discrimination was negatively related $(r=-.23, p<.01)$ to psychological well-being (Schmitt et al., 2014). The same study found that the inverse relationship between well-being and various adverse outcomes was significant across operationalizations of well-being; but was weaker for positive outcomes (Schmitt et al., 2014). This finding suggests that stronger results are found when measuring the presence of negative symptoms (i.e., anxiety, depression, stress) compared to positive symptoms (i.e., positive affect and self-esteem) when examining the relationship between perceived discrimination and psychological well-being. Lastly, the same study also compared studies that manipulated pervasive discrimination (general experiences within a group/identity) to studies that manipulated single-event discrimination (personal experiences) to determine if the form of perceived discrimination impacted psychological wellbeing differently. Researchers found that studies assessing perceptions of pervasive discrimination were found to have a significant negative effect, while studies assessing perceptions of a single negative event or personal discrimination did not (Schmitt et al., 2014). 
This finding suggests that perceptions of pervasive discrimination are more likely to impact psychological well-being than isolated events.

Minority stress theory is one theory that explains the possible links between perceived discrimination and psychological well-being (Meyer, 2003). The theory suggests that sexual minority individuals experience significantly more adverse mental health issues than heterosexual populations due to chronic exposure to stigma and prejudice (Meyer, 2003). Minority stress is distinguished from everyday stressors in that only those who hold minority identities experience it. Although Meyer (2003) initially used the theory to discuss sexual minorities' experiences, researchers have used it to examine physical and mental health disparities in other minority identities (Cyrus, 2017; Kessler et al., 1999; Lefevor et al., 2019; Modrakovic et al., 2021; Pittman, 2011; Polihronakis et al., 2021). Researchers have also used the minority stress theory to examine individuals' psychological well-being who hold multiple minority identities (Balsam et al., 2011).

Since introducing the minority stress theory, many studies have examined perceived discrimination with depression, anxiety, increased physical health problems, worsening health conditions, and substance use (Everett et al., 2019; Lefevor et al., 2019; Salfas et al., 2019). However, Bowleg (2008) noted that much of the research examines minority stress through the lens of mutually exclusive identities, not intersecting identities. Specifically, in her study on Black lesbians and the intersecting of their gender, race, and sexuality, Bowleg (2008) noted that women responded differently depending on how they ranked their identities. Most of the women indicated that they first identify as Black and then as their other identities. On rare occasions, participants identified gender or sexual minority identity first, but their racial identity was never 
last. This suggests that despite having held multiple identities, one identity may be more salient than others, effecting how participants responded to and coped with discrimination.

\section{Racial Discrimination}

One area to consider for BSM individuals is racial discrimination. Most (91\%) Black Americans believe they have experienced discrimination against them due to their race (Sue \& Sue, 2008). Even higher-income Black Americans experience discrimination, with six out of ten earning \$75,000 or higher reporting being victims of racism (Sue \& Sue, 2008). Racial discrimination is a factor in many social situations, including unequal access to housing, education, and employment for Black Americans (Pager \& Shepherd, 2008). In addition to the burden of social inequities, researchers have found correlations between racial discrimination experiences and increased health-related problems for both chronic and acute forms of racial stress (Isoya, \& Yamada, 2021; Joseph et al., 2021; Lewis \& Van Dyke, 2018; Madkour et al., 2015; Pittman, 2011). Specifically, mental and physical health consequences of racial discrimination among Black Americans include hypertension, depression, anxiety, and other forms of psychological distress (Burnett, 2020; Chambers et al., 2020; Hope et al., 2021; Joseph et al., 2021; Kessler et al., 1999; Taylor et al., 2019). In line with Meyer's (2003) theory, these studies suggest that having a racial minority identity is directly related to worse physical and mental health when compared to those who hold majority identities.

In a study exploring the relationships between chronic worry, perceived racial stress, and intolerance of uncertainty among Black individuals, researchers found significant correlations between perceived racial stress and excessive worry (Rucker et al., 2010). Researchers have also found positive correlations between perceived racial stress and intolerance of uncertainty and intolerance of uncertainty and excessive worry. These findings suggest that feelings of 
uncertainty in social situations or fear of experiencing discrimination increase the likelihood of experiencing perceived racial stress and/or excessive worrying. Researchers also found significant differences depending on how the participants viewed themselves. Individuals who reported stronger defined identities and low on private regard (the extent to which individuals feel positively or negatively toward a group and their membership in that group), or low on public regard (the extent to which an individual feels that outgroup members view a group positively or negatively) experienced higher levels of total depressive symptoms on the day before a racial event occurred (Hoggard et al., 2015). Participants who held strong ties to their Black identities but held low views of their racial group while also believing others have low views of their racial group experienced more depressive symptoms. Additional studies found significant correlations between perceived racial discrimination, anxiety (Carden et al., 2021), depression and sleep problems (Hart et al., 2021), and poor physical health outcomes (Zapolski et al., 2019).

Studies have also assessed how responses to racism may relate to mental health outcomes. Researchers found that active anger (overt), as a response to racism, influenced psychological distress and general well-being. Specifically, using active anger to respond to acute racism increased Black Americans' psychological distress (Pittman, 2011). These findings suggest that the form of coping also uniquely impacts well-being in Black Americans. Rucker et al. (2010) further supported these findings when they found that intolerance of uncertainty mediated the relationship between perceived racial stress and excessive worry. This finding suggests that ineffective coping (intolerance) may explain the relationship between perceived discrimination and consequential experienced stress. Thus, it is essential to consider other coping techniques and how they may positively influence psychological well-being. 
Another way of assessing the relationship between perceived discrimination and psychological well-being is by examining the experiences of covert discrimination, such as microaggressions. Sue et al. (2007) define microaggressions as brief everyday interactions that are subtle forms of disrespect and invalidating individuals who hold a racial minority status. Nadal and colleagues (2015) further clarified that these interactions can be experienced by individuals with other minority statuses such as gender, sexuality, religion, and the intersections of those identities. Compared to acts of explicit racism, microaggressions are subtler and more likely to be viewed as harmless by observers (Sue et al., 2007). However, its relationship with psychological well-being is well documented, especially in ethnic minority populations (Burrow \& Hill, 2012; Hernández \& Villodas, 2020; Kim, 2017; Ong et al., 2013). Sue et al. (2007) also introduced the microaggression taxonomy theory to explain the types of microaggression ethnic minorities experience. These microaggressions include an individual being asked what country/ where they are from because they are presumed to be immigrants (alien in one's land) and the presumption that an ethnic minority is dangerous (assumption of criminality).

In a study examining the relationship between microaggression, ethnic identity, and psychological distress in ethnic minority undergraduates (Black, Hispanic/Latino, and Asian), researchers found that experiencing microaggressions was positively related to ethnic identity for the total sample (Forrest-Bank \& Cuellar, 2018). Moreover, they found that ethnic identity was negatively associated with psychological distress and positively related to self-esteem and academic self-efficacy. Lastly, they found that ethnic identity mediated the independent relationships among microaggression and psychological distress, self-esteem, academic selfefficacy, and substance use. 
However, these relationships change when researchers analyzed the data for each ethnic group independently. For the Black undergraduate participants ( $n=71)$, ethnic identity did not mediate the relationship between microaggression and psychological distress, although the relationship between the two variables remained positive (Forrest-Bank \& Cuellar, 2018). Additionally, the relationship between microaggression and psychological distress was stronger in Black participants $(r=.29, p<.05)$ than for Latino/Hispanic students $(n=67 ; r=.26, p<.05)$ and Asian students where the relationship did not exist. Subsequently, ethnic identity was negatively related to participants' psychological distress $(r=-.34, p<.01)$ and positively related to self-esteem $(r=.30, p<.01)$. These findings explicitly demonstrate the adverse outcomes of racial microaggressions on psychological well-being for Black individuals.

Previous research exploring racial discrimination has helped provide a greater understanding of how chronic experiences of microaggressions negatively impact Black individuals. The relationships between racial discrimination and adverse mental and physical health outcomes help provide more context of people's lived experiences and self-perceptions of people who experience race-based microaggressions. These effects have also been linked to other forms of discrimination in individuals who identify as sexual minorities.

\section{Sexual Minority Discrimination}

Like racial/ethnic minority individuals, sexual minority individuals also continue to face discrimination, prejudice, and oppression and are regularly the targets of microaggressions (Burks et al., 2018; Casey et al., 2019; Herek, 2009; Herek et al., 2015; Nadal, 2019; Sults et al., 2017). Everyday microaggressions include using heterosexist language, being referred to by a derogatory term when an individual does not meet gender norm expectations (Capodilupo, 2016), over and under sexualization, sinfulness, and microaggressions as humor (Platt \& Lenzen, 
2013). Additionally, a study using data collected from a probability sample of adults living in the United States (U.S.) in 2005 found that approximately 20\% of the U.S. sexual minority population reported having experienced a crime due to their sexual orientation since age 18 (Herek, 2009).

A recent study examining how social stigma contributes to psychological distress in 1,248 LGBTQ individuals found that 1 in 3 adults reported experiencing discrimination in the past year, with half of the respondents reporting adverse psychological effects (Mahowald et al., 2020). Likewise, in a large community sample of 4,248 sexual minority individuals, researchers found that microaggressions positively correlated with self-stigma, sexuality acceptance concerns, rumination, anxiety, and depression; and negatively correlated with well-being (Timmins et al., 2020). Similar to these findings, researchers found a link between experienced microaggressions and increases in anxiety and perceived stress in young adult sexual minorities (Woodford et al., 2015).

Research suggests that sexual orientation prejudice can lead to severe emotional and psychological consequences and isolation (Engstrom \& Sedlacek, 1997; Herek et al., 2002; Stults et al., 2017). In addition to higher-than-average rates of suicidal ideation (Garofalo et al., 1999), sexual minority individuals also experience higher incidences of substance abuse, sexual abuse, homelessness, parental rejection, emotional isolation, school drop-out, and low selfesteem (Herek et al., 2002).

In a systematic review of mental health concerns in sexual minority individuals, researchers reviewed 199 empirical studies, 53\% of which were published after 2011 (Ploderl \& Tremblay, 2015). The review showed that $89 \%$ of the study results indicated elevated reports of depression in adults and $97 \%$ for adolescents who identified as sexual minority individuals. 
Similar results were reported, with $83 \%$ of the studies reporting elevated anxiety symptoms, 93\% of the studies reporting elevated risk for substance concerns, and nearly all studies reporting elevated rates of attempted and completed suicide among LGBTQ adults (Ploderl \& Tremblay, 2015).

Over time, research has detailed the relationship between sexual orientation-based discrimination and adverse psychological experiences in sexual minority individuals. Research has also detailed how these experiences impact self-perception in individuals who identify as a sexual minority. These associated psychological links are explored below.

\section{Internalized Sexuality Discrimination}

Another way chronic exposure to microaggressions and anti-LGBTQ attitudes may be explored is by examining how sexual minority individuals begin to view themselves. Numerous studies have established the relationship between experienced discrimination and the internalization of these oppressive messages by sexual minority individuals (Riggle et al., 2010; Szymanski \& Henrichs-Beck, 2014; Szymanski \& Ikizler, 2013). Meyer (2003) noted that internalized discrimination in sexual minority individuals occurs when they adopt negative societal views of same-sex attraction as part of their self-concept. He also noted that one of the ways this internalization manifests is through concealing one's sexuality. He proposed that sexual minority individuals hide their same-sex attraction from fear of experiencing more discrimination and rejection (Meyer, 2003).

Throughout the literature, researchers have used different terms to describe the internalization of discriminatory views that sexual minorities experience. Internalized homophobia has been used to describe sexual minority individuals' self-hatred regarding their sexual orientation (Szymanski et al., 2008). However, researchers have criticized using this term 
because it implies that sexual minorities "fear" themselves rather than dislike themselves. As a result, researchers have proposed additional terms such as internalized homonegativity (Mayfield, 2010) and internalized heterosexism (Herek, 1995; Szymanski et al., 2008). Internalized homonegativity refers to a person's negative beliefs and affect regarding their status as a sexual minority, while internalized heterosexism refers to a person's internalization of institutional and cultural messages regarding heterosexuality as the "norm" (Szymanski et al., 2008). Despite the differences in meaning, researchers have used the terms interchangeably to describe negative feelings sexual minority individuals experience towards themselves because of their same-sex attraction. For continuity throughout this document, internalized homophobia will be used, as the current study's measure uses this language. It is acknowledged that the term homophobia is controversial and dated.

Research suggests that internalized homophobia may be uniquely related to poor psychological well-being because of its connection to psychological processes, coping behavior in the absence of direct threats, and self-concept (Meyer, 1995). Internalized homophobia is significantly related to relationship satisfaction (Greene, \& Britton, 2015; Szymanski et al., 2016), relationship trajectory (Bauermeister et al., 2010), HIV serostatus (Skinta et al., 2019), membership of sexual minority groups, time spent with others who identify as a sexual minority (Ross, \& Rosser, 1996), and disclosure of sexual orientation (Durso, \& Meyer, 2013). Additional research revealed internalized homophobia explained differences in the severity of psychological distress symptoms and the positive affect (Herek et al., 2015).

For example, in a study assessing the relationship between positive lesbian, gay, and bisexual identity and psychological well-being in 322 sexual minority adults, researchers found that authenticity was positively statistically significantly correlated with psychological well- 
being (Rostosky et al., 2018). That is, participants who lived lives that were congruent with their values and beliefs reported better psychological well-being. These findings suggest that sexual minority individuals who are comfortable with their identity as a sexual minority are more likely to report better psychological well-being than sexual minority individuals that report experiencing internalized stigma.

In the same study, researchers found that self-acceptance was also significantly correlated to relationships with others (Rostosky et al., 2018). This finding is important because researchers of a separate study found that depressive symptoms mediated the relationship between internalized homophobia and relationship quality, suggesting that internalized homophobia leads to relationship problems primarily by increasing depressive symptoms (Frost \& Meyer, 2009). Both findings demonstrate why it is essential to further explore the relationship between psychological well-being and internalized homophobia with other factors that impact psychological well-being in sexual minority individuals.

Researchers further demonstrated the importance of self-acceptance and the psychological well-being of sexual minority individuals by examining anti-same-sex attraction views in college students. Researchers found that self-acceptance mediated the relationship between homophobia and psychological distress (Woodford et al., 2014). Explicitly, higher rates of self-acceptance weakened the relationship between the two. Additionally, researchers found that sexual orientation victimization did not contribute to the sample's self-acceptance or psychological distress (Woodford et al., 2014). These findings suggest that sexual minority individuals who already hold favorable views of their sexuality are less likely to be negatively impacted by discrimination. Thus, it is essential to assess how multiple identities may impact 
experiences of internalized homophobia and how some of them may be tied directly to specific identities.

Lastly, a systematic mapping of 201 studies examining the relationship between internalized homophobia, mental and physical health outcomes in adolescent and adult sexual minority groups, internalized homophobia was associated with substance use and risky sexual behaviors in adolescents (Bergr et al., 2016). For adults, results suggest that higher levels of internalized homophobia are associated with higher risks of depression, shame, low self-esteem, intimate partner violence, and negatively related to relationship satisfaction (Bergr et al., 2016). Results regarding substance use and sexual behaviors were mixed with studies reporting relationships with internalized homophobia and others reporting no significant relationship (Bergr et al., 2016). Furthermore, internalized homophobia was found to be positively related to eating concerns, body dissatisfaction, ideal body distress and negatively related to HIV testing use of healthcare resources and treatment program attendance in men (Bergr et al., 2016).

\section{Sexual Identity Disclosure: “Outness”}

Another important factor when assessing BSM individuals is sexual orientation disclosure, informally termed "coming out” or "outness." Coming out is a two-fold process that refers to accepting one's sexual orientation as part of one's identity and sharing this identity with others and is assumed to be a natural part of identifying as a sexual minority (Kitzinger \& Wilkinson, 1995). Outness is the degree to which a person discloses their sexuality to family, friends, coworkers, and other selective environments and situations (BrckaLorenz et al., 2021). For example, individuals may disclose their sexual orientation with a partner and close friends but not disclose it to coworkers or their religious community members. Because sexuality is a mostly invisible identity, sexual minority individuals may engage in visibility management, in 
which they determine with whom and which environments/settings they disclose their identity (Lasser \& Tharinger, 2003). About 54\% of people who identify as a sexual minority reported being out to important people in their lives, while 23\% reported being out to a few people, and 23\% reported not being out at all (Pew, 2015). In a review, Mosher (2001) noted that increased outness has been linked to positive self-concepts and better psychological well-being, signifying the relationship between sexual orientation disclosure and mental health outcomes. More recent studies have further supported these findings (Beard et al., 2017; Kosciw et al., 2015).

An example of this is demonstrated in a study that examined sexuality disclosure, certainty in sexual orientation, and psychological well-being. Researchers found increased disclosure to be significantly related to higher happiness, and general affect reports in the week preceding the study (Bejakovich \& Flett, 2018). Similarly, in a study of 2,401 sexual minority women, outness was negatively correlated with psychological distress (Morris et al., 2001). Also noteworthy is that both studies found that the participants were more likely to disclose their sexual orientation if they were comfortable and confident in their identity. The researchers found that participants who identified as bisexual or questioning reported lower levels of outness, and as a result, more psychological distress (Bejakovich \& Flett, 2018; Morris et al., 2001).

However, outness is not always associated with greater psychological well-being. A study that examined the relationships among outness, psychological well-being, depressive symptoms, and perceived stress on 377 sexual minority individuals provides a great example. Researchers found that increased outness significantly predicted increased depressive symptoms among the sample (Riggle et al., 2017). Additionally, higher levels of concealment of sexual minority identity were significantly associated with lower psychological well-being and more depressive symptoms, while higher levels of authenticity were significantly associated with 
better psychological well-being and more minor depressive symptoms (Riggle et al., 2017). The researchers suggested that increased outness may also put sexual minority individuals at risk for experiencing more discrimination. As a result, the participants reported higher psychological distress than previous studies (Rostosky et al., 2018; Timmins et al., 2020).

While outness and internalized homophobia have both been shown to relate to psychological well-being (Bejakovich \& Flett, 2018; Frost \& Meyer, 2009; Morris et al., 2001; Rostosky et al., 2018; Timmins et al., 2020; Woodford et al., 2014), it is essential to note that outness and internalized homophobia are not interchangeable. However, the two constructs are related in that higher reports of internalized homophobia are negatively related to outness (Weber-Gilmore et al., 2012; Wenjian Xu et al., 2017). In a study examining the associations between internalized homophobia, outness, community connectedness, depressive symptoms, and relationship quality in 396 sexual minority individuals, researchers found a strong negative correlation between outness and internalized homophobia (Frost \& Meyer, 2009). These researchers also found that internalized homophobia was negatively related to relationship quality, but outness was not (Frost \& Meyer, 2009). These findings are significant because they display a significant relationship between internalized homophobia and outness. However, they also suggest that the two constructs are experienced in sexual minority individuals differently. Because of this, both constructs are important to address when examining the experiences of BSM individuals.

\section{Faith}

An important factor that may influence sexual minority individuals' experience with internalized discrimination is religion. Faith, religion, and spirituality are often used interchangeably in the literature (Newman, 2004). However, each has a distinct meaning and 
represents different ideas for different people. The literature defines faith as an overarching term that is broadly defined as a "kind of intuitive cognition, with strong emotional over- and undertones, of a realm of being beyond our conscious grasp and that it is forward-looking with trust" (Stein, 2011, p. 401) and as a general religious attitude or an accepted set of personal beliefs (Newman, 2004). Newman (2004) noted that researchers have struggled to define religion and spirituality because of their broad expression. This is also noted in a review of studies that attempted to define faith, religiousness, and spirituality (Harris et al., 2018). Researchers determined that while separate, they share overlapping qualities and suggest defining spirituality as searching for a relationship with a higher power, religion/religiousness as ritual or institutional proceedings, and faith as a substitute for spirituality (Harris et al., 2018).

The current study will use the concept of faith to account for individuals who identify as religious and/or spiritual. Often Black Americans identify as spiritual and religious rather than solely spiritual (Chatters et al., 2008). Likewise, this study is interested in how participants' connectedness to their beliefs relates to psychological well-being, internalized homophobia, outness, and perceived discrimination, rather than how they specifically identify regarding religion.

Researchers have found strong associations between religious and spiritual beliefs with better mental health, physical health, survival, well-being measures, and quality of life (MoreiraAlmeida et al., 2014). Koenig (2012) proposed that religious beliefs may help improve mental health by providing an effective way of coping with stress, a social support group, and encouraging human virtues. In a study examining the relationship between intrinsic religious faith (belief in and reliance on a higher power) and psychological well-being, results indicated that participants who reported having higher levels of faith also reported lower anxiety and 
depression scores and significantly higher ego strength scores than those who reported lower levels of faith (Laurencelle et al., 2002; Peres et al., 2018). For these reasons, religion and spirituality are often considered healthy coping resources (Haney \& Rollock, 2020; Laurencelle et al., 2002; Paine et al., 2018; Peres et al., 2018). The same researchers also found that even those without a religious faith could have better outcomes if participants identified themselves as having meaning. However, there was a significant association between high religiousness and high meaning, suggesting the religion may indirectly play a role in well-being by providing meaning (Peres et al., 2018).

\section{Faith in Black Individuals}

Faith is essential to consider when looking at BSM individuals as the Black church plays a significant role in the Black community, even for those who do not identify as religious (Lassiter, 2016; Ward, 2005). A national survey examining religious values in the U.S. found that Black Americans are the most religiously committed racial group, attend worship services more frequently, and are more likely to support religious engagement on important social and political issues than any other group (Pew, 2015). The Black church is significant in the Black community because it is used as a protective factor against the prejudices and inequality experienced by many Black people living in the US (Ward, 2005). In fact, when compared to White Americans, Black Americans and Caribbean Blacks reported higher rates of using their faith to cope with hardships (Chatters et al., 2008; Taylor et al., 2009). Older Black Americans also report distinct differences in the use of faith and expectations of God in relation to their health when compared to older White Americans (McAuley et al., 2000). For this reason, faith is often positively related to the psychological well-being of Black Americans (Breland-Noble et al., 2015; Clark et al., 2018; Grill et al., 2020; Levin \& Taylor, 1998 Robbins et al., 2020). 
While having a strong faith may pose as a protective factor for many Black Americans, this may not be the case for BSM individuals as same-sex attraction is widely rejected in various religions worldwide (Janssen \& Scheepers, 2019). Ward (2005) noted that church affiliation and culture is strong among Black people and is often a significant element of their social lives. Consequently, Black men and women who no longer embrace the church or religious principles are still profoundly influenced by the church ideology and imagery with which they were raised (Lassiter, 2016; Lassiter et al., 2017), even after they stop attending religious services (Lassiter, 2016). Furthermore, like many religions worldwide that reject same-sex attraction (Janssen \& Scheepers, 2019), Black churches have been theorized as directly and indirectly fostering homophobia in Black communities (Ward, 2005).

Over the years, researchers have attributed much of the oppressive stigma toward BSM expressed in Black culture to religion (Bonilla \& Porter, 1990; Cohen, 2014; Herek \& Capitanio, 1995; Lewis, 2003; McKenzie \& Rouse, 2013). In a study comparing Black and White college students’ attitudes towards sexual minority individuals, Black participants endorsed more negative viewpoints than their White peers (Negy \& Eisenman, 2005). Interestingly, the frequency of church attendance and religious commitment also predicted negative views of sexual minority individuals. Researchers also found that the more immersed a Black participant was in the community and culture, the more they endorsed the negative values (Negy \& Eisenman, 2005).

In a more recent study, researchers found that Black participants were more likely to disagree with same-sex marriage rights than White participants (Irizarry \& Perry, 2018). They also found that Black participants reported higher disapproval rates of engaging in sexual acts with someone of the same sex. Conversely, views of marriage rights were relatively similar and 
consistent across socioeconomic status (SES) and the education level for both White and Black participants (Irizarry \& Perry, 2018). However, for White participants, negative views of samesex sexual activity were reduced with more education and higher SES. The disapproval rates remained relatively consistent for Black participants regardless of SES and education level (Irizarry \& Perry, 2018). Lastly, the researchers found the Black participants’ negative view of same-sex attraction to be practically explained by religion, supporting earlier findings (Negy \& Eisenman, 2005).

It is important to note that these views are found in Black individuals who identify as both heterosexual and sexual minorities. In a study assessing the connection between religion, internalized homophobia, and outness and Black, Latino, and White MSM, Black participants were more likely to be Evangelical Protestants (Wilkerson et al., 2012). This is important because a national survey found that Evangelical Protestants were less likely than Catholics and other Protestant denominations to approve of same-sex attraction (Pew, 2015). In another study assessing faith, internalized homonegativity, and resilience in young BSM individuals, researchers found that faith significantly positively impacted reported resiliency levels while also being related to higher internalized homonegativity levels (Walker \& Longmire-Avital, 2013). This finding is important because it effectively highlights the duality of faith for BSM individuals.

\section{Faith in Sexual Minorities}

As mentioned above, many people use religion and spirituality as an important source of psychological coping. However, religious conflict has also been associated with adverse outcomes, such as mortality and worse mental health (Fitchett et al., 2004). This becomes an issue for sexual minority individuals who also identify as religious because many American 
religions condemn same-sex attraction (Barnes \& Meyer, 2012) especially those in the Baptist and/or evangelical denominations (Wilkerson et al., 2012). Despite this fact, some sexual minority individuals still report identifying with a religion. In fact, in a study examining differences in religious affiliations between people identified as heterosexual or sexual minority individuals, about 5\% of 35,000 participants self-identified as sexual minority individuals. Of that group, 59\% reported being religiously affiliated, although only $48 \%$ reported belonging to a Christian faith group, compared with 71\% of the general public (Murphy, 2015).

In a review of qualitative studies exploring religion in sexual minority individuals, researchers noted that conflict between faith and sexual orientation identity was consistent in all studies (Wilkinson \& Johnson, 2020). However, the conflict was different among the samples, with some participants reporting more significant internal conflict and others reporting greater external conflict (Wilkinson \& Johnson, 2020). External conflicts were reported as discrimination or disapproval of sexuality by the religious community and/or disapproval of religious identity from the LGBTQ community (Wilkinson \& Johnson, 2020). Lastly, researchers reported issues regarding body, delayed sexual activity, reduction in self-esteem, self-harm, and suicide attempts as shared experiences amongst the samples of the different studies. (Wilkinson \& Johnson, 2020).

Further, a study assessing religion, internalized homophobia, and outness in 2,612 Black, Latino, and White MSM found Evangelical Protestants of all races reported higher religiosity and internalized homophobia (Wilkerson et al., 2012). They also found that while members of all religious groups were less likely to be out, religiosity was only found to be a contributing factor in Evangelical Protestants. In a similar study examining religiosity in young MSM, researchers found that increased religious affiliation was related to increased reports of internalized 
homophobia (Meanley et al., 2016). Additionally, they found that greater religious participation and commitment were negatively associated with psychological well-being outcomes. The researchers suggest that the men who reported more significant commitment and participation in religion were also more likely to be exposed to anti-same-sex attraction teachings. As a result, these messages were internalized, leading to lower psychological well-being reports (Meanley et al., 2016).

In additional research assessing the differences in religious participation between sexual minority individuals and heterosexual individuals, participants reported similarly in terms of religious upbringings (Scheitle \& Wolf, 2017). However, there were significant differences in terms of disaffiliation and reaffiliation. That is, sexual minority individuals were more likely to report leaving Christian traditions to practice other traditions than heterosexuals (Scheitle \& Wolf, 2017). This shift in beliefs may result from anti-same-sex messages that are often shared in Christian communities and beliefs.

However, disavowing is not the standard for all sexual minority individuals who identify with religions that have anti-same-sex sentiments (Rosenkrantz et al., 2016). In a research study assessing internalized homophobia in Catholic priests, researchers found that priests who endorsed more personalized homonegativity were those who had internalized harmful and discriminatory messages about sexual minority populations (Kappler et al., 2013). However, no significant difference was found in psychological well-being and depression scores between same-sex attracted priests and heterosexual priests, with both groups receiving high scorers on the measures of psychological well-being and happiness (Kappler et al., 2013). These findings suggest that while religion may impart negative views towards sexual minority individuals, 
adherence or participation in religious practices may still buffer the poor mental health outcomes associated with internalized homophobia.

\section{Intersectionality \& BSM Individuals}

BSM individuals hold many identities, many of which have been previously discussed in relation to psychological well-being. However, many of the studies mentioned assess the significance of these identities independently and do not fully contextualize the duality of experiences for BSM individuals. Furthermore, research explicitly conducted examining the lived experiences of BSM individuals primarily focuses on the experiences of Black men who have sex with men (BMSM; Barnes \& Hollingsworth, 2020; Buttram, 2020; Brooks et al., 2021; English et al., 2020; Friedman et al., 2019), BMSM, sexual behaviors and HIV/AIDS (Chittamuru et al., 2018; Foster et al., 2011; Jones et al., 2018; Moore et al., 2019; Wilson et al. 2011), with fewer studies focusing on Black queer women (Bowleg et al., 2003; Jones et al. 2019; Jones et al., 2020) or other populations. As a result, it is important to examine the intersections of these identities in a sample from the general population to help examine nuanced differences in how internalized homophobia, outness, and faith relate to psychological wellbeing in BSM individuals as a whole.

Intersectionality was first used to discuss the eraser of Black women’s experiences regarding racism, sexism (Crenshaw, 1989), and violence against women of color (Crenshaw, 1991). Intersectionality theory is founded on the principle that individuals hold multiple identities and that these identities interact to shape lived experiences (Warner \& Shields, 2013). Cole (2009) noted the need for more complex and multidimensional explorations of identities to develop a more holistic understanding of lived experiences. Intersectionality evaluates power dynamics to understand and explain how multiple identities such as race/ethnicity, gender, 
education, SES, sexuality, age, and ability interdependently impact the lived experience of those who hold multiple identities (Hill Collins \& Bilge, 2020). In both works, Crenshaw discussed how in-group (women and Black Americans independently) differences are ignored by exclusively discussing sexism from White women's perspectives and racism from Black men's perspectives. Because Black women hold two visible minority identities, Crenshaw argued that addressing the experiences of sexism for Black women cannot be done without also accounting for their Blackness, and racism cannot be fully explored without addressing their womanhood (1989/1991).

Although it is possible to hold only privileged identities, it is more likely that individuals hold privileged and oppressed identities (Grzanka et al., 2017). Researchers argue that it is essential to study and critique intersectionality accurately and intersect identities' systems of oppression that may shape an individual's social experiences similarly and differently (Grzanka et al., 2017). For BSM individuals, both race and sexuality impact their experiences with microaggressions, sexuality acceptance, religious participation, and psychological well-being, and as a result, they may feel unique, compounded effects from both identities.

Despite the growing interest in intersecting identities, only a few studies have looked exclusively at BSM individuals. A study examining intersectional experiences in BSM individuals found strong positive correlations between negative intersectional experiences (experiences that occur because of their intersectional identities as BSMs), identity conflict, and negative affect (Jackson et al., 2020). Researchers also found that positive intersectional experiences were positively related to positive rumination and positive affect, but not identity conflict (Jackson et al., 2020). 
In a qualitative study assessing gender, sexuality, and race as intersecting identities in Black gay and bisexual men, participants reported that they were "Black first," as it is a visible identity and because of racial microaggressions and racial discrimination they experienced in the LGBTQ community (Bowleg, 2013). Additionally, participants cited experiences of needing to relinquish their identities as Black men to fit into White sexual minority communities, with acts of racial discrimination in everyday life reminding them of their Blackness (Bowleg, 2013). Participants also noted that they identified with their race first because it could not be hidden, unlike their sexuality. In terms of their racial identity, participants expressed concerns about homophobia in Black communities. They noted experiences of being shunned by families, friends, and coworkers as the primary reason for not identifying as gay or bisexual or doing so only within specific contexts (Bowleg, 2013).

Similar themes were mentioned in a mixed-methods study examining same-sex attracted racial minorities (Balsam et al., 2011). Participants expressed concerns about racism in the LGBTQ community, homophobia in racial/ethnic minority communities, problems with relationships and dating concerning immigration status, and rejection by other same-sex attracted ethnic minorities (Balsam et al., 2011). Precisely, participants reported experiencing microaggressions related to race and sexuality; microinvalidation (being told race is not a necessary part of their identity); microinsults (sexual objectification by other sexual minority individuals because of their race); and microassaults (dating ads exclusively for White LGBTQ and not being accepted by other people of one’s race because of sexual orientation; Balsam et al., 2011). Additionally, reports of these experiences were found to be related to depression and perceived stress. 
Although Balsam et al. (2011) did not exclusively look at BSM individuals, their results support Black gay and bisexual men's reported experiences in other studies (Bowleg, 2013;

Garcia et al., 2016). The research findings suggest that most BSM samples perceive their lives to be more challenging due to the oppression that comes with simultaneously belonging to a racial minority group and identifying as a sexual minority (Bowleg, 2013). The experiences of BSM individuals can be further explored using Hill Collins’ (1986) outsider-within metaphor. The metaphor explains how BSM individuals get an insider's view of the privileges afforded to White LGBTQ and their Black heterosexual counterparts while remaining outsiders because of one of their identities. This metaphor suggests that BSM individuals only experience partial belongingness to both groups as neither community accepts their full identities (Bowleg, 2013).

Many factors have been shown to be related to psychological well-being in BSM individuals. These factors include perceptions of racial and sexual orientation discrimination, internalized homophobia, outness, and faith. However, there does not appear to be any studies assessing each of these factors in Black men and women who identify as sexual minorities. As such, key information is missing from the current literature and the understanding of their lived experiences.

\section{Current Study}

In sum, BSM individuals face discrimination from their racial community and the LGBTQ community. Nevertheless, few studies examine their unique experiences and how these experiences relate to their psychological well-being. The current study aimed to fill these gaps in the literature. As such, the current study's goal was to examine the relationships of faith, internalized homophobia, outness, perceived discrimination, and psychological well-being in BSM individuals. Because most past research on sexuality variables has primarily been with 
White participants (Balsam et al., 2011; Garcia et al., 2016), BSM individuals' nuanced experiences are often lost. Factors such as racial discrimination and sexuality discrimination place this population in a unique spot, as finding community support that accepts both of their identities is challenging (Balsam et al., 2011). Another unique characteristic of BSM individuals is the dual role of faith. While faith has primarily been used as a protective factor in the Black community (Chatters et al., 2008; Taylor et al., 2009; Ward, 2005) and linked to better psychological well-being (Moreira-Almeida et al., 2014), faith is also linked to lower rates of psychological well-being with higher rates of internalized stigma and sexuality concealment (Wilkerson et al., 2012). Because of this, each of these intersectional factors must be considered for BSM individuals.

\section{Research Question and Hypotheses}

The current study investigates the relationships amongst faith, internalized homophobia, outness, perceived discrimination, and psychological well-being in BSM individuals.

Hypothesis 1: Reported rates of internalized homophobia, perceived discrimination, outness, and faith will independently predict psychological well-being in BSM individuals.

Hypotheses 2\&3: Higher reports of faith will negatively predict reported levels of outness and positively predict reported levels of internalized homophobia. 


\section{CHAPTER 2: METHOD}

\section{Participants}

An a priori analysis was conducted using the latest version of G*Power (Faul et al., 2009) for Mac OS X (3.1.9.6) using a medium effect size $\left(f^{2}=.15\right)$, a Power (1- $\beta$ err prob) of .80, and an alpha $(\alpha)$ of .05 to determine the minimum sample size to conduct multiple regression analysis of the relationship amongst internalized homophobia, outness, faith, and perceived discrimination on psychological well-being. G*Power uses conventional effect size $\left(f^{2}\right)$ as recommended by Cohen $\left(\right.$ small $f^{2}=0.02$, medium $f^{2}=0.15$, large $f^{2}=0.35 ; 1988$, p. 412$)$ for multiple regression analyses (Faul et al., 2009). It also uses the assumption that a minimum power of .08, also recommended by Cohen (1962) is need to detect medium and small effect sizes (Faul et al., 2007).

It was determined that 85 participants were needed for an adequate sample size. Participants were eligible to participate in the study if they met the following criteria. Individuals had to:

1. Be 18 years of age or older.

2. Identify as being cisgender, non-transgender (male or female) as one of the measures is gendered and has not been validated on transgender, gender non-conforming, or nonbinary samples.

3. Identify as Black/ African American.

4. Report being fluent in English as all of the measures are in English.

5. Identify as a sexual minority, non-heterosexual.

After receiving approval from the WVU Office of Research Integrity and Compliance’s Institutional Review Board, participants were recruited using targeted sampling (Watters \& 
Biernacki, 1989), respondent-driven sampling (Heckathorn, 1997) and convenience sampling (Marshall, 1996) methods. The link for the survey was shared with specific Facebook groups such Black \& LGBT Lives Matter (800+ members), Black LGBT Alliance of New York, Inc. The Alliance (1k+ members), LGBTQ People of Color (3k+. members), Los Angeles BSMT Movement (1k+ members) and AA/Black SGLBTQ of Faith and Social Justice (800+ members). Follow-up Facebook posts were posted three and five weeks after the initial posts. Participants were encouraged to share the survey with family and friends. The first 71 participants recruited were given a \$5 Amazon gift card. Because of the specificity of the sample population, additional efforts were used to bolster recruitment.

Additionally, participants were recruited through Qualtrics research panel services. The research panel consists of a nationwide sample of people who have agreed to take surveys regularly. All of the members have been previously screened (demographics and interests) to allow for targeted advertising. The service's cost is determined by the number of needed participants and the specificity of eligibility requirements. A specialist was then assigned to advertise the study to individuals who met eligibility requirements. The specialist was also responsible for helping to monitor the data to ensure that only fully completed surveys were used for analysis. Similar crowdsourcing services were found to demonstrate efficient research results (Chandler \& Shapiro, 2016). As an incentive, five participants were randomly selected through the research panel to receive a \$20 Amazon gift card for participating.

A total of 786 individuals agreed to participate in the study. However, the final sample was 222, as most people were excluded for either identifying as heterosexual $(n=151)$ or as nonBlack $(n=362)$. Additional surveys were excluded if they had missing responses on the measures and could not yield a full total score $(n=37)$, completed the survey in less than two 
minutes $(n=14)$, and one completed survey was excluded for outlier responses. Thus, the final sample for the study was 221 . The majority $(67.9 \% ; n=150)$ of the participants were recruited using the Qualtrics research panels. The remaining participants (32.1\%; $n=71)$ were recruited using social media advertisements. There was no indication that a single participant completed the survey multiple times.

A summary of the demographic information of the sample can be found in Table 1. Participants' ages ranged from 18 to 85 years of age $(M=30 ; S D=13.51)$. The majority of the sample identified as women $(67 \%, n=150)$, with $32.1 \%$ identifying as men $(n=71)$. Regarding sexual orientation, $29.9 \%$ identified as gay or lesbian $(n=49), 43.0 \%$ identified as bisexual $(n=$ 95), 3.6\% identified as queer $(n=9), 5.9 \%$ identified as pansexual $(n=13)$ and $17.6 \%$ selfidentified ( $n=39$ ). Individuals who selected self-identify were provided a textbox to reflect their sexual orientation. About $49 \%$ of the participants $(n=19)$ who self-identified, wrote "straight" as their orientation. It is important to note that all participants who self-identified also endorsed same-sex attraction through survey responses. The majority (59.3\%) of the sample identified as single/ never married $(n=131)$.

Most participants reported a minimum of a 2-yr degree or higher ( $n=134 ; 60 \%)$, and 4.1\% did not report their education level $(n=9)$. Likewise, $57.5 \%$ of participants reported being employed at least part-time $(n=127), 15 \%$ were unemployed $(n=33), 3.6 \%$ were disabled $(n=$ 8), $15.4 \%(n=34)$, and .5\% $(n=1)$ did not respond to this item. Lastly, there was a widespread of reported household incomes in the sample. About 39\% of participants reported household incomes less than 30k $(n=86), 28 \%$ reported making at least $30 \mathrm{k}$ but less than $60 \mathrm{k}(n=62)$, $14 \%$ reported incomes of at least $60 \mathrm{k}$ but less than $90 \mathrm{k}(n=32), 17 \%$ reported income of at least 90k or more, and $1.4 \%$ did not report their income $(n=3)$. 


\section{Table 1}

Participant Demographics

\begin{tabular}{|c|c|c|}
\hline \multirow{2}{*}{ Variable } & \multicolumn{2}{|c|}{ Frequency } \\
\hline & $n$ & $\%$ \\
\hline \multicolumn{3}{|l|}{ Gender } \\
\hline Male & 71 & 32.1 \\
\hline Female & 150 & 67.9 \\
\hline \multicolumn{3}{|l|}{ Age (Years) } \\
\hline $18 / 19$ & 35 & 15.8 \\
\hline $20-29$ & 115 & 52.0 \\
\hline $30-39$ & 38 & 17.2 \\
\hline $40-49$ & 8 & 3.6 \\
\hline $50-59$ & 10 & 4.5 \\
\hline $60-69$ & 11 & 5.0 \\
\hline $70-79$ & 3 & 1.4 \\
\hline $80-89$ & 1 & .5 \\
\hline \multicolumn{3}{|l|}{ Sexual Orientation } \\
\hline Lesbian/Gay & 66 & 29.9 \\
\hline Bisexual & 95 & 43.0 \\
\hline Queer & 8 & 3.6 \\
\hline Pansexual & 13 & 5.9 \\
\hline Self-identify & 39 & 17.6 \\
\hline \multicolumn{3}{|l|}{ Marital Status } \\
\hline Never married/ Single & 131 & 59.3 \\
\hline Married & 35 & 15.8 \\
\hline Separated & 18 & 8.1 \\
\hline Divorced & 21 & 9.5 \\
\hline Widowed & 15 & 6.8 \\
\hline Missing & 1 & .5 \\
\hline \multicolumn{3}{|l|}{ Education } \\
\hline Less than High School Diploma & 8 & 3.6 \\
\hline High School Diploma & 35 & 15.8 \\
\hline Some College/ No Degree & 35 & 15.8 \\
\hline 2-yrs of College/ Associate Degree & 26 & 11.8 \\
\hline Bachelor’s Degree & 44 & 19.9 \\
\hline Master’s Degree & 38 & 17.2 \\
\hline
\end{tabular}




\section{Doctorate/ Professional Degree}

Missing

Employment

Unemployed not looking for work Unemployed looking for work Employed part-time Employed full time

\section{Retired}

Disabled

Student

Missing

Household Income
26

9

9

24

43

84

18

8

34

1
11.7

4.1

4.1

10.9

19.5

38.0

8.1

3.6

15.4

.5

12.7

12.7

13.6

10.0

7.7

10.4

6.3

5.9

2.3

4.5

6.3

6.3

1.4

Note. $N=221$

\section{Measures}

\section{Kessler Psychological Distress Scale (K6; Kessler et al., 2002; see Appendix A).}

Psychological well-being was measured using the Kessler Psychological Distress Scale, which is available in a ten-question version (K10) and a six-question version (K6). The K6 was used for its brevity. The K6 consists of statements reflecting both depressive and anxious symptoms. Items are rated on a 5-point Likert scale from 0 (None of the time) to 4 (All of the time) and assess participants’ symptomology over the past 30 days. Scores are totaled and range from 0 to 24. Researchers have identified a standard cutoff score of 13 or higher on the K6 to identify 
persons who are likely to meet the criteria for a mental illness diagnosis (Furukawa et al., 2003;

Kessler et al., 2003; Kim et al., 2012; Pratt, 2009). Sample items include “During the past 30 days, about how often did you feel nervous?” and “During the last 30 days, about how often did you feel everything was an effort?” This scale was used as the outcome variable to assess psychological well-being levels in the target population.

The K6 uses six of the same items as the K10. The K10 was developed using five community surveys, with the first survey containing 612 items. Researchers specifically focused on the 15 domains represented in the DSM-III-R diagnoses of major depression (MD) and generalized anxiety disorder (GAD) plus the positive affect domain to reduce the question pool further. This resulted in a scale of 45 questions. These questions were then used in the first pilot study. The survey was carried out in a nationally representative mail sample and included an oversampling of individuals with Hispanic surname and zip codes with high concentrations of Black individuals, with a total of 1403 respondents completed the questionnaire. The mail pilot survey resulted in a one-factor structure with a Cronbach's alpha of $\alpha=.93$. A revised set of 32 questions were then administered to a nationally representative telephone sample of 1574 respondents. Item response theory was then used to create both the K10 and K6. The measures were then used in two nationwide face-to-face surveys in the US (National Health Interview Survey; NHIS; $N=32,440$ ) and Australia (National Survey of Mental Health and Well-Being; NSMHWB; $N=10,641)$. Similarly, the K10 $(\alpha=.92)$ in the NSMHWB and the K6 $(\alpha=.92)$ in the NHIS and ( $\alpha=.89)$ in the NSMHWB had excellent internal consistency reliability. The current study yielded a Cronbach's alpha of $\alpha=.81$.

Evidence for the validity of the K10 and K6 was established by evaluating the scale's ability to discriminate between community cases and non-cases of DSM-IV disorders. 
Respondents were classified as community cases if they met the criteria for a 12-month DSM-IV diagnosis of either an anxiety disorder, mood disorder, or non-affective psychosis. Those who did not meet these requirements were considered non-cases. Both groups were administered the measures, followed by the 12-month version of the Structured Clinical Interview for DSM-IV (SCID) during an in-person interview. The K10 and K6 were found to have excellent discrimination with the area under the curve of .876 for the K10 and .879 for the K6. Additionally, a separate analysis of the NSMHWB data showed that the K10 and K6 both significantly outperform the widely used and validated Short General Health Questionnaire (GHQ 12) in discriminating cases of anxiety and mood disorders (Furukawa et al. 2003).

The LGBT People of Color Microaggressions Scale (LGBT-PCMS; Balsam et al., 2011; see Appendix B). Perceived discrimination was assessed using the LGBT-PCMS. The LGBT-PCMS is an 18-item questionnaire that was developed to measure the occurrence and perceived distress or perceived stressfulness of racial microaggressions in sexual minority communities, same-sex microaggressions in communities of color, and racial microaggressions in the context of same-sex relationships as self-reported by ethnic minorities who also identified as sexual minorities (Balsam et al., 2011). The LGBT-PCMS uses a six-point Likert scale with responses ranging from 0 (Did not happen/not applicable to me) to 5 (It happened, and it bothered me immensely). Scores range from 0 to 90, with a higher score indicating a higher occurrence of experienced microaggression and resulting stress.

The LGBT-PCMS was developed using a mixed-methods design. The first study consisted of focus groups and in-depth interviews of 53 participants identified as ethnic and sexual minorities. This study resulted in a 34-item questionnaire about LGBT racism, POC heterosexism, and LGBT relationship racism. Sample items include "Being told that race is 
important by White LGBT people” and “Not being accepted by other people of your race/ethnicity because you are LGBT.” Total scores are calculated by summing the responses to each item. Higher scores indicate higher occurrences of microaggression from both the LGBT and racial communities. This scale was used to measure perceived discrimination in BSMT. These scores will then be used to examine the relationship between perceived discrimination and psychological well-being.

Internal consistency was tested by conducting another exploratory factor analysis with a forced three-factor solution on the following subscales: LGBT Racism, POC Heterosexism, and LGBT Relationship Racism. Balsam et al. (2011) reported that the final measure resulted in an 18-item questionnaire with overall reliability resulting in a Cronbach’s alpha of $\alpha=.92$. Each of the subscales also demonstrated adequate internal consistency reliability with Cronbach alpha values of $\alpha=.89$ for LGBT Racism, $\alpha=.81$ for POC Heterosexism, and $\alpha=.83$ for LGBT Relationship. In the current study, Cronbach’s alphas ranged from .85 to .93. The full scale was $\alpha$ $=.93, \alpha=.86$ for LGBT Racism, $\alpha=.85$ for POC Heterosexism, and $\alpha=.86$ for LGBT Relationship, which are consistent with previous findings.

Construct validity was established by using bivariate correlations with measures of psychological distress such as depression and perceived stress. Explicitly, higher scores on LGBT-PCMS were correlated with depression $(r=.18 ; p<.01)$, perceived stress $(r=.16 ; p<.01)$, and internalized homonegativity $(r=.14 ; p<.01)$. Additionally, researchers found significant correlations with the two general LGBT discrimination items ("How much has homophobia interfered with your ability to live a fulfilling and productive life"; "How different do you think your life would be if you had not had to deal with the challenges of being LGBT?”). Significant correlations were also found with the three subscales of Lesbian, Gay, and Bisexual Identity 
Scale (LGBIS; Stigma Sensitivity, Internalized Homonegativity, Superiority). Outness was not associated with the overall score or with subscales. Significant gender differences were found with men receiving higher total scores and higher relationship subscale scores (Balsam et al., 2011).

\section{Internalized Homophobia Revised (IHP-R; Martin \& Dean, 1992; Herek et al.,}

1998; see Appendices $C$ and D). Self-directed feelings of sexuality stigma were assessed using the IHP-R developed by Herek and colleagues (1998). The original scale (IHP) consisted of nine items and was derived from the diagnostic criteria for ego-dystonic homosexuality contained in the 3rd edition of the Diagnostic and Statistical Manual of the American Psychiatric Association (1980). The IHP-R consists of five items and is administered with a 5-point Likert-type response scale ranging from 1 (disagree strongly) to 5 (agree strongly). Items are specified as to whether the participant is a lesbian/bisexual woman or gay/bisexual man. Example items for lesbians and bisexual women include "I feel alienated from myself because of being lesbian/bisexual” or "I wish that I could develop more erotic feelings about men,” with lesbian being replaced by gay and women replaced by men in the gay/bisexual version. Scores are computed by summing all responses. Scores range from 5 to 25, with higher scores indicating more significant internalized sexuality stigma.

Scores on the IHP-R were positively correlated $(r>.90)$ with the full IHP for all sexual orientation groups (Herek et al., 2009). Internal reliability for the IHP among a sample of men was reported at $\alpha=.85$ and IHP-R $\alpha=.82$ among a mixed-gender sample (Herek et al., 2009). For the current study, the IHP-R displayed high internal consistency reliability for both men and women with Cronbach’s alphas of .94 and .92, respectively. The IHP-R demonstrated evidence of construct validity through high correlations in gay men's self-esteem and collective self- 
esteem in gay men and lesbian individuals (Herek et al. 1998). It was also found to be positively correlated with another internalized homophobia measure (Nungesser Homosexuality Attitudes Inventory; Nungesser, 1983) in an unpublished dissertation (Sobordone, 1993).

Outness Inventory (OI; Mohr \& Fassinger, 2000; see Appendix E). Outness was measured using the OI. The OI consists of 11 items and assesses (a) the degree to which individuals in a respondent's life know about their sexual orientation and (b) how they speak openly with these individuals about their sexual orientation. Sample items include "mother," "siblings," "my new straight friends," and "leaders of my religious community (e.g., church, temple)." Each response is given on a 7-point Likert-type scale with responses ranging from 1 (person does NOT know about your sexual orientation status) to 7 (person definitely knows about your sexual orientation status, and it is OPENLY talked about). Participants also have the option to choose 0 (not applicable to your situation; there is no such person or group of people in your life) if the given situation does not apply. Scores are derived by summing the responses of each item. Scores range from 0 to 77 , with higher scores indicate more openness about sexuality (being out), while lower scores indicate more sexuality concealment.

The 11 items were organized into three subscales using exploratory factor analysis (EFA). The three subscales are Out to World (OTW), Out to Family (OTF), and Out to Religion (OTR) with reported alphas of $\alpha=.79, \alpha=.74$, and $\alpha=.97$ respectively. It is important to note that researchers only reported the OTR data for participants who responded to those items, acknowledging that this area may not be relevant to everyone. Researchers report that the overall OI's internal consistency has varied from acceptable ( $\alpha=$.79; Rickard, 2014) to good ( $\alpha=.87$; Balsam \& Mohr, 2007). Similar results were produced during this study with the full-scale reliability being $\alpha=.84$, OTW $\alpha=.80$, OTF $\alpha=.71$, and OTR $\alpha=.84$. 
Evidence of validity was established by examining correlations between self-esteem measures, identification with the LGBTQ community, stage in sexual identity development, and time in the identity development process. Specifically, gay men with high self-esteem were more likely to score higher on OI. Same-group orientation (SGO; identification with LGBTQ community) was also negatively related to internalized homonegativity and identity confusion and positively related to outness in all three domains (family, public, and religion).

Demographic questionnaire; (see Appendix F). This survey also included eight demographic questions. The demographic responses were used to describe the study sample and as control variables in the analyses. After consenting to participate in the study, participants were immediately asked to identify their gender (male or female) to ensure that they received the corresponding IHP-R reflective of their gender. Participants were also asked the degree to which they consider themselves to be a person of faith (religious or spiritual). The responses were given on a 6-point Likert-type scale of 1 (strongly disagree) to 6 (strongly agree). Although various religious ideologies may impact the model differently, this study aimed to see how participants' strength of identifying faith predicted psychological well-being rather than specific practices or beliefs.

Given the diversity that exists within the sexual minority community, participants were provided with a list of identities (lesbian, gay, bisexual, queer, questioning, and pansexual) to choose from. An open-ended space was also provided should the participants not identify with the provided terms. All participants who identify as having same-sex attraction (nonheterosexual) were included in the study. Additional demographic questions included age, education level, employment level, socioeconomic status, and marital status.

\section{Procedure}


IHP-R, K6, LGBT-PCMS, OI, and demographics were entered into the online survey engine Qualtrics. The measures were counterbalanced to reduce order effects. Instructions were presented for each specific measure as they appeared for the participants. Instructions included information about how to respond as well as the values of the responses. The survey was also designed so that the study could only be completed once on a given device. This was done to reduce the chances of multiple surveys being completed by a single participant. Likewise, each initiated survey remained open for a week to allow participants to complete the study if their initial attempt was interrupted for any reason. Incomplete surveys were locked after this time.

After receiving approval from the WVU Office of Research Integrity and Compliance’s Institutional Review Board, participants were recruited by sharing the information about the study and a hyperlink to the survey in various Facebook groups and Craigslist (see Appendix H). Follow-up posts were made at two and five weeks out from the original posts.

Despite the widespread social media posts, recruitment was slow and inconsistent. As a result, the Qualtrics research panel was also used to help recruit additional participants. The research panel aided in recruitment by contacting study participants who previously completed surveys targeting sexual minority individuals and/or identified as Black. Participants who were recruited through social media postings were compensated with \$5 Amazon gift cards. Participants who were recruited through the research panel were compensated directly by Qualtrics.

Upon clicking the link, participants were presented with a study description detailing its purpose and eligibility criteria. In the event participants became distressed while completing the survey, general information on mental health and The Substance Abuse and Mental Health Services Administration (SAMHSA) was provided to use at their discretion. Participants were 
required to acknowledge that they are at least 18 years of age. Participants that indicated that they were younger than 18 were not permitted to complete the study. For the IHP-R, which is gender-specific, participants were also required to provide their gender before beginning the survey to ensure appropriate terms were used in the items. Subsequently, participants were required to indicate their race to ensure homogeneity of the sample.

The remaining items did not require a response for participants, but participants were encouraged to respond to missing items by a prompt informing them that they missed a question. This prompt was only presented the first time, allowing participants to skip any question they did not want to answer. The survey consisted of a total of 48 items, including all measures. Participants took anywhere from 5 to 25 minutes to complete the survey. Longer completion times were the result of the survey remaining open until completed or locked after a week. Surveys completed in less than two minutes were discarded to ensure that participants attended to the items sufficiently.

\section{Research Design}

This study used a cross-sectional, correlational, quantitative survey research design to explore the relationship between faith, outness, internalized heterosexism, and perceived discrimination on BSM's psychological well-being. Creswell (2005) noted that a quantitative cross-sectional survey design is an appropriate tool to examine individuals' attitudes about specific issues prevalent to diversity. Using this design provides evidence of the nuanced differences that exist within the BSM community while also informing critical areas to focus on when working with this group. As a result, the diverse attitudes and beliefs within the BSM group are often left unexplored. Cross-sectional survey designs do not provide causal information (Levin, 2006) but will help illuminate relationships that may exist. 
Correlational designs have also been consistently used to examine the relationship between the study variables, such as microaggressions and psychological well-being, throughout the literature (e.g., Helm 2013; Knauer, 2016; Sellers, Copeland-Linder, Martin, \& Lewis, 2006). Likewise, this study aimed to explore the relationships amongst the proposed variables; as such, a correlational design was appropriate.

\section{Data Analysis Plan}

The study data was analyzed using the latest version of the Statistical Package for the Social Sciences (SPSS). The data were examined for missing records, errors, and outliers. Surveys with incomplete data (missing responses to the IHP-R, K6, LGBT-PCMS, \& OI) were not used as the minimum number needed for the analysis was exceed by completed surveys. Descriptive statistics, correlations, and linear multiple regression analyses were conducted to explore the role of faith as related to internalized sexuality stigma, perceived discrimination, and psychological well-being in BSM individuals. Descriptive statistics (i.e., mean and standard deviation) were calculated and used to describe each variable's distribution. A Pearson’s correlation matrix was created for preliminary analyses to assess each variable's relationships with one another. Assumptions testing was also conducted as part of the preliminary analysis. A series of independent samples $t$-tests were conducted as an exploratory analysis to assess differences between women and men on the study variables.

Linear regression analyses were used to conduct the primary analyses to test the hypotheses.

Hypothesis 1: Reported rates of internalized homophobia, perceived discrimination, outness, and faith will independently predict psychological well-being in BSM individuals. Total 
scores for the IHP-R, LGBT-PCMS, OI, K6, and a single item about faith were used to test this hypothesis. This was tested using multiple regression analysis.

Hypothesis 2: Higher reports of faith will negatively predict reported levels of outness. Hypothesis 3: Higher reports of faith will positively predict reported levels of internalized homophobia. The total scores of the IHP-R, OI, and a single item about faith were used to test hypotheses 2 and 3, using linear regression analysis. 


\section{CHAPTER 3: RESULTS}

The purpose of this study was to examine the relationships among internalized homophobia, outness, faith, and perceived discrimination on psychological well-being in Black sexual minority (BSM) individuals. This line of research is important because much of the previous research assessing these factors has been done on White sexual minority participants, despite evidence of different experiences based on race (Garcia et al., 2016). There is empirical evidence that internalized homophobia (Rostosky et al., 2018), outness (Riggle et al., 2017), faith (Scheitle \& Wolf, 2017), and perceived discrimination (Balsam et al., 2011; Bowleg, 2013; Hebl \& Dovidio, 2005; Kessler et al., 1999) individually relate to psychological well-being. However, there is limited research looking at all of the factors in one model. Additionally, the study aimed to explore the role of faith as it has been both found to be a protective factor (Chatters et al., 2008) and the foundation of homophobia in Black communities (Fitchett et al., 2004; Wilkerson et al., 2012). Therefore, the LGBT People of Color Microaggressions Scale (LGBT-PCMS), the Outness Inventory (OI), Internalized Homophobia Scale-Revised (IHP-R), and a single item assessing faith were used as predictor variables of psychological well-being as measured by the Kessler Psychological Distress Scale (K6).

\section{Preliminary Analysis}

\section{Measure Descriptive Statistics}

A descriptive analysis of the variables was performed using means, standard deviations, and ranges of scores for the continuous variables of perceived discrimination, internalized homophobia, outness, and psychological well-being. A summary of this information can be found below in Table 2. Frequencies and percentages were calculated for the single item assessing faith. A summary of this information can be found below in Table 3. 


\section{Table 2}

Descriptive Statistics of Study Variables

\begin{tabular}{lcccccc}
\hline \multicolumn{1}{c}{ Measure } & \multirow{2}{c}{ Range } \\
\# of items & Cronbach's alpha & Min & Max & M & SD \\
\hline 1. LGBT-PCMS & 18 & .93 & 0 & 90 & 32.58 & 20.52 \\
2. OI & 11 & .84 & 0 & 77 & 30.50 & 14.38 \\
3. IHP-R & 5 & $.94 / .92$ & 5 & 25 & $3.56 / 7.14$ & $5.83 / 6.32$ \\
4. K6 & 6 & .81 & 0 & 24 & 9.76 & 5.38
\end{tabular}

Note. $N=221$; LGBT-PCMS = LGBT People of Color Microaggressions Scale; OI = Outness

Inventory; IHP-R = Internalized Homophobia Scale-Revised; K6 = Kessler Psychological Distress

Scale; IHP-R scores reflect male and female values respectfully.

\section{Table 3}

Frequency Statistics of Faith Variable

\begin{tabular}{lcc}
\hline Responses & \multicolumn{2}{c}{ Frequency } \\
\hline Strongly disagree & $n$ & $\%$ \\
Disagree & 49 & 22.2 \\
Somewhat disagree & 41 & 18.6 \\
Somewhat agree & 30 & 13.6 \\
Agree & 34 & 15.4 \\
Strongly agree & 38 & 17.2 \\
& 29 & 13.1 \\
Total & & \\
\hline
\end{tabular}

Note. $N=221$; To what extent do you agree with this statement: "I consider myself to be a person of faith (religious or spiritual)?”

\section{Correlations}

A bivariate correlation analysis was conducted to determine the relationships between the predictor variables and outcome variables (see Table 4). LGBT-PCMS is positively correlated with OI $(r(219)=.28, p<.01)$ and IHP-R $(r(219)=.35, p<.01)$. This supports previous findings, which suggested that people are more likely to experience discrimination the more out 
they are (Riggle et al., 2017). It also supports previous research suggesting that increased discrimination experiences may lead to higher internalization of anti-LGBTQ views (Szymanski \& Henrichs-Beck, 2014; Szymanski \& Ikizler, 2013). Additionally, K6 was statistically significantly positively correlated with LGBT-PCMS $(r(219)=.46, p=.01)$, OI $(r(219)=.18, p$ $=.01$ ), and positively significantly correlated IHP-R $r(219)=.20, p=.01$. Contrary to previous studies, faith was not related to any other variables.

\section{Table 4}

Bivariate Correlation Analysis for Predictor Variables

\begin{tabular}{|c|c|c|c|c|c|}
\hline Variable & 1 & 2 & 3 & 4 & 5 \\
\hline 1. LGBT-PCMS & -- & & & & \\
\hline 2. $\mathrm{OI}$ & $* * .28$ & -- & & & \\
\hline 3. IHP-R & $* * .35$ & -.40 & -- & & \\
\hline 4. K6 & $* * .46$ & $* * .18$ & $* * .20$ & -- & \\
\hline 5. Faith & .01 & .4 & -.03 & -.01 & - \\
\hline \multicolumn{6}{|c|}{ Note. $N=$ 221; LGBT-PCMS = LGBT People of Color Microaggressions Scale; OI = Outness } \\
\hline \multicolumn{6}{|c|}{ Inventory; IHP-R = Internalized Homophobia Scale-Revised; K6 = Kessler Psychological Distress } \\
\hline Scale $* * p<.01$ & & & & & \\
\hline
\end{tabular}

\section{Multiple Regression Assumptions and Testing}

Ernst and Albers (2017) identified the following four linear regression model assumptions as essential when conducting multiple regression analyses to reduce Type I and Type II error: 1) linearity, 2) normality, 3) homoscedasticity, and 4) independence.

\section{Linearity}

The assumption of linearity states that there must be a linear relationship between the outcome variable and the predictor variables. As Wilkinson (1999) suggested, this linear relationship is presented graphically to show the linear relationship between variables. In figure 1 , the line represents a theoretical linear relationship between variables. The dots, the observed 
data, closely follow the theoretical line suggesting that the relationship between the predictor variables and the outcome variable is linear.

Figure 1. Line Graph of The Relationship Between K6 And IHP-R, LGBT-PCM, And OI Scores.

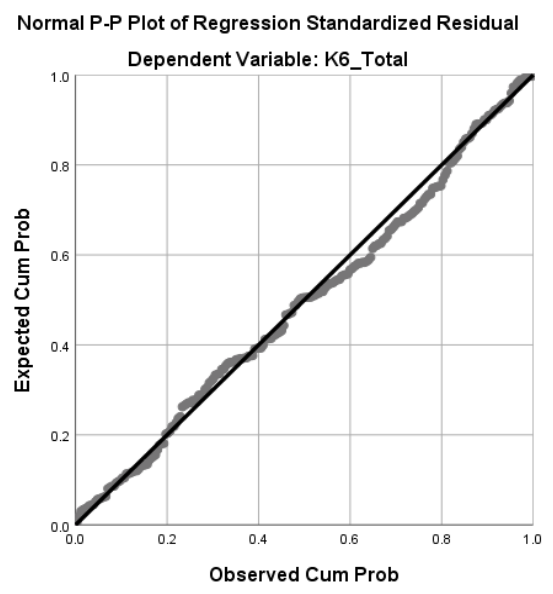

\section{Normality}

The normality assumption states that the residuals of the outcome variable are normally distributed. Williams et al. defined residuals as the differences between the observed response values and predicted response values (2013). As suggested by Wilkinson (1999), the normality of the residuals is presented in Figure 2. The data follows a natural bell curve, meeting the assumption of normality.

Figure 2. Histogram K6 Score Residuals.

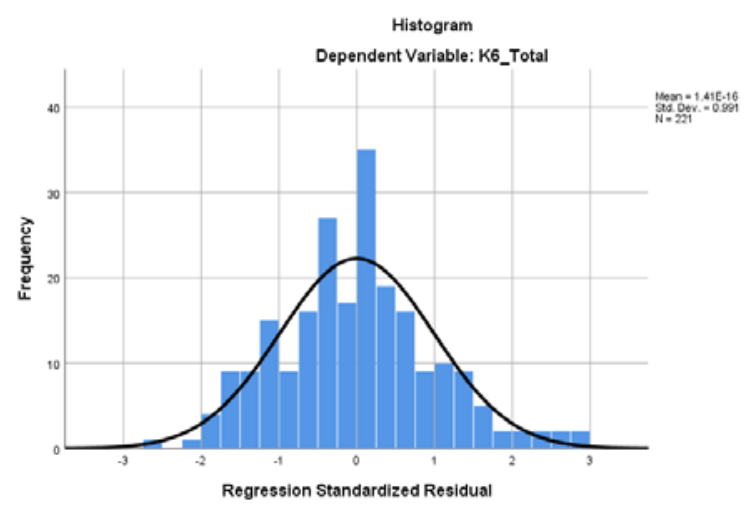




\section{Homoscedasticity}

Homoscedasticity assumes that the error term has equal variance or is similar across all predictor variables. As seen in Figure 3, the error terms are equally spread, and there is no distinct pattern/relationship, meeting the assumption of homoscedasticity.

Figure 3. Scatterplot of K6 Scores and Predictor Variable Error Terms.

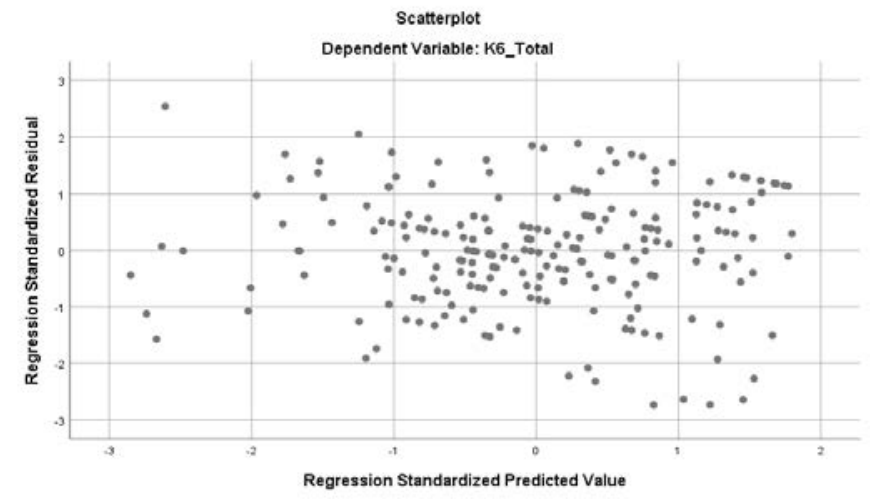

\section{Independence}

The last assumption of independence states that there is no relationship between the predictor variable and the error term. This assumption was checked by inspection of the autocorrelation of the residuals (Rubinfeld, 2011). Figure 3 shows no clear relationship, and the plats appear to be random, meeting the assumption of independence.

Williams et al. (2013) noted that multicollinearity is not an assumption but still should be tested to prevent chances of error. An analysis of collinearity indicated that multicollinearity was not a concern as tolerance was less than one and the variance inflation factors (VIF) were less than 10 (IHP-Rs, Tolerance $=.79, \mathrm{VIF}=1.27 ;$ LGBT-PCM, Tolerance $=.74, \mathrm{VIF}=1.35$; OI, Tolerance $=.876, \mathrm{VIF}=1.142$ ). Williams et al. (2013) also recommended testing for outliers. Cook’s Distance values were all under 1, suggesting individual cases were not unduly influencing the model. Additionally, standardized residuals were between 3 and -3. 


\section{Primary Analysis}

The purpose of this study was to examine the relationships among internalized homophobia, outness, faith, and perceived discrimination on psychological well-being in BSM individuals. Four hypotheses were tested using linear regression analyses. A total of 221 participant survey responses were included in the final data analysis.

\section{Hypothesis 1}

It was hypothesized that reported rates of internalized homophobia, perceived discrimination, outness, and faith would independently predict psychological well-being in BSM individuals. Internalized homophobia, perceived discrimination, outness, and psychological wellbeing were measured using the IHP-R, LGBT-PCM, OI, and K6, respectively. Faith was measured using a single item asking participants the degree to which they consider themselves a person of faith.

Results of the multiple linear regression, as seen in Table 5, indicate that the overall model is significant, $\left(F(20,189)=7.43, p<.01, R^{2}=.44 R_{\text {Adjusted }}^{2} .38\right)$. The individual predictors within the model indicate that perceived discrimination, LGBT-PCM, $(\beta=.38, p<$ .01) significantly predicts psychological well-being but internalized homophobia, IHP-R, $(\beta=$ $.08, p=.22)$, outness, OI, $(\beta=.09, p=.14)$, and faith $(\beta=.08, p=.18)$ do not. Regarding control variables, unemployment $(\beta=.13, p<.05)$, disability $(\beta=.20, p<.01)$, income $(\beta=-.16, p<$ $.05)$, and age $(\beta=-.39, p<.01)$, significantly predict psychological well-being. This finding indicates that perceived discrimination is the only factor predicting psychological well-being when accounting for control variables. A summary of the model can be found in Table 5 .

\section{Table 5}

Summary of Multiple Regression Analyses for Variables Predicting Psychological Well-being 


\begin{tabular}{|c|c|c|c|c|c|c|}
\hline \multirow{3}{*}{ Variable } & \multirow{2}{*}{\multicolumn{3}{|c|}{$\begin{array}{c}\text { Control Variables } \\
\text { adj } R^{2}=.20(S E=4.85)\end{array}$}} & \multirow{2}{*}{\multicolumn{3}{|c|}{$\begin{array}{c}\text { Control Variables + IHP-R + IO + } \\
\text { LGBT-PCMS + Faith } \\
\text { adj } R^{2}=.38(S E=4.27) \\
\end{array}$}} \\
\hline & & & & & & \\
\hline & $B$ & SE B & $\beta$ & $B$ & $S E B$ & $\beta$ \\
\hline \multicolumn{7}{|c|}{ Gender (ref: Female) } \\
\hline Male & -1.12 & .76 & -.10 & -.84 & .66 & -.07 \\
\hline \multicolumn{7}{|c|}{ Employment(ref: Employed) } \\
\hline Unemployed & 1.06 & 1.03 & .07 & 1.89 & .92 & $.13^{*}$ \\
\hline Retired & -.41 & 1.73 & -.02 & 1.77 & 1.55 & .09 \\
\hline Disabled & 4.06 & 2.02 & .13 & 5.88 & 1.81 & $.20 * *$ \\
\hline Student & -1.80 & 1.03 & -.12 & -1.35 & .92 & -.09 \\
\hline \multicolumn{7}{|c|}{ Marital Status (ref: Single) } \\
\hline Married & .83 & 1.01 & .05 & 1.42 & .90 & .09 \\
\hline Separated & -.55 & 1.32 & -.03 & .36 & 1.19 & .02 \\
\hline Divorced & -1.43 & 1.20 & -.08 & -.66 & 1.08 & -.04 \\
\hline Widowed & -1.73 & 1.38 & -.08 & -.25 & 1.25 & -.01 \\
\hline Income & -.27 & .12 & $-.17 *$ & -.23 & .10 & $-.14 *$ \\
\hline Education & .01 & .21 & .00 & -.13 & .18 & -.04 \\
\hline \multicolumn{7}{|c|}{ Sexual Orientation (ref: Lesbian/Gay) } \\
\hline Bisexual & 1.28 & .82 & .12 & 1.46 & .74 & .13 \\
\hline Queer & -1.37 & 1.86 & -.05 & -.77 & 1.64 & -.03 \\
\hline Pansexual & 3.32 & 1.55 & $.14^{*}$ & 2.73 & 1.38 & .12 \\
\hline Self-identify & -1.015 & 1.091 & -.07 & -.938 & 1.00 & -.06 \\
\hline Age & -.15 & .04 & $-.37 * *$ & -.16 & .03 & $-.39 * *$ \\
\hline IHP-R & -- & -- & -- & .09 & .07 & .08 \\
\hline OI & -- & -- & -- & .03 & .02 & .09 \\
\hline LGBT-PCMS & -- & -- & -- & .10 & .02 & $.38 * *$ \\
\hline Faith & -- & -- & -- & .24 & .18 & .08 \\
\hline \multicolumn{7}{|c|}{ Note. $N=$ 221; IHP-R = Internalized Homophobia Scale-Revised; OI = Outness Inventory; LGBT- } \\
\hline \multicolumn{7}{|c|}{ PCMS = The LGBT People of Color Microaggressions Scale; K6 = Kessler Psychological Distress } \\
\hline Scale $* p<.05 ; * * p$ & & & & & & \\
\hline
\end{tabular}

In conducting the initial bivariate correlation analyses, and the regression analyses seen in Table 5, perceived discrimination mediates the relationship between internalized homophobia, outness, and psychological well-being. Both variables have a significant effect on psychological well-being in the absence of perceived discrimination; however, neither the coefficient for 
outness nor internalized homophobia is significant after perceived discrimination is entered in the model.

Results of the multiple linear regression, as seen in Table 6, indicate that the overall model is significant, $\left(F(19,190)=7.69, p<.01, R^{2}=.43 R^{2}\right.$ Adjusted $\left.=.38\right)$. Models 1 and 2 of these analyses suggest that internalized homophobia, IHP-R $(\beta=.23, p<.01)$, and outness, OI $(\beta$ $=.17, p<.05)$ significantly predict psychological well-being before accounting for control variables, as well as after. However, neither coefficient for internalized homophobia, IHP-R, $(\beta=$ $.08, p=.19)$, nor outness, OI, $(\beta=.09, p=.14)$ are significant after perceived discrimination LGBT-PCM, $(\beta=.38, p<.01)$ is entered into the model. This finding indicates perceived discrimination is a mediator variable. This suggests that perceived discrimination helps to explain how internalized homophobia and outness relate to psychological well-being in BSM individuals. In that, internalized homophobia and outness relate to psychological well-being depending on the level of reported perceived discrimination experienced.

\section{Table 6}

Summary of Multiple Regression Analyses for Variables Predicting Psychological Well-being

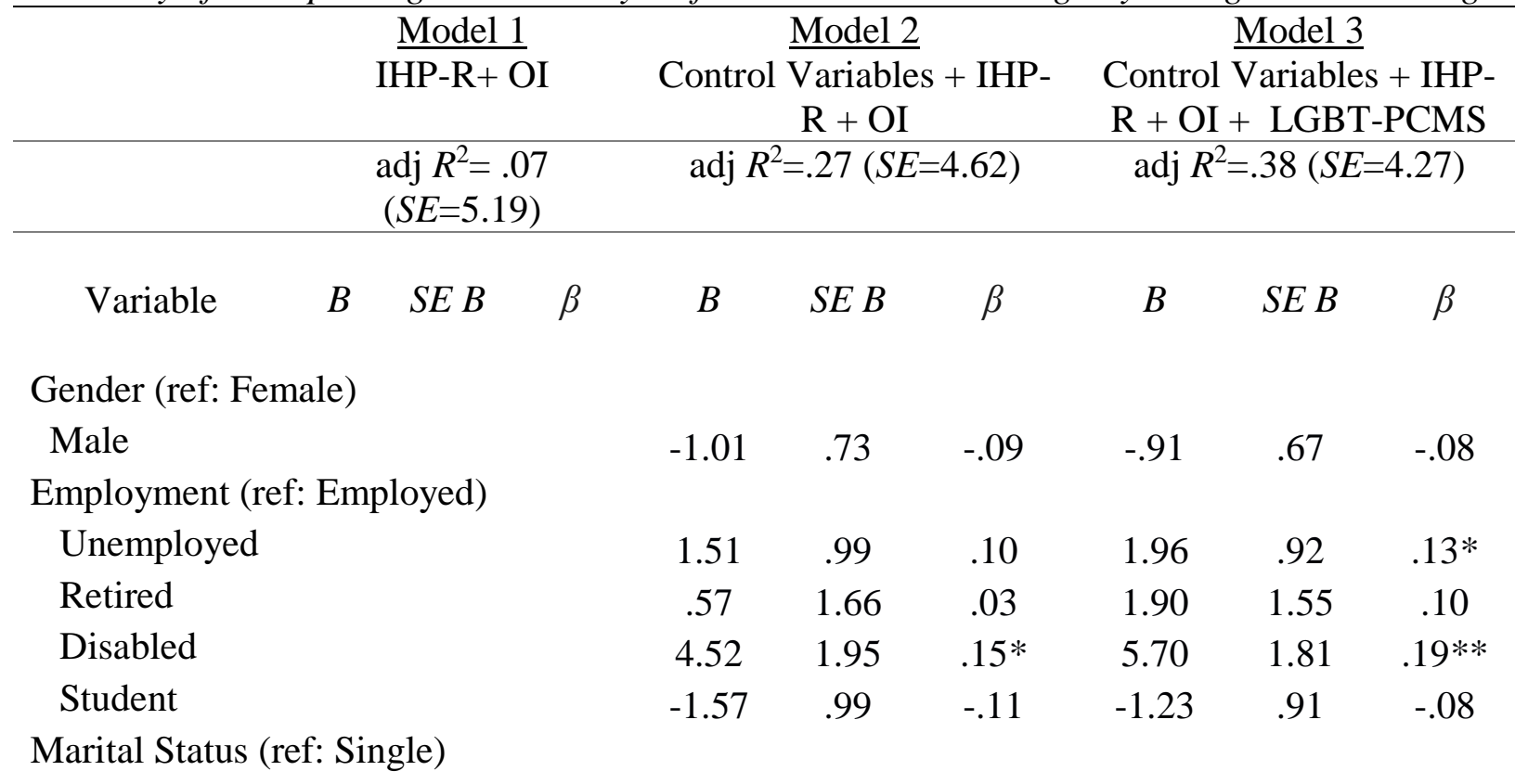




$\begin{array}{lccccccccc}\text { Married } & -- & -- & -- & .99 & .96 & .06 & 1.32 & .89 & .09 \\ \text { Separated } & -- & -- & -- & -.78 & 1.26 & -.04 & .08 & 1.18 & .00 \\ \text { Divorced } & -- & -- & -- & -1.51 & 1.16 & -.08 & -.82 & 1.08 & -.05 \\ \text { Widowed } & -- & -- & -- & -1.79 & 1.32 & -.09 & -.40 & 1.25 & -.02 \\ \text { Income } & -- & -- & -- & -.30 & .11 & -.19^{*} & -.22 & .10 & -.14^{*} \\ \text { Education } & -- & -- & -- & .01 & .20 & .00 & -.13 & .18 & -.04 \\ \text { Sexual Orientation (ref: Lesbian/Gay) } & & & & & & \\ \text { Bisexual } & -- & -- & -- & 1.32 & .79 & .12 & 1.38 & .74 & .13 \\ \text { Queer } & -- & -- & -- & -.90 & 1.78 & -.03 & -.82 & 1.64 & -.03 \\ \text { Pansexual } & -- & -- & -- & 3.72 & 1.48 & .16^{*} & 2.67 & 1.38 & .11 \\ \text { Self-identify } & -- & -- & -- & -1.30 & 1.08 & -.09 & -1.04 & 1.00 & -.07 \\ \text { Age } & -- & -- & -- & -.15 & .03 & -.37 * * & -.15 & .03 & -.38^{* *} \\ & & & & & & & & & \\ \text { IHP-R } & .24 & .07 & .21^{* *} & .27 & .07 & .23 * * & .09 & .07 & .08 \\ \text { OI } & .07 & .02 & .18^{*} & .06 & .02 & .17 * & .03 & .02 & .09 \\ \text { LGBT-PCMS } & -- & -- & -- & -- & -- & -- & .10 & .02 & .38 * *\end{array}$

Note. $N=221$; IHP-R = Internalized Homophobia Scale-Revised; OI = Outness Inventory;

LGBT-PCMS $=$ The LGBT People of Color Microaggressions Scale; ${ }^{*} p<.05 ;{ }^{* *} p<.01$

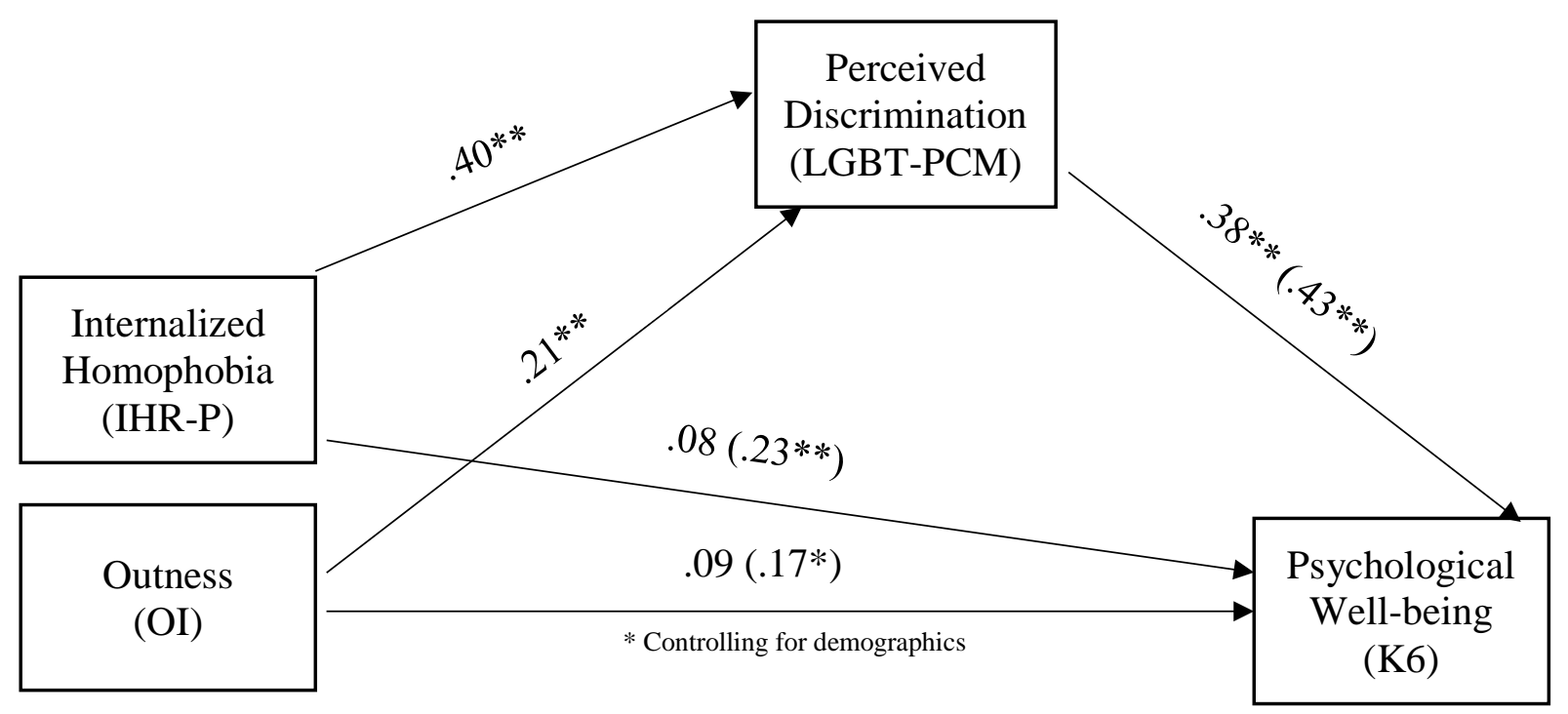

Figure 4: Indirect effects of internalized homophobia and outness on psychological well-being through perceived discrimination.

Note. ${ }^{*} p<.05 ;{ }^{* *} p<.01$ 


\section{Hypotheses 2 and 3}

Additional regressions were conducted to understand how the measure of faith in participants relates to the sexual orientation-related variables. It was hypothesized that higher reports of faith would negatively predict reported levels of outness (hypothesis 2) and positively predict reported levels of internalized homophobia (hypothesis 3). The results of the overall models for both hypotheses were not significant $\left(F(17,192)=1.40, p=.14, R^{2}=.11, R_{\text {Adjusted }}=\right.$ $.03)$ and $\left(F(17,192)=1.38, p=.15, R^{2}=.11, R_{\text {Adjusted }}^{2} .03\right)$ respectively. Regarding outness, when compared to participants that identify as lesbian or gay, participants who identified as bisexual $(\beta=-.19, p<.05)$ or self-identified $(\beta=-.19, p<.05)$ reported lower levels of outness. Regarding internalized homophobia, when compared to participants who identify as lesbian or gay, participants who self-identify $(\beta=.23, p<.05)$ also reported higher levels of internalized homophobia. However, this was not the case for participants who identify as bisexual $(\beta=.12, p$ $=.13)$. Summaries of this can be found in Table 7 and Table 8 .

\section{Table 7}

Summary of Linear Regression Analyses for Faith Independently Predicting Outness

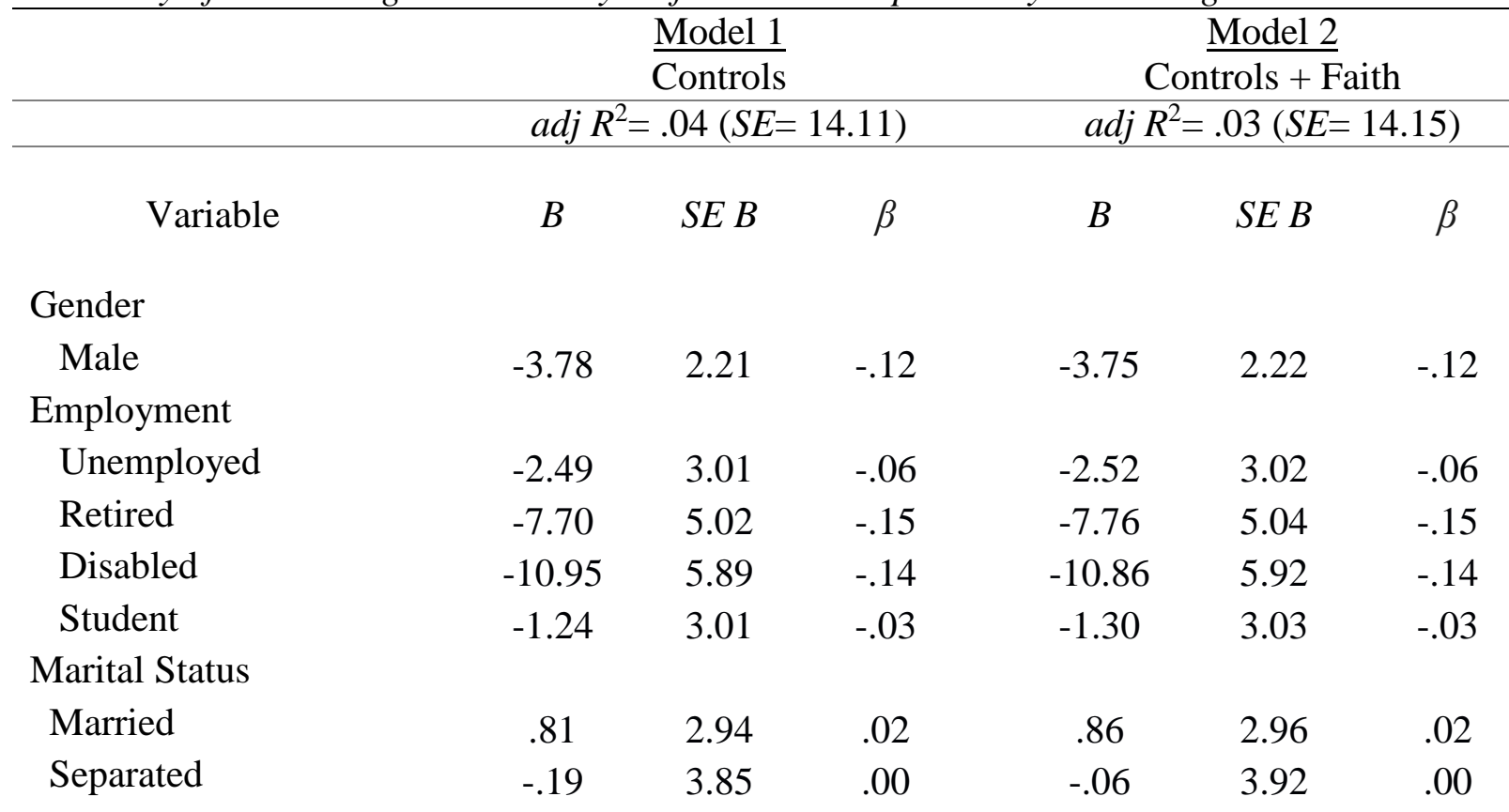




\begin{tabular}{lcccccc} 
Divorced & -4.95 & 3.50 & -.10 & -4.87 & 3.53 & -.10 \\
Widowed & -5.25 & 4.00 & -.09 & -5.18 & 4.03 & -.09 \\
Income & -.02 & .34 & .00 & -.02 & .34 & -.01 \\
Education & .60 & .60 & .08 & .60 & .60 & .08 \\
Sexual Orientation & & & & & & \\
$\quad$ Bisexual & -5.59 & 2.38 & $-.19 *$ & -5.55 & 2.40 & $-.19 *$ \\
Queer & -2.00 & 5.42 & -.03 & -1.97 & 5.43 & -.03 \\
Pansexual & -4.59 & 4.51 & -.07 & -4.56 & 4.53 & -.07 \\
Self-identify & -7.67 & 3.18 & $-.19 *$ & -7.62 & 3.19 & $-.19 *$ \\
Age & .08 & .10 & .08 & .08 & .11 & .08 \\
Faith & -- & -- & -- & .12 & .60 & .01 \\
\hline
\end{tabular}

Note. $N=221$; Marital Status: Never married/ Single, Married, Separated, Divorced,

Widowed; Sexual Orientation: Lesbian/Gay, Bisexual, Queer, Pansexual, Self-identify; $* p<.05 ; * * p<.01$

\section{Table 8}

Summary of Linear Regression Analyses for Faith Independently Predicting Internalized Homophobia

\begin{tabular}{|c|c|c|c|c|c|c|}
\hline \multirow[b]{2}{*}{ Variable } & \multicolumn{3}{|c|}{$\frac{\text { Model } 1}{\text { Controls }}$} & \multicolumn{3}{|c|}{$\begin{array}{c}\text { Model 2 } \\
\text { Controls + Faith } \\
\text { adj } R^{2}=.03(S E=4.69)\end{array}$} \\
\hline & B & $S E B$ & $\beta$ & $B$ & $S E B$ & $\beta$ \\
\hline \multicolumn{7}{|l|}{ Gender } \\
\hline Male & .46 & .73 & .04 & .50 & .74 & .05 \\
\hline \multicolumn{7}{|l|}{ Employment } \\
\hline Unemployed & -1.12 & 1.00 & -.09 & -1.17 & 1.00 & -.09 \\
\hline Retired & -1.88 & 1.67 & -.11 & -1.96 & 1.67 & -.11 \\
\hline Disabled & .84 & 1.95 & .03 & .96 & 1.96 & .04 \\
\hline Student & -.57 & 1.00 & -.04 & -.65 & 1.00 & -.05 \\
\hline \multicolumn{7}{|l|}{ Marital Status } \\
\hline Married & -.76 & .98 & -.06 & -.69 & .98 & -.05 \\
\hline Separated & .88 & 1.28 & .05 & 1.06 & 1.30 & .06 \\
\hline Divorced & 1.47 & 1.16 & .09 & 1.58 & 1.17 & .10 \\
\hline Widowed & 1.49 & 1.33 & .08 & 1.59 & 1.34 & .09 \\
\hline
\end{tabular}




\begin{tabular}{lcccccc} 
Income & .11 & .11 & .08 & .10 & .11 & .07 \\
Education & -.16 & .20 & -.06 & -.16 & .20 & -.06 \\
$\begin{array}{l}\text { Sexual Orientation } \\
\text { Bisexual }\end{array}$ & & & & & & \\
$\quad$ Queer & 1.14 & .79 & .12 & 1.19 & .79 & .12 \\
Pansexual & -1.29 & 1.80 & -.05 & -1.25 & 1.80 & -.05 \\
Self-identify & -.43 & 1.50 & -.02 & -.39 & 1.50 & -.02 \\
Age & 2.88 & 1.05 & $.22^{*}$ & 2.94 & 1.06 & $.23^{*}$ \\
Faith & -.03 & .03 & -.08 & -.03 & .03 & -.09 \\
\hline
\end{tabular}

Note. $N=$ 221; Marital Status: Never married/ Single, Married, Separated, Divorced, Widowed; Sexual

Orientation: Lesbian/Gay, Bisexual, Queer, Pansexual, Self-identify; ${ }^{*} p<.05 ;{ }^{* *} p<.01$

\section{Exploratory Analysis}

Gender Differences. Given the previous findings in gender difference regarding total scores on the LGBT-PCMS and LGBT relationship racism subscale (Balsam et al., 2011), each of the measures and subscales were examined to see if this relationship was supported by the current study data. The data were analyzed using Welch's $t$-test as it has been shown to provide better control of Type 1 error in data with unequal sample sizes and/or unequal variance (Delacre et al., 2017). No significant differences were found between men and women for LGBTPCMS, $t(128.66)=.82, p=.41$, OI, $t(163.33)=1.56, p=.12$, or IHP-R, $t(139.72)=-.79, p=.43$, total score. The mean scores for the K6 were significantly different, $t(127.143)=2.13, p<.05$, with women $(M=10.31, S D=5.17, n=150)$ scoring higher on the K6 than men $(M=8.62, S D$ $=5.65, n=71$ ). A summary of this information can be found in Table 9 .

Moreover, no significant differences for the subscales LGBT Racism, $t(147.76)=$ 1.22, $p=.22$, LGBT Relationship Racism, $t(131.17)=-1.02, p=.31$, Out to Family (OTF), $t(164.48)=1.40, p=.17$, or Out to Religion (OTR) $t(161.17)=-.82, p=.41$ were found. However, significant differences were found on subscales POC Heterosexism, $t(141.22)=$ 2.10, $p<.05$, with women $(M=12.14, S D=7.61, n=150)$ scoring higher than men $(M=9.89$, 
$S D=7.39, n=71)$ and Out to World (OTW), $t(167.33)=2.02, p<.05$, with women $(M=15.33$,

$S D=8.57)$ scoring higher than men $(M=13.15, S D=6.91)$. A summary of this information can be found in Table 10 .

\section{Table 9}

Summary of t-tests and Descriptive Statistics LGBT-PCMS, OI, IHP-R, and K6 by Gender

\begin{tabular}{|c|c|c|c|c|c|c|c|c|c|}
\hline \multirow[t]{3}{*}{ Outcome } & \multicolumn{6}{|c|}{ Group } & \multirow{3}{*}{$\begin{array}{c}\text { 95\% CI for } \\
\text { Mean } \\
\text { Difference }\end{array}$} & \multirow[b]{3}{*}{$\mathrm{t}$} & \multirow[b]{3}{*}{$\mathrm{df}$} \\
\hline & \multicolumn{3}{|c|}{ Male } & \multicolumn{3}{|c|}{ Female } & & & \\
\hline & $M$ & $S D$ & $\mathrm{n}$ & $M$ & $S D$ & $\mathrm{n}$ & & & \\
\hline LGBT-PCMS & 30.89 & 21.57 & 71 & 33.38 & 20.02 & 150 & $-3.52-8.50$ & .82 & 128.66 \\
\hline OI & 28.45 & 12.53 & 71 & 31.47 & 15.12 & 150 & $-.79-6.84$ & 1.56 & 163.33 \\
\hline IHP-R & 11.07 & 4.73 & 71 & 10.53 & 4.81 & 150 & $-1.90-.81$ & -.79 & 139.72 \\
\hline K6 & 8.62 & 5.65 & 71 & 10.31 & 5.17 & 150 & $.12-3.26$ & $2.13^{*}$ & 127.14 \\
\hline
\end{tabular}

Note. $N=221$; LGBT-PCMS = The LGBT People of Color Microaggressions Scale; OI =

Outness Inventory; IHP-R = Internalized Homophobia Scale-Revised; K6 = Kessler

Psychological Distress Scale; ${ }^{*} p<.05$, two-tailed.

\section{Table 10}

Summary of t-tests and Descriptive Statistics LGBT-PCMS and OI Subscales by Gender

\begin{tabular}{|c|c|c|c|c|c|c|c|c|c|}
\hline \multirow[t]{3}{*}{ Outcome } & \multicolumn{6}{|c|}{ Group } & \multirow{3}{*}{$\begin{array}{l}\text { 95\% CI for } \\
\text { Mean } \\
\text { Difference }\end{array}$} & \multirow[b]{3}{*}{$\mathrm{t}$} & \multirow[b]{3}{*}{$\mathrm{df}$} \\
\hline & \multicolumn{3}{|c|}{ Male } & \multicolumn{3}{|c|}{ Female } & & & \\
\hline & $M$ & $S D$ & $\mathrm{n}$ & $M$ & $S D$ & $\mathrm{n}$ & & & \\
\hline LGBTR & 10.45 & 7.68 & 71 & 11.84 & 8.31 & 150 & $-.86-3.64$ & 1.22 & 147.76 \\
\hline POCH & 9.89 & 7.39 & 71 & 12.14 & 7.61 & 150 & $.13-4.38$ & $2.10 *$ & 141.22 \\
\hline LGBTRR & 10.55 & 7.93 & 71 & 9.40 & 7.52 & 150 & $-3.37-1.07$ & -1.02 & 131.17 \\
\hline OTF & 11.31 & 5.60 & 71 & 12.52 & 6.81 & 150 & $-.50-2.92$ & 1.40 & 164.48 \\
\hline OTW & 13.15 & 6.91 & 71 & 15.33 & 8.57 & 150 & $.05-4.31$ & $2.02 *$ & 167.33 \\
\hline OTR & 3.99 & 2.91 & 71 & 3.62 & 3.46 & 150 & $-1.25-.51$ & -.82 & 161.17 \\
\hline
\end{tabular}

Note. $N=221$; LGBTR = LGBT racism; POCH = People of color heterosexism; LGBTRR =

LGBT relationship racism; OTF = Out to Family; OTW; Out to World; OTR = Out to Religion;

Distress Scale; ${ }^{*} p<.05$, two-tailed.

Perceived Discrimination. The LGBT-PCSM was further analyzed to examine specific forms of perceived discrimination that may impact psychological well-being. Results of a multiple regression analysis show that the overall model was significant $(F(21,188)=7.25, p<$ 
$.01, R^{2}=.45, R^{2}$ Adjusted $\left.=.39\right)$. The individual predictors within the model indicate that racism with the LGBTQ community, from the subscale LGBTR, $(\beta=.06, p=.50)$, and relationship racism, from the subscale LGBTRR, $(\beta=.05, p=.59)$ do not significantly predict psychological well-being, but heterosexism within the racial community, from the subscale POCH $(\beta=.31, p$ $<.01)$ does. In this analysis, internalized homophobia and outness remain insignificant. Because outness remained insignificant, the subscales were not explored. A summary of these findings can be found in Table 11 .

\section{Table 11}

Summary of Linear Regression Analyses for LGBT-PCMS Subscales Independently Predicting Psychological Well-being

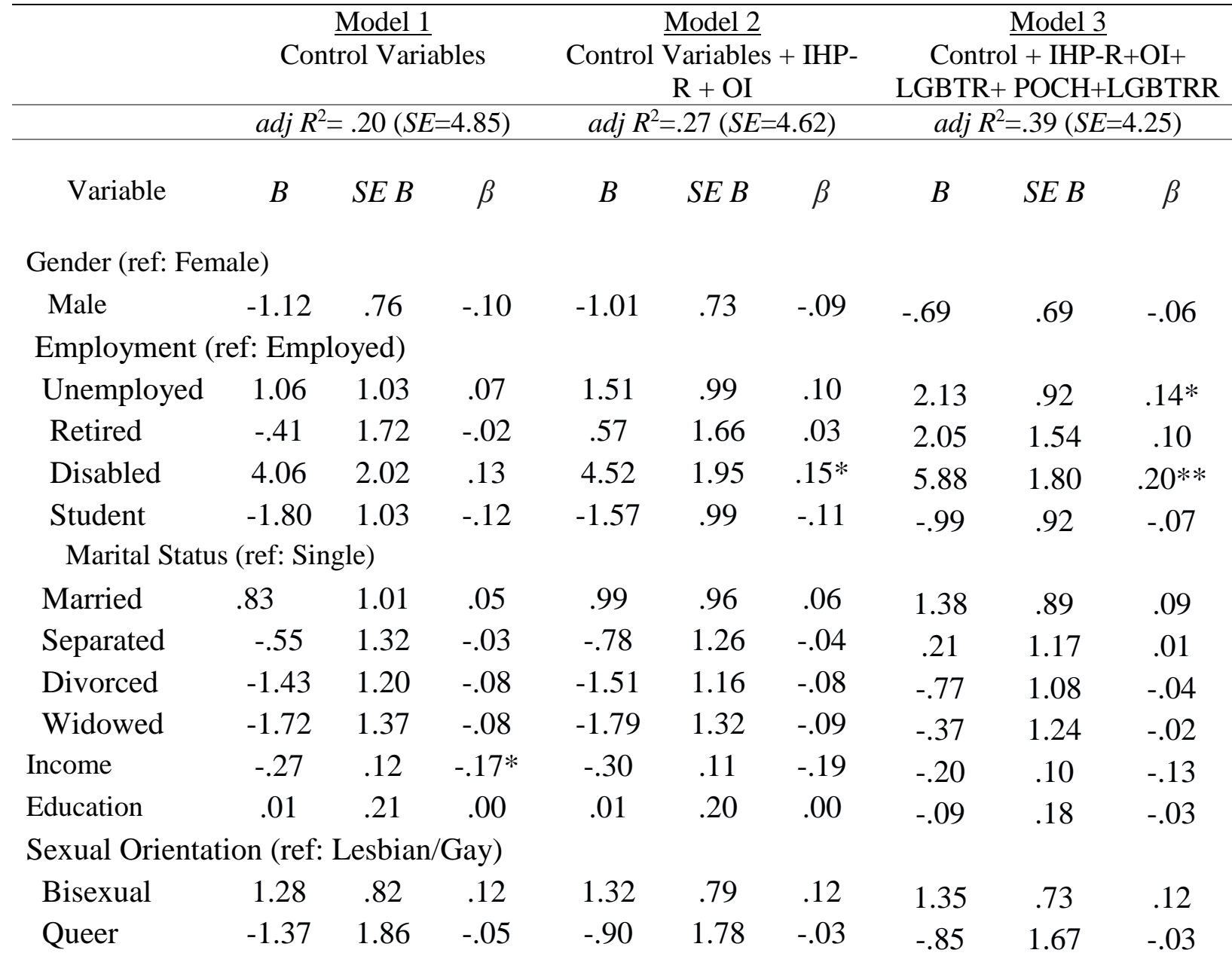




\begin{tabular}{|c|c|c|c|c|c|c|c|c|c|}
\hline Pansexual & 3.32 & 1.55 & $.14^{*}$ & 3.72 & 1.48 & .16 & 3.01 & 1.39 & $.13^{*}$ \\
\hline Self-identify & -1.01 & 1.09 & -.07 & -1.30 & 1.08 & -.09 & -1.09 & .99 & -.07 \\
\hline Age & -.15 & .04 & $-.37 * *$ & -.15 & .03 & $-.37 * *$ & -.16 & .03 & $-.39 * *$ \\
\hline IHP-R & -- & -- & -- & .27 & .07 & $.23^{* *}$ & .12 & .07 & .11 \\
\hline $\mathrm{OI}$ & -- & -- & -- & .06 & .02 & $.17^{*}$ & .03 & .02 & .09 \\
\hline LGBTR & -- & -- & -- & -- & -- & -- & .04 & .05 & .06 \\
\hline LGBTRR & -- & -- & -- & -- & -- & -- & .04 & .07 & .05 \\
\hline $\mathrm{POCH}$ & -- & -- & -- & -- & -- & -- & .22 & .06 & $.31 * *$ \\
\hline \multicolumn{10}{|c|}{ Note. $N=221 ;$ IHP-R = Internalized Homophobia Scale-Revised; OI = Outness Inventory; } \\
\hline $\mathrm{LGBTR}=\mathrm{LG}$ & & & & & & & & & \\
\hline
\end{tabular}




\section{Chapter 4: Discussion}

Psychological well-being has been studied in ethnic minorities (Molix \& Bettencourt, 2010) and sexual minorities in the U.S. (Diamond \& Lucas, 2004; Meyer, 2003). Researchers have explored the relationships between well-being and perceived discrimination (Garofalo et al., 1999; Kessler et al., 2010), sexuality acceptance (Rostosky et al., 2018), sexual orientation outness (Riggle et al., 2017), and faith (Moreira-Almeida et al., 2014). However, few studies have explored how each of these factors relates to psychological well-being as a whole. Given that previous research shows that perceived discrimination regarding race (Kessler et al., 1999; Rucker et al., 2010), sexuality acceptance (Bejakovich \& Flett, 2018; Morris et al., 2001; (Rostosky et al., 2018; Szymanski \& Henrichs-Beck, 2014; Szymanski \& Ikizler, 2013), and faith (Cohen, 2014; Levin \& Taylor, 1998; Pecchioni, \& Grant, 2000) each independently impact psychological well-being in Black and sexual minority individuals, the current study addresses how the relationships between each of these factors impact psychological well-being for individuals who hold these intersecting identities.

The purpose of this study was to examine the relationships among internalized homophobia, outness, faith, and perceived discrimination on psychological well-being in BSM individuals. It was hypothesized that 1 ) reported rates of internalized homophobia, perceived discrimination, outness, and faith would independently predict psychological well-being in BSM individuals; 2) higher reports of faith will negatively predict reported levels of outness; and 3) faith will positively predict reported levels of internalized homophobia. This study aimed to provide greater insight into factors that impact psychological well-being in BSM individuals. The study results provide more information about critical factors that may be explored further in future research. It also reflects the importance of exploring how intersecting marginalized 
identities impact individuals who hold them and the need for more nuanced considerations when providing services.

\section{Summary of the Findings}

Significant findings suggest that internalized homophobia, outness, and perceived discrimination independently predict BSM individuals' psychological well-being. Explicitly, higher reports of internalized homophobia and higher reports of outness both predicted poorer psychological well-being after controlling for demographics. However, both factors only directly predicted psychological well-being in the absence of perceived discrimination. After accounting for all factors and controlling for the demographics, internalized homophobia and outness were no longer statistically significantly predicted by psychological well-being. As a result, it was determined that perceived discrimination mediates the relationship between these two factors and psychological well-being. Higher reports of internalized homophobia and increased outness were also related to increased reports of perceived discrimination, leading to poorer psychological well-being. These findings support previous research, which found that individuals who were out were more likely to experience discrimination (Riggle et al., 2017) and how increased discrimination also predicts higher internalization of those negative messages (Riggle et al., 2010; Szymanski \& Henrichs-Beck, 2014; Szymanski \& Ikizler, 2013) in sexual minority individuals.

In the present study, internalized homophobia and outness indirectly relate to psychological well-being through perceived discrimination, while perceived discrimination directly relates to psychological well-being. These findings are noteworthy because they differ from previous research, which found that perceived discrimination is directly related to physical health but indirectly related to mental health through internalized homophobia in 474 LGBT 
individuals (Walch et al., 2016). However, it is important to note that the majority of the sample ( $n=382,81 \%)$ identified as White, while only 5\% $(n=23)$ identified as Black. The current study findings are likely different, given that all of the participants identify as Black.

Additionally, the study mentioned above also looked at perceived discrimination in terms of sexual orientation and not race/ethnicity, which may also explain differences in findings. These differences further support the need for more research exploring intersecting identities as assessing single identities does not fully explain the relationships amongst the variables, nor does it represent differences that may exist. While BSM individuals may be able to engage invisibility management (Lasser \& Tharinger, 2003) regarding their sexuality, they cannot do so with their race.

Additionally, the study revealed that faith does not appear to predict psychological wellbeing in BSM individuals. This is an important finding because it does not support previous findings that faith is related to psychological well-being in Black Americans (Levin \& Taylor, 1998). It also does not support findings that religious conflict in sexual minorities negatively impacts individuals' mental health (Fitchett et al., 2004). Likewise, Walker and Longmire-Avital (2013) found that faith played a dual role for BSM individuals where religious faith was positively correlated with internalized homonegativity. The researchers found that religious faith did not contribute to resiliency for participants who reported low internalized homonegativity. Conversely, religious faith significantly contributed to resiliency in participants who reported high levels of internalized homonegativity. That is, religious faith, while predicting higher reports of internalized homophobia in the sample, was positively related to participants' ability to cope with adversity. This study demonstrates how faith can negatively and positively impact BSM individuals. 
The lack of findings are surprising given that many conservative religions condemn same-sex attraction and behavior (Barnes \& Meyer, 20212; Janssen \& Scheepers, 2019), and Black Americans are the most religious ethnic group in the country (Pew 2015). It seems likely that faith would relate to psychological well-being in BSM individuals, positive (Chatters et al., 2008; Taylor, Chatters, \& Jackson, 2009; Levin \& Taylor, 1998; McAuley, Pecchioni, \& Grant, 2000) or negative (Bonilla \& Porter, 1990; Cohen, 2014; Herek \& Capitanio, 1995; Lewis, 2003;

McKenzie \& Rouse, 2013). Additionally, faith was not found to be significantly related to internalized homophobia or outness.

The lack of significant findings regarding faith may be due to several reasons. First, it is possible that the single item evaluating faith was not sufficient in capturing the full impact of spiritual/religious beliefs in the sample. Likewise, the question did not assess the level of adherence to anti-LGBTQ messages. As a result, participants could identify as religious and/or spiritual to a high degree, without holding traditional anti- LGBTQ beliefs. An additional reason may be based on the geographical location and demographics of the community the participants lived. Researchers found that non-religious individuals (no religious affiliation or attendance) were more likely to hold anti-same-sex views if they lived in an area with high religious service attendance, and/or the majority of the community identified as evangelical Protestants in the area (Moore et al., 2021). Individuals who lived in the southern part of the US were also more likely to disapprove of sexual minority individuals (Moore et al., 2021). Conversely, participants who lived in larger cities that were highly populated were less likely to share anti-LGBTQ views (Moore et al., 2021). They also noted that participants who reported lower levels of religious attendance and weaker affiliations were more likely to accept same-sex relations. Because this study did not assess for location, community makeup, or religious attendance, the study 
participants may or may not live in communities that were more accepting of sexual minority individuals.

An additional factor that may have minimized the effects of faith regarding LGBTQ stigma is the level of completed education. Researchers found that participants who completed some college were more accepting of LGBTQ individuals (Moore et al., 2021). This is important because most of this study's sample (81\%; $n=178)$ completed some college. Equally important, the level of education does not appear to diminish religiousness regarding individuals who identify as Christians, as highly-college-educated and less-college-educated reported similar levels of religiosity (Pew, 2017). Conversely, highly-college-educated Christian respondents reported attending weekly church services more frequently than less-educated respondents (Pew, 2017). However, as a whole, religion is correlated with more education in the US (Pew, 2017).

These findings suggest that more information regarding religious identification, such as religious affiliation and dedication, may help explain the lack of findings in this study

\section{Exploratory Findings}

Perceived Discrimination. Exploratory analyses were conducted to help further examine the data. Regarding perceived discrimination, results show that the LGBT-PCMS subscale assessing sexuality-discrimination within one's racial/ethnic community (POC Heterosexism) was solely responsible for mediating the relationships between internalized homophobia, outness, and psychological well-being. This finding suggests that sexual orientation discrimination from the Black community is potentially more impactful than discrimination based on race from the LGBTQ community. This finding may be because previous findings have shown that BSM individuals identify as Black first (Bowleg, 2013). Because BSM individuals identify with their race first, it is reasonable that they would also identify more strongly with the 
Black community over the LGBTQ community, thus making backlash from this group more impactful.

These findings are different from previous research that assessed perceived discrimination and self-stigma in a sample of ethnic/racial minority individuals and sexual minorities. This study found that sexual orientation self-stigma predicted anxiety and depressive symptoms in the sample over and above perceived discrimination (Ramirez \& Galupo, 2019). Although perceived discrimination (measured by the LGBT-PCMS) remained significant after accounting for self-stigma, it accounted for less of the variance in reported anxiety and depression symptoms in the sample. One explanation for this difference may be that sexual orientation self-stigma was measured differently. Additionally, the sample was made up of individuals who held different racial/ethnic identities.

Lastly, the researchers (Ramirez \& Galupo, 2019) noted that the data was collected shortly after the Pulse nightclub shooting, making participants' sexual orientation identity more salient at the time. This is noteworthy because the data from the current study were collected from February 2020 to October 2020. Two notable events occurred during this time, the COVID19 pandemic and the murders of Breonna Taylor and George Floyd. These two events are important because Black Americans were disproportionately impacted by the virus (Wright \& Merritt, 2020), and the murders of Breonna Taylor and George Floyd sparked large protests across the country, thus potentially making participants more aware of their race.

Gender Differences. No significant differences were found on the LGBT-PCMS or the LGBT racism and LGBT relationship racism subscales. This finding is different from research which found that men scored higher overall and on the relationship subscale (Balsam et al., 2011) than women. Conversely, women and men differed significantly on POC Heterosexism 
scores, with women reporting more perceived discrimination within the Black community. Because the LGBT-PCMS does not address gender discrimination/microaggressions, gender may have impacted women's responses on this subscale. Specifically, item 8 on the LGBT-PCMS ("Feeling misunderstood by people in your ethnic/racial community") does not explicitly address sexuality and could account for issues within the Black community that were not assessed in the study. The level of endorsement for this item was significantly different, $t(158.20)=$ 3.02, $p<.01$, with women $(M=2.28, S D=1.64, n=150)$ scoring higher than men $(M=1.63, S D$ $=1.41, n=71)$. Although the item responses are not scaled, the mean difference suggests that women endorsed this item more frequently than men.

This finding is further supported by a qualitative study examining the experiences of Black women where participants reported experiencing discrimination based on skin tone and hair, primarily from family members and potential Black male partners (Davis Tribble et al., 2019). Participants reported experiencing discriminatory messages such as a preference for lighter-skinned women, encouragement to embrace European standards of beauty, and messages of being "ghetto" based on their hairstyles (Davis Tribble et al., 2019). Additional issues include Black women being viewed as more masculine because of their independent, self-reliant attitudes and behaviors, and gender role strain in the Black community, thus making them less desirable by Black male peers (Hurt et al., 2014).

Finally, women scored significantly higher on the K6, suggesting less reported psychological well-being. This finding is reasonable given Meyer's (2003) minority stress theory which suggests that individuals with minority identities experience worse mental health outcomes, and intersectionality theory (Crenshaw, 1989; Hill Collins \& Bilge, 2020; Warner \& Shields, 2013) which suggests that holding multiple minority identities compounds the effects of 
minority stress. Unlike the men in this study, the women participants hold three marginalized identities, thus adding gender discrimination as a factor. In addition, while no gender differences were reported for OI (Mohr \& Fassinger, 2000), women scored higher on the subscale Out to World (OTW) than men, which research has demonstrated the positive relationship between outness and lower psychological well-being (Riggle et al., 2017). Higher rates of outness have also been associated with increased substance use and worse mental health in women who identify as bisexual and non-monosexual (exclusively lesbian) (Feinstein et al., 2017; Xavier et al., 2021). This finding is noteworthy because $52 \%$ of all participants $(n=114)$ and $76 \%(n=$ 114) of women participants identified as non-monosexual.

\section{Implications for Counseling Psychology}

Understanding and addressing psychological well-being can be challenging when addressing the intersections of race and sexual identity, particularly when working with BSM individuals as there are multiple factors to consider, including anti-LGBTQ messages from the Black community and religious organizations, discrimination based on race in the LGBTQ community, and the internalization of these harmful messages. Consequently, it is essential for psychology professionals to be aware of these different contextual factors and how microaggressions directly or indirectly impact mental well-being. Professionals working with BSM individuals should be aware there may be barriers to accessing social support due to the complex relationship between internalized homophobia and religious faith. Although identifying as a sexual minority and/or identifying as religious is not mutually exclusive, both should be explored to better understand how these factors impact the lived experiences of clients. This may include exploring resources that are both LGBTQ- and faith-affirming. It may also mean seeking more continuing education to better help understand the nuances of this population. 
Identity is complex and fluid and can be difficult to define or represent in any given interaction. As a result, it is important for clinicians to consider and acknowledge how their privileged and/or oppressed identities may differ from clients who identify as BSM individuals. Clinicians should also explore how their lived experiences and biases may impact the work they do with BSM clients. While this is especially important for clinicians who predominately hold majority identities, it is also important for clinicians who may share and/or hold separate marginalized identities. This may help in reducing clients’ exposure to further microaggressions and over generalizing their experiences.

Likewise, it will be important for clinicians to periodically check-in with clients regarding their identities when appropriate. Depending on the sociopolitical climate and other historical events, the saliency of one’s identity may shift throughout treatment. Consequently, issues regarding their identities may fluctuate based on the clients' recent lived experiences and messages they are receiving. In any case, acknowledging recent events does not need to be the main focus of any given session, but should be addressed to further show that the clinician recognizes the magnitude of its impact on clients.

Clinicians should be mindful in exploring how faith/religion may play a role in clients' lives, even if they do not identify as religious themselves. Additionally, exploring views about same-sex attraction, support systems, and affirming communities may help better understand individual clients' experiences. Relationships with one's identity are complex and can be challenging for BSM individuals. While some individuals may feel comfortable with supporting and belonging to the LGBTQ, others may not. Likewise, family members and religious institutions may not support or accept the individual's sexual minority identity, leaving these individuals to feel excluded from all of their identities, which may impact clients’ psychological 
well-being. More importantly, it is essential for clinicians to remember that no identity is a monolith and that there is diversity in every group/identity and that the most informative information will often come directly from the clients themselves.

\section{Limitations}

Although the current findings add to the scholarship in several important ways, it is important to acknowledge the study's limitations. First, although electronic surveys allow for easier and broader distribution, they also pose several issues. As with any online survey, participant attention variables can be a factor. These issues include participants completing the survey multiple times, bots or illegitimate responding, and participant inattentiveness. Using the Qualtrics research panel, these issues were minimized, as the specialist assigned to recruitment evaluated each survey for time spent completing the survey, random responding, and multiple responses from a single device.

Additionally, participation incentives were offered to random participants, minimizing the opportunity for a single participant to receive multiple gift cards. Although some participants were randomly sampled and the research panel is from a nationwide sample, the responses may be biased as more than half of the participants regularly complete surveys. However, using a research panel also means that the sample is not necessarily representative of BSM individuals in the US. There is no way to know if any of the participants recently responded to similar survey questions. Likewise, those who chose to participate in the study may differ in ways from those who chose not to participate in ways that may have impacted responses. The use of electronic surveys also excludes individuals who do not have access to the internet or smartphones.

Additional issues regarding the use of surveys include socially desirable responses, misinterpretation of items, and lack of depth to responses. Because the surveys are completed 
independently, researchers are not readily available to answer any questions participants may have about the survey. Participants may experience difficulties with interpreting some of the questions in the way they were intended. Furthermore, survey studies limit participants' responses to those that are provided. While participants may choose the same responses, the reasoning behind the responses might be different. This further speaks to the issues raised by Garcia et al. (2016) that the MSM research often fails to explore the diversity in responses that exist within the group. Lastly, allowing participants to self-identify regarding their sexuality allowed for a broader range of responses; the responses were vastly different. Regardless of the written response provided, all participants were grouped into "self-identified."

Although there are measures to assess both internalized homophobia and outness, operationalizing these constructs can be difficult, making them harder to measure effectively. The OI measured how open individuals are about their sexuality but does not measure active concealment of their sexuality. Exploring concealment versus openness may produce different outcomes. Similarly, the IHP-R only measures negative feelings about one's sexual identity, and it is possible that these experiences can be expressed in different ways other than feelings alone. Likewise, the single item used for faith likely played a significant role in the lack of findings in this study. Using a more robust questionnaire regarding faith may help yield results.

Similarly, the K6 does not measure psychological well-being directly. Instead, psychological well-being was assumed with lower scores on the K6. Although prior research shows stronger relationships between adverse outcomes and well-being using questions that measure negative affect versus positive affect (Schmitt et al., 2014), it is possible that using a measure that assesses the presence of positive affect would produce different results. 
Lastly, some of the data were collected at the start of the nationwide shutdown due to the COVID-19 global pandemic and Black Lives Matter (BLM) movement. This is important because the study specifically looked at psychological well-being. As a result, some of the scores on the K6 may be more related to stress and emotional concerns related to loss of jobs and wages, sudden isolation from others, fear/uncertainty of one's safety and the safety of loved ones, or the perpetual violence displayed against Black individuals by the police. Additionally, the number of women participants was more than double the number of men. Consequently, the data may be heavily influenced by gender differences. This also leads to additional concerns regarding transgender, gender-nonconforming, and gender non-binary individuals who may also identify as sexual minorities. Again, having a more comprehensive range of gender expression could also influence the data.

\section{Future Research}

Future research may look to address some of the limitations in this study. These limitations could include using a national-representative sample to capture the full diversity of the group. Using a more robust questionnaire to explore faith in participants may also be helpful. Inquiring about a specific religion, denomination, religious service attendance, religious participation (prayer, tithing, fasting, etc.), use of faith to cope with discrimination versus use faith to cope with other hardships, and specific information about LGBTQ teachings at one's religious institution may provide information about how faith is related to psychological wellbeing in BSM individuals.

Future studies may also examine how family and cultural groups link to psychological well-being. This is important because POC Heterosexism was found to be the most predictive form of discrimination in this study. This generates issues related to support, connectedness, and 
acceptance, all of which may also impact psychological well-being. Regardless of religious and/or spiritual beliefs, family and community support may also impact reports of internalized homophobia and outness. In turn, these factors may impact reports of perceived discrimination and illuminate additional areas of focus.

This study also did not assess gender discrimination and tension within the Black community and only included individuals identified as cisgender. As women reported poorer psychological well-being than men, it is possible that gender played a role in their experiences. It would also be interesting to see how TGNC individuals may respond differently as there would also be added discrimination. However, adding TGNC individuals would also require different instruments as the IHP-R has not been validated on non-cisgender individuals.

Lastly, using a mixed-methods design could yield more information about participants' responses_-particularly individuals who self-identified. Researchers could gain a better understanding of how self-identification impacts reporting on the study's variables. This is because previous research found that individuals held more positive views of their sexuality when self-identifying (Garcia et al., 2016). However, the sample of self-identified individuals was not large enough to conduct exploratory analyses to see if differences exist.

In sum, there is still much work that needs to be done to understand the experiences of BSM individuals fully. This study adds to the literature by illuminating issues such as the correlations of POC heterosexism with psychological well-being, specifically in BSM individuals. It also adds to the literature by further supporting the relationship between perceived discrimination and psychological well-being. Equally, the data regarding the role of faith, religion, and spirituality in internalized homophobia and coping continues to be mixed and should be continued to be explored through various avenues. 


\section{References}

Balsam, K. F., \& Mohr, J. J. (2007). Adaptation to sexual orientation stigma: A comparison of bisexual and lesbian/gay adults. Journal of Counseling Psychology, 54(Suppl 3), 306319. https://doi-org.wvu.idm.oclc.org/10.1037/0022-0167.54.3.306.supp

Balsam, K. F., Molina, Y., Beadnell, B., Simoni, J., \& Walters, K. (2011). Measuring multiple minority stress: The LGBT People of Color Microaggressions Scale. Cultural Diversity and Ethnic Minority Psychology, 17(2), 163-174. https://doiorg.wvu.idm.oclc.org/10.1037/a0023244

Barnes, D. M., \& Meyer, I. H. (2012). Religious affiliation, internalized homophobia, and mental health in lesbians, gay men, and bisexuals. American Journal of Orthopsychiatry, 82(4), 505-515. https://doi-org.wvu.idm.oclc.org/10.1111/j.1939-0025.2012.01185.x

Barnes, S. L., \& Hollingsworth, C. (2020). Spirituality and social media: The search for support among Black men who have sex with men in Tennessee. Journal of Homosexuality, 67(1), 79-103. https://doiorg.wvu.idm.oclc.org/10.1080/00918369.2018.1525945

Bauermeister, J. A., Johns, M. M., Sandfort, T. G. M., Eisenberg, A., Grossman, A. H., \& D’Augelli, A. R. (2010). Relationship trajectories and psychological well-being among sexual minority youth. Journal of Youth and Adolescence, 39(10), 1148-1163. https://doi-org.wvu.idm.oclc.org/10.1007/s10964-010-9557-y

Beard, K., Eames, C., \& Withers, P. (2017). The role of self-compassion in the well-being of self-identifying gay men. Journal of Gay \& Lesbian Mental Health, 21(1), 77-96. https://doi-org.wvu.idm.oclc.org/10.1080/19359705.2016.1233163 
Bejakovich, T., \& Flett, R. (2018). “Are you sure?”: Relations between sexual identity, certainty, disclosure, and psychological well-being. Journal of Gay \& Lesbian Mental Health, 22(2), 139-161. https://doi.org/10.1080/19359705.2018.1427647

Berg, R. C., Munthe-Kaas, H. M., \& Ross, M. W. (2016). Internalized Homonegativity: A Systematic Mapping Review of Empirical Research. Journal of Homosexuality, 63(4), 541-558. https://doi-org.wvu.idm.oclc.org/10.1080/00918369.2015.1083788

Bonilla, L., \& Porter, J. (1990). A comparison of Latino, Black, and non-Hispanic White attitudes toward homosexuality. Hispanic Journal of Behavioral Sciences, 12(4), 437452. https://doi-org.wvu.idm.oclc.org/10.1177/07399863900124007

Bowleg, L. (2013). “Once you’ve blended the cake, you can’t take the parts back to the main ingredients”: Black gay and bisexual men’s descriptions and experiences of intersectionality. Sex Roles, 68(11-12), 754-767. https://doiorg.wvu.idm.oclc.org/10.1007/s11199-012-0152-4

Bowleg, L., Huang, J., Brooks, K., Black, A., \& Burkholder, G. (2003). Triple Jeopardy and Beyond: Multiple Minority Stress and Resilience Among Black Lesbians. Journal of Lesbian Studies, 7(4), 87-108. https://doi-org.wvu.idm.oclc.org/10.1300/J155v07n04_06

BrckaLorenz, A., Duran, A., Fassett, K., \& Palmer, D. (2021). The within-group differences in LGBQ+ college students’ belongingness, institutional commitment, and outness. Journal of Diversity in Higher Education, 14(1), 135-146. https://doiorg.wvu.idm.oclc.org/10.1037/dhe0000135

Breland-Noble, A. M., Wong, M. J., Childers, T., Hankerson, S., \& Sotomayor, J. (2015). Spirituality and religious coping in African-American youth with depressive 
illness. Mental Health, Religion \& Culture, 18(5), 330-341. https://doiorg.wvu.idm.oclc.org/10.1080/13674676.2015.1056120

Brooks, D., Wirtz, A. L., Celentano, D., Beyrer, C., Hailey-Fair, K., \& Arrington-Sanders, R. (2021). Gaps in science and evidence-based interventions to respond to intimate partner violence among Black gay and bisexual men in the U.S.: A call for an intersectional social justice Approach. Sexuality \& Culture, 25(1), 306-317. https://doiorg.wvu.idm.oclc.org/10.1007/s12119-020-09769-7

Burks, A. C., Cramer, R. J., Henderson, C. E., Stroud, C. H., Crosby, J. W., \& Graham, J. (2018). Frequency, nature, and correlates of hate crime victimization experiences in an urban sample of lesbian, gay, and bisexual community members. Journal of Interpersonal Violence, 33(3), 402-420. https://doiorg.wvu.idm.oclc.org/10.1177/0886260515605298

Burnett, D. A. (2020). Anti-Blackness as the lynchpin of the structured violence of diet-related disease. American Anthropologist, 122(3), 641-642. https://doiorg.wvu.idm.oclc.org/10.1111/aman.13438

Burrow, A. L., \& Hill, P. L. (2012). Flying the unfriendly skies?: The role of forgiveness and race in the experience of racial microaggressions. The Journal of Social Psychology, 152(5), 639-653. https://doiorg.wvu.idm.oclc.org/10.1080/00224545.2012.686461

Buttram, M. E. (2020). The social environmental context of resilience among substance-using African American/Black men who have sex with men. Journal of Homosexuality, 67(6), 816-832. https://doi-org.wvu.idm.oclc.org/10.1080/00918369.2018.1557952 
Capodilupo, C. M. (2016). Microaggressions in counseling and psychotherapy. In Sue, D. W., Sue, D., \& Sue, D. W. (Ed.). Counseling the culturally diverse: Theory and practice. (7th ed., pp. 179-208). Wiley.

Carden, K. D., McDuffie, D. L., Murry, K., Bui, C., \& Allen, R. S. (2021). Minority stress process among older black Americans: The role of age, perceived discrimination, and anxiety. Aging \& Mental Health. Advanced Online Publication. https://doiorg.wvu.idm.oclc.org/10.1080/13607863.2021.1904380

Casey, L. S., Reisner, S. L., Findling, M. G., Blendon, R. J., Benson, J. M., Sayde, J. M., \& Miller, C. (2019). Discrimination in the United States: Experiences of lesbian, gay, bisexual, transgender, and queer Americans. Health Services Research, 54, 1454-1466. https://doi-org.wvu.idm.oclc.org/10.1111/1475-6773.13229

Chambers, B. D., Arabia, S. E., Arega, H. A., Altman, M. R., Berkowitz, R., Feuer, S. K., Franck, L. S., Gomez, A. M., Kober, K., Pacheco, W. T., Paynter, R. A., Prather, A. A., Spellen, S. A., Stanley, D., Jelliffe, P. L. L., \& McLemore, M. R. (2020). Exposures to structural racism and racial discrimination among pregnant and early post-partum Black women living in Oakland, California. Stress and Health: Journal of the International Society for the Investigation of Stress, 36(2), 213-219. https://doiorg.wvu.idm.oclc.org/10.1002/smi.2922

Chandler, J., \& Shapiro, D. (2016). Conducting clinical research using crowdsourced convenience samples. Annual review of clinical psychology, 12, 53-81. https://doiorg.wvu.idm.oclc.org/10.1146/annurev-clinpsy-021815-093623 
Chatters, L. M., Taylor, R. J., Jackson, J. S., \& Lincoln, K. D. (2008). Religious coping among African Americans, Caribbean Blacks and Non-Hispanic Whites. Journal of Community Psychology, 36(3), 371-386. https://doi-org.wvu.idm.oclc.org/10.1002/jcop.20202

Chittamuru, D., Icard, L. D., Jemmott, J. B., III, \& O’Leary, A. (2018). Prospective predictors of multiple sexual partners among African American men who have sex with men. Archives of Sexual Behavior, 47(7), 2081-2090. https://doi-org.wvu.idm.oclc.org/10.1007/s10508$\underline{018-1207-6}$

Clark, E. M., Williams, B. R., Huang, J., Roth, D. L., \& Holt, C. L. (2018). A longitudinal study of religiosity, spiritual health locus of control, and health behaviors in a national sample of African Americans. Journal of Religion and Health, 57(6), 2258-2278. https://doiorg.wvu.idm.oclc.org/10.1007/s10943-017-0548-0

Cohen, J. (1962). The statistical power of abnormal-social psychological research: A review. The Journal of Abnormal and Social Psychology, 65(3), 145-153. https://doiorg.wvu.idm.oclc.org/10.1037/h0045186

Cohen, J. (1988). Statistical power analysis for the behavioral sciences. Hillsdale, New Jersey: Lawrence Erlbaum Associates.

Cohen, C. J. (2014). Deviance as resistance: A new research agenda for the study of Black politics. In T. L. Anderson (Ed.), Understanding deviance: Connecting classical and contemporary perspectives. (pp. 478-495). Routledge/Taylor \& Francis Group.

Crenshaw, K. (1989) Demarginalizing the intersection of race and sex: A Black feminist critique of antidiscrimination doctrine, feminist theory and antiracist politics. University of Chicago Legal Forum: Vol. 1989, Article 8. https://doi.org/10.4324/9780429500480-5 
Crenshaw, K. (1991). Mapping the margins: intersectionality, identity politics, and violence against women of color. Stanford Law Review, 43(6), 1241-1241. https://doi.org/10.2307/1229039

Creswell, J. W. (2005). Educational research: Planning, conducting, and evaluating quantitative and qualitative research. Pearson Education, Inc

Crocker, J., \& Major, B. (1989). Social stigma and self-esteem: The self-protective properties of stigma. Psychological Review, 96(4), 608-630. https://doiorg.wvu.idm.oclc.org/10.1037/0033-295X.96.4.608

Cyrus, K. (2017). Multiple minorities as multiply marginalized: Applying the minority stress theory to LGBTQ people of color. Journal of Gay \& Lesbian Mental Health, 21(3), 194202. https://doi-org.wvu.idm.oclc.org/10.1080/19359705.2017.1320739

Davis Tribble, B. L., Allen, S. H., Hart, J. R., Francois, T. S., \& Smith-Bynum, M. A. (2019). “No [right] way to be a Black woman”: Exploring gendered racial socialization among Black women. Psychology of Women Quarterly, 43(3), 381-397. https://doiorg.wvu.idm.oclc.org/10.1177/0361684318825439

de Freitas, D. F., Fernandes-Jesus, M., Ferreira, P. D., Coimbra, S., Teixeira, P. M., de Moura, A., Gato, J., Marques, S. C., \& Fontaine, A. M. (2018). Psychological correlates of perceived ethnic discrimination in Europe: A meta-analysis. Psychology of Violence, 8(6), 712-725. https://doi-org.wvu.idm.oclc.org/10.1037/vio0000215

Deci, E. L., \& Ryan, R. M. (2006). Hedonia, eudaimonia, and well-being: An introduction. Journal of Happiness Studies, 9(1), 1-11. https://doiorg.wvu.idm.oclc.org/10.1007/s10902-006-9018-1 
Delacre, M., Lakens, D., \& Leys, C. (2017). Why psychologists should by default use Welch’s ttest instead of Student's t-test. International Review of Social Psychology, 30(1), 92101. http://doi.org/10.5334/irsp.82

Diamond, L. M., \& Lucas, S. (2004). Sexual-minority and heterosexual youths’ peer relationships: Experiences, expectations, and implications for well-being. Journal of Research on Adolescence, 14(3), 313-340. https://doi.org/10.1111/j.15327795.2004.00077.x

Durso, L. E., \& Meyer, I. H. (2013). Patterns and predictors of disclosure of sexual orientation to healthcare providers among lesbians, gay men, and bisexuals. Sexuality Research \& Social Policy: A Journal of the NSRC, 10(1), 35-42. https://doi.org/10.1007/s13178-012$\underline{0105-2}$

English, D., Carter, J. A., Forbes, N., Bowleg, L., Malebranche, D. J., Talan, A. J., \& Rendina, H. J. (2020). Intersectional discrimination, positive feelings, and health indicators among Black sexual minority men. Health Psychology, 39(3), 220-229. https://doiorg.wvu.idm.oclc.org/10.1037/hea0000837

Engstrom, C. M., \& Sedlacek, W. (1997). Attitudes of heterosexual students toward their gay male and lesbian peers. Journal of College Student Development, 38, 565-575.

Ernst, A. F., \& Albers, C. J. (2017). Regression assumptions in clinical psychology research practice - A systematic review of common misconceptions. PeerJ, 5, e3323. https://doi.org/10.7717/peerj.3323

Everett, B. G., Steele, S. M., Matthews, A. K., \& Hughes, T. L. (2019). Gender, race, and minority stress among sexual minority women: An intersectional approach. Archives of 
Sexual Behavior, 48(5), 1505-1517. https://doi-org.wvu.idm.oclc.org/10.1007/s10508$\underline{019-1421-X}$

Faul, F., Erdfelder, E., Lang, A.-G., \& Buchner, A. (2007). GPower 3: A flexible statistical power analysis program for the social, behavioral, and biomedical sciences. Behavior Research Methods, 39(2), 175-191. https://doiorg.wvu.idm.oclc.org/10.3758/BF03193146

Faul, F., Erdfelder, E., Buchner, A., \& Lang, A.-G. (2009). Statistical power analyses using G*Power 3.1: Tests for correlation and regression analyses. Behavior Research Methods, 41, 1149-1160. doi:10.3758/BRM.41.4.1149

Feinstein, B. A., Dyar, C., \& London, B. (2017). Are outness and community involvement risk or protective factors for alcohol and drug abuse among sexual minority women? Archives of Sexual Behavior, 46(5), 1411-1423. https://doi-org.wvu.idm.oclc.org/10.1007/s10508$\underline{016-0790-7}$

Fitchett, G., Murphy, P. E., Kim, J., Gibbons, J. L., Cameron, J. R., \& Davis, J. A. (2004). Religious struggle: Prevalence, correlates, and mental health risks in diabetic, congestive heart failure, and oncology patients. The International Journal of Psychiatry in Medicine, 34(2), 179-196. https://doi.org/10.2190/ucj9-dp4m-9c0x-835m

Forrest-Bank, S. S., \& Cuellar, M. J. (2018). The mediating effects of ethnic identity on the relationships between racial microaggression and psychological well-being. Social Work Research, 42(1), 44-56. https://doi.org/10.1093/swr/svx023

Foster, M., Arnold, E., Rebchook, G., \& Kegeles, S. (2011). “It’s my inner strength”: spirituality, religion and HIV in the lives of young African American men who have sex with 
men. Culture, Health \& Sexuality, 13(9), 1103-1117. https://doiorg.wvu.idm.oclc.org/10.1080/13691058.2011.600460

Friedman, M. R., Bukowski, L., Eaton, L. A., Matthews, D. D., Dyer, T. V., Siconolfi, D., \& Stall, R. (2019). Psychosocial health disparities among black bisexual men in the US: Effects of sexuality nondisclosure and gay community support. Archives of Sexual Behavior, 48(1), 213-224. https://doi-org.wvu.idm.oclc.org/10.1007/s10508-018-1162-2

Frost, D. M., \& Meyer, I. H. (2009). Internalized homophobia and relationship quality among lesbians, gay men, and bisexuals. Journal of Counseling Psychology, 56(1), 97-109. https://doi-org.wvu.idm.oclc.org/10.1037/a0012844

Furukawa, T. A., Kessler, R. C., Slade, T., \& Andrews, G. (2003). The performance of the K6 and K10 screening scales for psychological distress in the Australian National Survey of Mental Health and Well-Being. Psychological Medicine, 33(2), 357-362. https://doiorg.wvu.idm.oclc.org/10.1017/S0033291702006700

Garcia, J., Parker, R. G., Parker, C., Wilson, P. A., Philbin, M., \& Hirsch, J. S. (2016). The limitations of “Black MSM” as a category: Why gender, sexuality, and desire still matter for social and biomedical HIV prevention methods. Global Public Health, 11(7-8), 10261048. https://doi.org/10.4324/9781315151120-15

Garofalo, R., Wolf, R. C., Wissow, L. S., Woods, E. R., \& Goodman E. (1999). Sexual orientation and risk of suicide attempts among a representative sample of youth. Archives of Pediatric Adolescent Medicine, 153, 487- 493. https://doi.org/10.1001/archpedi.153.5.487

Gisladottir, B., Gronfeldt, B., Kristjansson, A. L., \& Sigfusdottir, I. D. (2018). Psychological well-being of sexual minority young adults in Iceland: Assessing differences by sexual 
attraction and gender. Sex Roles: A Journal of Research, 78(11-12), 822-832. https://doi-org.wvu.idm.oclc.org/10.1007/s11199-017-0847-7

Greene, D. C., \& Britton, P. J. (2015). Predicting relationship commitment in gay men: Contributions of vicarious shame and internalized homophobia to the investment model. Psychology of Men \& Masculinity, 16(1), 78- 87. https://doiorg.wvu.idm.oclc.org/10.1037/a0034988

Grill, K. B., Wang, J., Cheng, Y. I., \& Lyon, M. E. (2020). The role of religiousness and spirituality in health-related quality of life of persons living with HIV: A latent class analysis. Psychology of Religion and Spirituality, 12(Suppl 4), 494-504. https://doiorg.wvu.idm.oclc.org/10.1037/rel0000301.supp

Grzanka, P. R., Santos, C. E., \& Moradi, B. (2017). Intersectionality research in counseling psychology. Journal of Counseling Psychology, 64(5), 453-457. https://doi.org/10.1037/cou0000237

Haney, A. M., \& Rollock, D. (2020). A matter of faith: The role of religion, doubt, and personality in emerging adult mental health. Psychology of Religion and Spirituality, 12(Suppl 2), 247-253. https://doi-org.wvu.idm.oclc.org/10.1037/rel0000231.supp

Hart, A. R., Lavner, J. A., Carter, S. E., \& Beach, S. R. H. (2021). Racial discrimination, depressive symptoms, and sleep problems among Blacks in the rural South. Cultural Diversity and Ethnic Minority Psychology, 27(Suppl 1), 123-134. https://doiorg.wvu.idm.oclc.org/10.1037/cdp0000365.supp

Hebl, M. R., \& Dovidio, J. F. (2005). Promoting the "social” in the examination of social stigmas. Personality and Social Psychology Review, 9(2), 156-182. https://doi.org/10.1207/s15327957pspr0902_4 
Heckathorn, D. D. (1997). Respondent-driven sampling: A new approach to the study of hidden populations. Social Problems, 44(2), 174-199. https://doi.org/10.1525/sp.1997.44.2.03x0221m

Herek, G. M. (2009). Hate crimes and stigma-related experiences among sexual minority adults in the United States: Prevalence estimates from a national probability sample. Journal of Interpersonal Violence, 24, 54-74. https://doi.org/10.1177/0886260508316477

Herek, G. M., \& Capitanio, J. P. (1995). Black heterosexuals’ attitudes toward lesbians and gay men in the United States. Journal of Sex Research, 32(2), 95-105. https://doiorg.wvu.idm.oclc.org/10.1080/00224499509551780

Herek, G. M., Cogan, J. C., Gillis, J. R., \& Glunt, E. K. (1998). Correlates of internalized homophobia in a community sample of lesbians and gay men. Journal of the Gay \& Lesbian Medical Assn, 2(1), 17-25.

Herek, G. M., Gillis, J. R., \& Cogan, J. C. (2009). Revised internalized homophobia scale. PsycTESTS Dataset. https://doi.org/10.1037/t10966-000

Herek, G. M., Gillis, J. R., \& Cogan, J. C. (2015). Internalized stigma among sexual minority adults: Insights from a social psychological perspective. Stigma and Health, 1(S), 18-34. https://doi-org.wvu.idm.oclc.org/10.1037/2376-6972.1.S.18.supp

Herek, G., Cogan, J., \& Gillis, J. (2002). Victim experiences in hate crimes based on sexual orientation. Journal of Social Issues, 58, 319-339. https://doiorg.wvu.idm.oclc.org/10.1111/1540-4560.00263

Hernández, R. J., \& Villodas, M. T. (2020). Overcoming racial battle fatigue: The associations between racial microaggressions, coping, and mental health among Chicana/o and 
Latina/o college students. Cultural Diversity and Ethnic Minority Psychology, 26(3), 399-411. https://doi-org.wvu.idm.oclc.org/10.1037/cdp0000306

Hill Collins, P. (1986). Learning from the outsider within: The sociological significance of Black feminist thought. Social Problems, 33(6), S14-S32. https://doiorg.wvu.idm.oclc.org/10.1525/sp.1986.33.6.03a00020

Hill Collins, P., \& Bilge, S. (2020). Intersectionality: Vol. 2nd edition. Polity.

Hope, E. C., Brinkman, M., Hoggard, L. S., Stokes, M. N., Hatton, V., Volpe, V. V., \& Elliot, E. (2021). Black adolescents’ anticipatory stress responses to multilevel racism: The role of racial identity. American Journal of Orthopsychiatry. Advanced Online Publication. https://doi-org.wvu.idm.oclc.org/10.1037/ort0000547

Hurt, T. R., McElroy, S. E., Sheats, K. J., Landor, A. M., \& Bryant, C. M. (2014). Married Black men’s opinions as to why Black women are disproportionately single: A qualitative study. Personal Relationships, 21(1), 88-109. https://doiorg.wvu.idm.oclc.org/10.1111/pere.12019

Irizarry, Y., A., \& Perry, R. K. (2018). Challenging the Black church narrative: Race, class, and homosexual attitudes. Journal of Homosexuality, 65(7), 884-911. https://doi.org/10.1080/00918369.2017.1364566

Isoya, H., \& Yamada, H. (2021). Hidden internet-based measure of discrimination and mental health of Black people. Social Science \& Medicine, 273. Advanced Online Publication. https://doi-org.wvu.idm.oclc.org/10.1016/j.socscimed.2021.113776

Israel, T., Choi, A. Y., Goodman, J. A., Matsuno, E., Lin, Y.-J., Kary, K. G., \& Merrill, C. R. S. (2019). Reducing internalized binegativity: Development and efficacy of an online 
intervention. Psychology of Sexual Orientation and Gender Diversity, 6(2), 149-159. https://doi-org.wvu.idm.oclc.org/10.1037/sgd0000314

Jackson, S. D., Mohr, J. J., Sarno, E. L., Kindahl, A. M., \& Jones, I. L. (2020). Intersectional experiences, stigma-related stress, and psychological health among Black LGBQ individuals. Journal of Consulting and Clinical Psychology, 88(5), 416-428. https://doiorg.wvu.idm.oclc.org/10.1037/ccp0000489

Janssen, D.-J., \& Scheepers, P. (2019). How religiosity shapes rejection of homosexuality across the globe. Journal of Homosexuality, 66(14), 1974-2001. https://doiorg.wvu.idm.oclc.org/10.1080/00918369.2018.1522809

Jones, K., \& Devos, T. (2014). Gay men’s implicit attitudes towards sexual orientation: Disentangling the role of sociocultural influences and social identification. Psychology \& Sexuality, 5(4), 322-338. https://doi.org/10.1080/19419899.2013.790320

Jones, R. M., Simpson, G. M., \& Stansbury, K. (2018). Informal support experiences of older African-American gay men living with HIV/AIDS. Journal of Gay \& Lesbian Social Services: The Quarterly Journal of Community \& Clinical Practice, 30(3), 209-219. https://doi-org.wvu.idm.oclc.org/10.1080/10538720.2018.1463886

Jones, V. N. (2020). Assessing multiple minority stress among African American LGBT women: A review of psychometric scales. Journal of Behavioral \& Social Sciences, 7(3), 206217.

Jones, V. N., Herron, F., Mindrup, R. M., Patterson, D. A., \& Conner, L. R. (2019). Discrimination, stress, variability: What affords Black gay women protection? Journal of Behavioral \& Social Sciences, 6(3), 133-142. 
Joseph, N. T., Peterson, L. M., Gordon, H., \& Kamarck, T. W. (2021). The double burden of racial discrimination in daily-life moments: Increases in negative emotions and depletion of psychosocial resources among emerging adult African Americans. Cultural Diversity and Ethnic Minority Psychology, 27(2), 234-244. https://doiorg.wvu.idm.oclc.org/10.1037/cdp0000337

Kappler, S., Hancock, K. A., \& Plante, T. G. (2013). Roman Catholic gay priests: Internalized homophobia, sexual identity, and psychological well-being. Pastoral Psychology, 62(6), 805-826. https://doi.org/1007/s11089-012-0505-5

Kessler, R. C., Andrews, G., Colpe, L. J., Hiripi, E., Mroczek, D. K., Normand, S.-L. T., Walters, E. E., Zaslavsky, A. M. (2002). Short screening scales to monitor population prevalence and trends in non-specific psychological distress. Psychological Medicine, 32(6), 959976. https://doi.org/10.1017/s0033291702006074

Kessler, R. C., Barker, P. R., Colpe, L. J., Epstein, J. F., Gfroerer, J. C., Hiripi, E., Howes, M. J., Normand, S.-L. T., Manderscheid, R. W., Walters, E. E., \& Zaslavsky, A. M. (2003). Screening for serious mental illness in the general population. Archives of General Psychiatry, 60(2), 184-189. https://doi-org.wvu.idm.oclc.org/10.1001/archpsyc.60.2.184

Kessler, R. C., Green, J. G., Gruber, M. J., Sampson, N. A., Bromet, E., Cuitan, M., Furukawa, T. A., Gureje, O., Hinkov, H., Hu, C.-Y., Lara, C., Lee, S., Mneimneh, Z., Myer, L., OakleyBrowne, M., Posada-Villa, J., Sagar, R., Viana, M. C., \& Zaslavsky, A. M. (2010). Screening for serious mental illness in the general population with the K6 screening scale: Results from the WHO World Mental Health (WMH) survey initiative. International Journal of Methods in Psychiatric Research, 19(Suppl 1), 4-22. https://doiorg.wvu.idm.oclc.org/10.1002/mpr.310 
Kessler, R. C., Mickelson, K. D., \& Williams, D. R. (1999). The prevalence, distribution, and mental health correlates of perceived discrimination in the United States. Journal of Health and Social Behavior, 40(3), 208-230. https://doiorg.wvu.idm.oclc.org/10.2307/2676349

Kim, G., Bryant, A. N., \& Parmelee, P. (2012). Racial/ethnic differences in serious psychological distress among older adults in California. International Journal of Geriatric Psychiatry, 27(10), 1070-1077. https://doiorg.wvu.idm.oclc.org/10.1002/gps.2825

Kim, P. Y. (2017). Religious support mediates the racial microaggressions-mental health relation among Christian ethnic minority students. Psychology of Religion and Spirituality, 9(2), 148-157. https://doi.org/10.1037/rel0000076

Kitzinger, C., \& Wilkinson, S. (1995). Transitions from heterosexuality to lesbianism: The discursive production. Developmental Psychology, 31(1), 95. https://doiorg.wvu.idm.oclc.org/10.1037/0012-1649.31.1.95

Koenig, H. G. (2012). Religion, spirituality, and health: The research and clinical implications. ISRN Psychiatry, 2012, 1-33. https://doi.org/10.5402/2012/278730

Kosciw, J. G., Palmer, N. A., \& Kull, R. M. (2015). Reflecting Resiliency: Openness about sexual orientation and/or gender identity and its relationship to well-being and educational outcomes for LGBT students. American Journal of Community Psychology, 55(1/2), 167-178. https://doi-org.wvu.idm.oclc.org/10.1007/s10464-0149642-6 
Lasser, J., \& Tharinger, D. (2003). Visibility management in school and beyond: A qualitative study of gay, lesbian, bisexual youth. Journal of Adolescence, 26(2), 233-244. https://doi-org.wvu.idm.oclc.org/10.1016/S0140-1971(02)00132-X

Lassiter, J. M. (2016). Religious participation and identity salience of Black men who have sex with men: Findings from a nationally recruited sample. Psychology of Sexual Orientation and Gender Diversity, 3(3), 304-312. https://doiorg.wvu.idm.oclc.org/10.1037/sgd0000176

Lassiter, J. M., Saleh, L., Starks, T., Grov, C., Ventuneac, A., \& Parsons, J. T. (2017). Race, ethnicity, religious affiliation, and education are associated with gay and bisexual men's religious and spiritual participation and beliefs: Results from the One Thousand Strong cohort. Cultural Diversity and Ethnic Minority Psychology, 23(4), 468-476. https://doi.org/10.1037/cdp0000143

Laurencelle, R. M., Abell, S. C., \& Schwartz, D. J. (2002). The relation between intrinsic religious faith and psychological well-being. International Journal for the Psychology of Religion, 12(2), 109-123. https://doi.org/10.1207/s15327582ijpr1202_03

Lefevor, G. T., Boyd-Rogers, C. C., Sprague, B. M., \& Janis, R. A. (2019). Health disparities between genderqueer, transgender, and cisgender individuals: An extension of minority stress theory. Journal of Counseling Psychology, 66(4), 385-395. https://doi.org/10.1037/cou0000339

Levin, J. S., \& Taylor, R. J. (1998). Panel analyses of religious involvement and well-being in African Americans: Contemporaneous vs. longitudinal effects. Journal for the Scientific Study of Religion, 37(4), 695-709. https://doi.org/.2307/1388151 
Levin, K. A. (2006). Study design III: Cross-sectional studies. Evidence-Based Dentistry, 7(1), 24-25. https://doi.org/10.1038/sj.ebd.6400375

Lewis, G. B. (2003). Black-White differences in attitudes toward homosexuality and gay rights. Public Opinion Quarterly, 67, 59-78. https://doi.org/10.1086/346009

Lewis, T. T., \& Van Dyke, M. E. (2018). Discrimination and the health of African Americans: The potential importance of intersectionalities. Current Directions in Psychological Science, 27(3), 176-182. https://doi-org.wvu.idm.oclc.org/10.1177/0963721418770442

Madkour, A. S., Jackson, K., Wang, H., Miles, T. T., Mather, F., \& Shankar, A. (2015). Perceived discrimination and heavy episodic drinking among African-American youth: Differences by age and reason for discrimination. Journal of Adolescent Health, 57(5), 530-536. https://doi-org.wvu.idm.oclc.org/10.1016/j.jadohealth.2015.07.016

Mahowald, L., Sharita Gruberg, S., \& Halpin, J. (2020). The state of the LGBTQ community in 2020 a national public opinion study. Prepared by the Center for American Progress.

\section{LGBTQpoll-report.pdf (americanprogress.org)}

Marquet, M., Chasteen, A. L., Plaks, J. E., \& Balasubramaniam, L. (2019). Understanding the mechanisms underlying the effects of negative age stereotypes and perceived age discrimination on older adults’ well-being. Aging \& Mental Health, 23(12), 1666-1673. https://doi-org.wvu.idm.oclc.org/10.1080/13607863.2018.1514487

Marshall, M. N. (1996). Sampling for qualitative research. Family Practice, 13(6), 522-526. https://doi.org/10.1093/fampra/13.6.522

Mason, T. B., Lewis, R. J., Winstead, B. A., \& Derlega, V. J. (2015). External and internalized heterosexism among sexual minority women: The moderating roles of social constraints 
and collective self-esteem. Psychology of Sexual Orientation and Gender Diversity, 2(3), 313-320. https://doi-org.wvu.idm.oclc.org/10.1037/sgd0000115

McKenzie, B. D., \& Rouse, S. M. (2013). Shades of faith: Religious foundations of political attitudes among African Americans, Latinos, and Whites. American Journal of Political Science, 57, 218-235. https://doi.org/10.1111/j.1540-5907.2012.00611.x

Meanley, S., Pingel, E. S., \& Bauermeister, J. A. (2016). Psychological well-being among religious and spiritual-identified young gay and bisexual men. Sexuality Research \& Social Policy: A Journal of the NSRC, 13(1), 35-45. https://doi.org/10.1111/j.1540$\underline{\text { 5907.2012.00611.x }}$

Meyer, I. H. (1995). Minority stress and mental health in gay men. Journal of Health and Social Behavior, 36(1), 38-56. https://doi-org.wvu.idm.oclc.org/10.2307/2137286

Meyer, I. H. (2003). Prejudice as stress: Conceptual and measurement problems. American Journal of Public Health, 93(2), 262-265. https://doi.org/10.2105/ajph.93.2.262

Modrakovic, D., Way, N., Forssell, S., \& Calabrese, S. K. (2021). Moderating effects of minority stress on the association between adherence to norms of masculinity and psychological well-being in a diverse sample of gay male emerging adults. Psychology of Men \& Masculinities, 22(2), 412-421. https://doi-org.wvu.idm.oclc.org/10.1037/men0000339

Mohr, J., \& Fassinger, R. (2000). Outness Inventory. PsycTESTS Dataset. https://doi.org/10.1037/t07106-000

Molero, F., Recio, P., García-Ael, C., \& Pérez-Garín, D. (2019). Consequences of perceived personal and group discrimination against people with physical disabilities. Rehabilitation Psychology, 64(2), 212-220. https://doiorg.wvu.idm.oclc.org/10.1037/rep0000277 
Molix, L., \& Bettencourt, B. A. (2010). Predicting well-being among ethnic minorities: Psychological empowerment and group identity. Journal of Applied Social Psychology, 40(3), 513-533. https://doi.org/10.1111/j.1559-1816.2010.00585.x

Moore, L. M., Adamczyk, A., Ryan, J. M., \& Ovadia, S. (2021). Shifting religious influences on attitudes towards same-sex behavior and civil liberties: A multilevel across-time analysis. Journal for the Scientific Study of Religion. Advanced Online Publication 1. https://doi-org.wvu.idm.oclc.org/10.1111/jssr.12718

Moore, S., Jones, M., Smith, J. C., Hood, J., Harper, G. W., Camacho-Gonzalez, A., del Rio, C., \& Hussen, S. A. (2019). Homonegativity experienced over the life course by young black gay, bisexual and other men who have sex with men (YB-GBMSM) living with HIV in Atlanta, Georgia. AIDS and Behavior, 23(Suppl 3), 266-275. https://doiorg.wvu.idm.oclc.org/10.1007/s10461-019-02658-7

Moreira-Almeida, A., Koenig, H. G., \& Lucchetti, G. (2014). Clinical implications of spirituality to mental health: Review of evidence and practical guidelines. Revista Brasileira de Psiquiatria, 36(2), 176-182. https://doi.org/10.1590/1516-4446-2013-1255

Morris, J. F., Waldo, C. R., \& Rothblum, E. D. (2001). A model of predictors and outcomes of outness among lesbian and bisexual women. American Journal of Orthopsychiatry, 71(1), 61-71. https://doi.org/0.1037/0002-9432.71.1.61

Mosher, C. M. (2001). The social implications of sexual identity formation and the coming-out process: A review of the theoretical and empirical literature. The Family Journal, 9(2), 164-173. https://doi.org/10.1177/1066480701092011 
Murphy, C. (2015). Lesbian, gay, and bisexual Americans differ from general public in their religious affiliations. http://www.pewresearch.org/fact-tank/2015/05/26/lesbian-gay-andbisexualamericans-differ-from-general-public-in-their-religious-affiliations/

Nadal, K. L. (2019). A decade of microaggression research and LGBTQ communities: An introduction to the special issue. Journal of Homosexuality, 66(10), 1309-1316. https://doi-org.wvu.idm.oclc.org/10.1080/00918369.2018.1539582

Nadal, K. L., Davidoff, K. C., Davis, L. S., Wong, Y., Marshall, D., \& McKenzie, V. (2015). A qualitative approach to intersectional microaggressions: Understanding influences of race, ethnicity, gender, sexuality, and religion. Qualitative Psychology, 2(2), 147-163. https://doi-org.wvu.idm.oclc.org/10.1037/qup0000026

Negy, C., \& Eisenman, R. (2005). A comparison of African American and White college students’ affective and attitudinal reactions to lesbian, gay, and bisexual individuals: An exploratory study. Journal of Sex Research, 42(4), 291-298. https://doi.org/10.1080/00224490509552284

Newman, L.L. (2004). Faith, spirituality, and religion: A model for understanding the differences. The College Student Affairs Journal, 23(2), 102-110. https://files.eric.ed.gov/fulltext/EJ956981.pdf

Nungesser, L. (1983). Homosexual acts, actors, and identities. Praeger.

Ong, A. D., Burrow, A. L., Fuller-Rowell, T. E., Ja, N. M., \& Sue, D. W. (2013). Racial microaggressions and daily well-being among Asian Americans. Journal of Counseling Psychology, 60(2), 188-199. https://doi.org/10.1037/a0031736.supp 
Pager, D., \& Shepherd, H. (2008). The sociology of discrimination: Racial discrimination in employment, housing, credit, and consumer markets. Annual Review of Sociology, 34(1), 181-209. https://doi.org/10.1146/annurev.soc.33.040406.131740

Paine, D. R., Sandage, S. J., Ruffing, E. G., \& Hill, P. C. (2018). Religious and spiritual salience, well-being, and psychosocial functioning among psychotherapy clients: Moderator effects for humility. Journal of Religion and Health, 57(6), 2398-2415. https://doiorg.wvu.idm.oclc.org/10.1007/s10943-018-0612-4

Pascoe, E. A., \& Smart Richman, L. (2009). Perceived discrimination and health: A metaanalytic review. Psychological Bulletin, 135(4), 531-554. https://doi.org/10.1037/a0016059

Peres, M. F. P., Kamei, H. H., Tobo, P. R., \& Lucchetti, G. (2018). Mechanisms behind religiosity and spirituality’s effect on mental health, quality of life and well-being. Journal of Religion and Health, 57(5), 1842-1855. https://doiorg.wvu.idm.oclc.org/10.1007/s10943-017-0400-6

Pew Research Center. (2015). Religious landscape study. Retrieved from http://www.pewforum.org/religious-landscape-study/racial-and-ethnic-composition/

Pew Research Center. (2017). In America, does more education equal less religion?: Overall, U.S. adults with college degrees are less religious than others, but this pattern does not hold among Christians. Retrieved from https://www.pewforum.org/2017/04/26/inamerica-does-more-education-equal-less-religion/

Platt, L. F., \& Lenzen, A. L. (2013). Sexual orientation microaggressions and the experience of sexual minorities. Journal of Homosexuality, 60(7), 1011-1034. https://doi.org/10.1080/00918369.2013.774878 
Polihronakis, C. J. (CJ), Velez, B. L., \& Brewster, M. E. (2021). Bisexual men’s sexual health: A test of minority stress theory. Psychology of Men \& Masculinities, 22( Suppl 1), 201215. https://doi-org.wvu.idm.oclc.org/10.1037/men0000304.supp

Pratt, L. A. (2009). Serious psychological distress, as measured by the K6, and mortality. Annals of Epidemiology, 19(3), 202-209. https://doi.org/10.1016/j.annepidem.2008.12.005

Riggle, E. D. B., Rostosky, S. S., \& Horne, S. G. (2010). Psychological distress, well-being, and legal recognition in same-sex couple relationships. Journal of Family Psychology, 24, 82-86. https://doi.org/10.1037/a0017942

Riggle, E. D. B., Rostosky, S. S., Black, W. W., \& Rosenkrantz, D. E. (2017). Outness, concealment, and authenticity: Associations with LGB individuals’ psychological distress and well-being. Psychology of Sexual Orientation and Gender Diversity, 4(1), 54-62. https://doi.org/0.1037/sgd0000202

Robbins, P. A., Bentley-Edwards, K. L., Blackman Carr, L. T., Conde, E., Van Vliet, R., \& Darity, W. A., Jr. (2020). Shades of Black: Gendered denominational variation in depression symptoms among Black Christians. Psychology of Religion and Spirituality. https://doi-org.wvu.idm.oclc.org/10.1037/rel0000398

Rosenkrantz, D. E., Rostosky, S. S., Riggle, E. D. B., \& Cook, J. R. (2016). The positive aspects of intersecting religious/spiritual and LGBTQ identities. Spirituality in Clinical Practice, 3(2), 127-138. https://doi-org.wvu.idm.oclc.org/10.1037/scp0000095

Rostosky, S. S., Cardom, R. D., Hammer, J. H., \& Riggle, E. D. B. (2018). LGB positive identity and psychological well-being. Psychology of Sexual Orientation and Gender Diversity, 5(4), 482-489. https://doi.org/10.1037/sgd0000298 
Rubinfeld, D. L. (2011). Reference guide on multiple regression. Reference Manual on Scientific Evidence: Third Edition. Washington, DC: The National Academies Press. https://doi.org/10.17226/13163.

Salfas, B., Rendina, H. J., \& Parsons, J. T. (2019). What is the role of the community? Examining minority stress processes among gay and bisexual men. Stigma and Health, 4(3), 300-309. https://doi.org/10.1037/sah0000143

Scheitle, C. P., \& Wolf, J. K. (2017). The religious origins and destinations of individuals identifying as a sexual minority. Sexuality \& Culture, 21(3), 719-740. https://doi.org/10.1007/s12119-017-9417-y

Schmitt, M. T., Branscombe, N. R., Postmes, T., \& Garcia, A. (2014). The consequences of perceived discrimination for psychological well-being: A meta-analytic review. Psychological Bulletin, 140(4), 921-948. https://doi.org/10.1037/a0035754

Skinta, M. D., Fekete, E. M., \& Williams, S. L. (2019). HIV-stigma, self-compassion, and psychological well-being among gay men living with HIV. Stigma and Health, 4(2), 179-187. https://doi.org/10.1037/sah0000133

Sosoo, E. E., Bernard, D. L., \& Neblett, E. W., Jr. (2020). The influence of internalized racism on the relationship between discrimination and anxiety. Cultural Diversity and Ethnic Minority Psychology, 26(4), 570-580. https://doiorg.wvu.idm.oclc.org/10.1037/cdp0000320

Stein, M. (2011). Faith and the practicing analyst. The Journal of Analytical Psychology, 56(3), 397-406. https://doi.org/10.1111/j.1468-5922.2011.01916.x

Stults, C. B., Kupprat, S. A., Krause, K. D., Kapadia, F., \& Halkitis, P. N. (2017). Perceptions of safety among LGBTQ people following the 2016 Pulse nightclub shooting. Psychology of 
Sexual Orientation and Gender Diversity, 4(3), 251-256. https://doiorg.wvu.idm.oclc.org/10.1037/sgd0000240

Sue, D. W., Capodilupo, C. M., Torino, G. C., Bucceri, J. M., Holder, A. M., Nadal, K. L., \& Esquilin, M. (2007). Racial microaggressions in everyday life: Implications for clinical practice. American Psychologist, 62, 271-286. https://doiorg.wvu.idm.oclc.org/10.1037/0003-066X.62.4.271

Sue, D., \& Sue, D. (2008). Counseling the culturally diverse: Theory and practice $\left(5^{\text {th }}\right.$ ed.). Hoboken, John Wiley \& Sons Inc.

Szymanski, D. M. (2005). Heterosexism and sexism as correlates of psychological distress in lesbians. Journal of Counseling and Development, 83, 355-360.

\section{https://doi.org/10.1002/j.15566678.2005.tb00}

Szymanski, D. M., \& Henrichs-Beck, C. (2014). Exploring sexual minority women’s experiences of external and internalized heterosexism and sexism and their links to coping and distress. Sex Roles, 70, 28-42. https://doi.org/10.1007/s11199-013-0329-5

Szymanski, D. M., \& Ikizler, A. S. (2013). Internalized heterosexism as a mediator in the relationship between gender role conflict, heterosexist discrimination, and depression among sexual minority men. Psychology of Men \& Masculinity, 14(2), 211-219. https://doi.org/1010.1037/a0027787

Szymanski, D. M., Ikizler, A. S., \& Dunn, T. L. (2016). Sexual minority women’s relationship quality: Examining the roles of multiple oppressions and silencing the self. Psychology of Sexual Orientation and Gender Diversity, 3(1), 1-10. https://doi.org/10.1037/sgd0000145 
Szymanski, D. M., Kashubeck-West, S., \& Meyer, J. (2008). Internalized heterosexism: A historical and theoretical overview. The Counseling Psychologist, 36(4), 510-524. https://doi.org/10.1177/0011000007309488

Taylor, R. J., Chatters, L. M., \& Jackson, J. S. (2009). Correlates of Spirituality among African Americans and Caribbean Blacks in the United States: Findings from the National Survey of American Life. The Journal of black psychology, 35(3), 317-342. https://doi.org/10.1177/0095798408329947

Taylor, R. J., Forsythe-Brown, I., Mouzon, D. M., Keith, V. M., Chae, D. H., \& Chatters, L. M. (2019). Prevalence and correlates of everyday discrimination among Black Caribbeans in the United States: The impact of nativity and country of origin. Ethnicity \& Health, 24(5), 463-483. https://doi-org.wvu.idm.oclc.org/10.1080/13557858.2017.1346785

Timmins, L., Rimes, K. A., \& Rahman, Q. (2020). Minority stressors, rumination, and psychological distress in lesbian, gay, and bisexual individuals. Archives of Sexual Behavior, 49(2), 661-680. https://doi-org.wvu.idm.oclc.org/10.1007/s10508-019-01502$\underline{2}$

Walch, S. E., Ngamake, S. T., Bovornusvakool, W., \& Walker, S. V. (2016). Discrimination, internalized homophobia, and concealment in sexual minority physical and mental health. Psychology of Sexual Orientation and Gender Diversity, 3(1), 37-48. https://doiorg.wvu.idm.oclc.org/10.1037/sgd0000146

Walker, J. J., \& Longmire-Avital, B. (2013). The impact of religious faith and internalized homonegativity on resiliency for black lesbian, gay, and bisexual emerging adults. Developmental Psychology, 49(9), 1723-1731. https://doi.org/10.1037/a0031059 
Ward, E. G. (2005). Homophobia, hypermasculinity and the US black church. Culture, Health \& Sexuality, 7(5), 493-504. https://doi.org/10.1080/13691050500151248

Warner, L. R., \& Shields, S. A. (2013). The intersections of sexuality, gender, and race: Identity research at the crossroads. Sex Roles, 68(11-12), 803-810. https://doi.org/10.1007/s11199-013-0281-4

Watters, J. K., \& Biernacki, P. (1989). Targeted sampling: Options for the study of hidden populations. Social Problems, 36(4), 416-430. https://doi.org/10.2307/800824

Weber-Gilmore, G., Rose, S., \& Rubenstein, R. (2012). The impact of internalized homophobia on outness for lesbian, gay, and bisexual individuals. The Professional Counselor, 1(3), 163-175. http://doi.org/10.15241/gwv.1.3.163

Wenjian Xu, Lijun Zheng, Yin Xu, \& Yong Zheng. (2017). Internalized homophobia, mental health, sexual behaviors, and outness of gay/bisexual men from Southwest China. International Journal for Equity in Health, 16, 1-10. https://doiorg.wvu.idm.oclc.org/10.1186/s12939-017-0530-1

Wilkerson, J. M., Smolenski, D. J., Brady, S. S., \& Rosser, B. R. S. (2012). Religiosity, internalized homonegativity, and outness in Christian men who have sex with men. Sexual and Relationship Therapy, 27(2), 122-132. https://doi.org/10.1080/14681994.2012.698259

Wilkinson, D. J., \& Johnson, A. (2020). A systematic review of qualitative studies capturing the subjective experiences of Gay and Lesbian individuals’ of faith or religious affiliation. Mental Health, Religion \& Culture, 23(1), 80-95. https://doiorg.wvu.idm.oclc.org/10.1080/13674676.2020.1724919 
Wilkinson, L. (1999). Statistical methods in psychology journals: Guidelines and explanations. American Psychologist, 54(8), 594-604. https://doi.org10.1037/0003-066x.54.8.594

Williams, M., Grajales, C.A., \& Kurkiewicz, D. (2013). Assumptions of multiple regression: Correcting two misconceptions. Practical Assessment, Research and Evaluation, 18, Article 11. https://doi.org/10.7275/55hn-wk47

Wilson, P. A., Wittlin, N. M., Muñoz-Laboy, M., \& Parker, R. (2011). Ideologies of Black churches in New York City and the public health crisis of HIV among Black men who have sex with men. Global Public Health: An International Journal for Research, Policy and Practice, 6(Suppl 2), S227-S242. https://doiorg.wvu.idm.oclc.org/10.1080/17441692.2011.605068

Woodford, M. R., Kulick, A., Sinco, B. R., \& Hong, J. S. (2014). Contemporary heterosexism on campus and psychological distress among LGBQ students: The mediating role of selfacceptance. American Journal of Orthopsychiatry, 84(5), 519-529. https://doi.org/10.1037/ort0000015

Woodford, M. R., Paceley, M. S., Kulick, A., \& Hong, J. S. (2015). The LGBQ social climate matters: Policies, protests, and placards and psychological well-being among LGBQ emerging adults. Journal of Gay \& Lesbian Social Services: The Quarterly Journal of Community \& Clinical Practice, 27(1), 116-141. https://doi.org/10.1080/10538720.2015.990334

Wright, J. E., \& Merritt, C. C. (2020). Social equity and COVID-19: The case of African Americans. Public Administration Review, 80(5), 820-826. https://doiorg.wvu.idm.oclc.org/10.1111/puar.13251 
Xavier, H. C. D., Feinstein, B. A., Sales, J. M., Girod, C., \& Yount, K. M. (2021). Outness, Discrimination, and Depressive Symptoms Among Bi + Women: The Roles of Partner Gender and Sexual Identity. Journal of Bisexuality, 21(1), 24-41. https://doiorg.wvu.idm.oclc.org/10.1080/15299716.2021.1886219

Zapolski, T. C. B., Beutlich, M. R., Fisher, S., \& Barnes-Najor, J. (2019). Collective ethnicracial identity and health outcomes among African American youth: Examination of promotive and protective effects. Cultural Diversity and Ethnic Minority Psychology, 25(3), 388-396. https://doi-org.wvu.idm.oclc.org/10.1037/cdp0000258 


\section{APPENDIX A}

Kessler Psychological Distress Scale (K6)

The following questions ask about how you have been feeling during the past 30 days. For each question, please circle the number that best describes how often you had this feeling.

(1) All of the time, (2) Most of the time, (3) Some of the time, (4) A little of the time, (5) None of the time

Q1. During the past 30 days, about how often did you feel ...?

\begin{tabular}{|l|c|c|c|c|c|}
\hline a. ...nervous? & 1 & 2 & 3 & 4 & 5 \\
\hline b. ...hopeless? & 1 & 2 & 3 & 4 & 5 \\
\hline c. ...restless or fidgety? & 1 & 2 & 3 & 4 & 5 \\
\hline d. ...so depressed that nothing could cheer you up? & 1 & 2 & 3 & 4 & 5 \\
\hline e. ...that everything was an effort? & 1 & 2 & 3 & 4 & 5 \\
\hline f. ... worthless? & 1 & 2 & 3 & 4 & 5 \\
\hline
\end{tabular}

Q2. The last six questions asked about feelings that might have occurred during the past 30 days. Taking them altogether, did these feelings occur more often in the past 30 days than is usual for you, about the same as usual, or less often than usual? (If you never have any of these feelings, circle response option “4.”)

More often than usual (1) A lot, (2) Sometime, (3) A little) (4)About the same as usual Less often than usual (5) A little, (6) Some, (7) A lot

\begin{tabular}{|l|l|l|l|l|l|l|l|}
\hline a. ...nervous? & 1 & 2 & 3 & 4 & 5 & 6 & 7 \\
\hline b. ...hopeless? & 1 & 2 & 3 & 4 & 5 & 6 & 7 \\
\hline c. ...restless or fidgety? & 1 & 2 & 3 & 4 & 5 & 6 & 7 \\
\hline d. ...so depressed that nothing could cheer you up? & 1 & 2 & 3 & 4 & 5 & 6 & 7 \\
\hline e. ...that everything was an effort? & 1 & 2 & 3 & 4 & 5 & 6 & 7 \\
\hline f. ...worthless? & 1 & 2 & 3 & 4 & 5 & 6 & 7 \\
\hline
\end{tabular}

The next few questions are about how these feelings may have affected you in the past 30 days. You need not answer these questions if you answered "None of the time" to all of the six questions about your feelings.

Q3. During the past 30 days, how many days out of 30 were you totally unable to work or carry out your normal activities because of these feelings?

(Number of days)

Q4. Not counting the days, you reported in response to Q3, how many days in the past 30 were you able to do only half or less of what you would normally have been able to do, because of these feelings?

(Number of days)

Q5. During the past 30 days, how many times did you see a doctor or other health professional about these feelings?

(Number of times)

Q6. During the past 30 days, how often have physical health problems been the main cause of these feelings? 
(1) All the time, (2) Most of the time, (3) Some of the time, (4) A little of the time, (5) None of the time Thank you for completing this questionnaire. 


\section{APPENDIX B}

\section{LGBT People of Color Microaggressions Scale}

Permissions: Test content may be reproduced and used for non-commercial research and educational purposes without seeking written permission. Distribution must be controlled, meaning only to the participants engaged in the research or enrolled in the educational activity. Any other type of reproduction or distribution of test content is not authorized without written permission from the author and publisher.

Instructions in the Survey: Think about your life experiences as a lesbian, gay, bisexual, and/or transgender (LGBT) person of color. Answer the questions to the best of your ability.

\section{Items}

1. Not being able to trust White LGBT people

2. Feeling misunderstood by White LGBT people

3. Having to educate White LGBT people about race issues

4. Being the token LGBT person of color in groups or organizations

5. Being told that "race isn't important" by White LGBT people

6. White LGBT people saying things that are racist

7. Not being accepted by other people of your race/ethnicity because you are LGBT

8. Feeling misunderstood by people in your ethnic/racial community

9. Feeling invisible because you are LGBT

10. Difficulty finding friends who are LGBT and from your racial/ethnic background

11. Feeling unwelcome at groups or events in your racial/ethnic community

12. Not having any LGBT people of color as positive role models

13. Being rejected by other LGBT people of your same race/ethnicity

14. Being rejected by potential dating or sexual partners because of your race/ethnicity

15. Being seen as a sex object by other LGBT people because of your race/ethnicity

16. Reading personal ads that say "White people only"

17. Feeling like White LGBT people are only interested in you for your appearance

18. Being discriminated against by other LGBT people of color because of your race

Response Options: 0 - Did not happen/not applicable to me, 1 - It happened to me, and it bothered me NOT AT ALL, 2 - It happened to me, and it bothered me A LITTLE BIT, 3 - It happened to me, and it bothered me MODERATELY, 4 - It happened to me, and it bothered me QUITE A BIT, 5 - It happened to me, and it bothered me EXTREMELY 


\section{APPENDIX C \\ IHP-R Scale Women}

1. I have tried to stop being attracted to women in general.

Disagree strongly

Agree strongly

$\begin{array}{lllll}1 & 2 & 3 & 4 & 5\end{array}$

2. If someone offered me the chance to be completely heterosexual, I would accept the chance.

Disagree strongly

Agree strongly

$\begin{array}{lllll}1 & 2 & 3 & 4 & 5\end{array}$

3. I wish I weren't lesbian/bisexual/queer/etc.

Disagree strongly

Agree strongly

$\begin{array}{lllll}1 & 2 & 3 & 4 & 5\end{array}$

4. I feel that being lesbian/bisexual/queer/etc. is a personal shortcoming for me.

Disagree strongly

Agree strongly

$\begin{array}{lllll}1 & 2 & 3 & 4 & 5\end{array}$

5. I would like to get professional help in order to change my sexual orientation from lesbian/bisexual/queer/etc. to straight.

Disagree strongly

1

Agree strongly

(




\section{APPENDIX D}

\section{IHP-R Scale Men}

1. I have tried to stop being attracted to men in general.

Disagree strongly

12
Agree strongly

$4 \quad 5$

2. If someone offered me the chance to be completely heterosexual, I would accept the chance.

Disagree strongly

Agree strongly

1

2

3

4

5

3. I wish I weren't gay/bisexual/queer/etc.

Disagree strongly

Agree strongly

1

2

3

4

5

4. I feel that being gay/bisexual/queer/etc. is a personal shortcoming for me.

Disagree strongly

Agree strongly

12 3

4

5

5. I would like to get professional help in order to change my sexual orientation from gay/bisexual/queer/etc. to straight.

Disagree strongly

1 


\section{APPENDIX E}

\section{Outness Inventory (OI)}

Use the following rating scale to indicate how open you are about your sexual orientation to the people listed below. Try to respond to all of the items but leave items blank if they do not apply to you. If an item refers to a group of people (e.g., work peers), then indicate how out you generally are to that group.

$1=$ person definitely does NOT know about your sexual orientation status

2 = person might know about your sexual orientation status, but it is NEVER talked about

$3=$ person probably knows about your sexual orientation status, but it is NEVER talked about

$4=$ person probably knows about your sexual orientation status, but it is RARELY talked about $5=$ person definitely knows about your sexual orientation status, but it is RARELY talked about $6=$ person definitely knows about your sexual orientation status, and it is SOMETIMES talked about

7 = person definitely knows about your sexual orientation status, and it is OPENLY talked about $0=$ not applicable to your situation, there is no such person or group of people in my life

1. mother

2. father

3. siblings (sisters, brothers)

4. extended family/relatives

5. my new straight friends

6. my work peers

7. my work supervisor(s)

8. members of my religious community (e.g., church, temple)

9. leaders of my religious community (e.g., church, temple)

10. strangers, new acquaintances

11. my old heterosexual friends

$\begin{array}{llllllll}1 & 2 & 3 & 4 & 5 & 6 & 7 & 0 \\ 1 & 2 & 3 & 4 & 5 & 6 & 7 & 0 \\ 1 & 2 & 3 & 4 & 5 & 6 & 7 & 0 \\ 1 & 2 & 3 & 4 & 5 & 6 & 7 & 0 \\ 1 & 2 & 3 & 4 & 5 & 6 & 7 & 0 \\ 1 & 2 & 3 & 4 & 5 & 6 & 7 & 0 \\ 1 & 2 & 3 & 4 & 5 & 6 & 7 & 0 \\ 1 & 2 & 3 & 4 & 5 & 6 & 7 & 0 \\ 1 & 2 & 3 & 4 & 5 & 6 & 7 & 0 \\ 1 & 2 & 3 & 4 & 5 & 6 & 7 & 0 \\ 1 & 2 & 3 & 4 & 5 & 6 & 7 & 0\end{array}$




\section{APPENDIX F \\ Demographics}

Age

Gender
1. Male
2. Female

Marital Status

1. Single

2. In a committed relationship

3. Married

4. Divorced

5. Widowed

Highest level of education completed

1. Middle school

2. High school/ GED

3. Some college/ Associates degree

4. Bachelor's degree

5. Master's degree

6. Doctoral/ profession degree

Current level of employment

1. Unemployed/ not looking

2. Unemployed/ looking

3. Part-time

4. Full-time

5. Student

6. Disabled

Household income

1. Less than $\$ 25,000$

2. $\$ 25,000$ to $\$ 34,999$

3. $\$ 35,000$ to $\$ 49,999$

4. $\$ 50,000$ to $\$ 74,999$

5. $\$ 75,000$ to $\$ 99,999$

6. $\$ 100,000$ to $\$ 149,999$

7. $\$ 150,000$ or more

To what extent do you agree with this statement: "I consider myself to be a person of faith (religious or spiritual)?”

1. Strongly disagree

2. Disagree

3. Somewhat disagree

4. Somewhat agree

5. Agree

6. Strongly agree

What is your sexual orientation? 

a. Lesbian
b. Gay
c. Bisexual
d. Queer
e. Questioning
f. Pansexual
g. Indicate different answer 


\title{
APPENDIX G
}

\author{
Recruitment
}

\section{Dear Participant,}

This letter is a request for you to take part in a research project to examine the relationship between faith, perceived discrimination, sexuality acceptance, and psychological well-being in Black sexual minorities. Sandra C. Fanning, MS, is conducting this project in the Office of Research Compliance at WVU with the supervision of Dr. Lisa Platt, an assistant professor in the College of Education and Human Services. Your participation in this project is greatly appreciated and will take approximately 15-20 minutes to fill out the attached questionnaire. All participants who complete the study will be awarded a \$5 Amazon gift card.

Your involvement in this project will be kept as confidential as legally possible. All data will be reported in the aggregate. You must identify as Black/ African American, 18 years of age or older, identify as a sexual minority (not heterosexual), and as a binary gender (male or female, non-transgender) to participate. I will not ask any information that should lead back to your identity as a participant. Your participation is entirely voluntary. You may skip any question that you do not wish to answer, and you may discontinue at any time. Your relationship with the university will not be affected if you decide either not to participate or to withdraw. West Virginia University's Institutional Review Board's acknowledgment of this project is on file. In the event that you become distressed while completing the survey, please end the survey immediately and contact The Substance Abuse and Mental Health Services Administration (SAMHSA) Treatment Referral Helpline - 1-877-SAMHSA7 (1-877-726-4727) for general information on mental health and locate treatment services in your area

I hope that you will participate in this research project. Thank you very much for your time. Should you have any questions about this letter or the research project, please feel free to contact Sandra C. Fanning by e-mail at SCF0008@MIX.WVU.EDU, or Dr. Lisa Platt at (304)293-2176 or Lisa.Platt@mail.WVU.EDU.

Thank you for your time and help with this project.

Sincerely, Sandra Fanning 


\section{APPENDIX H}

Example Images of Facebook Pages

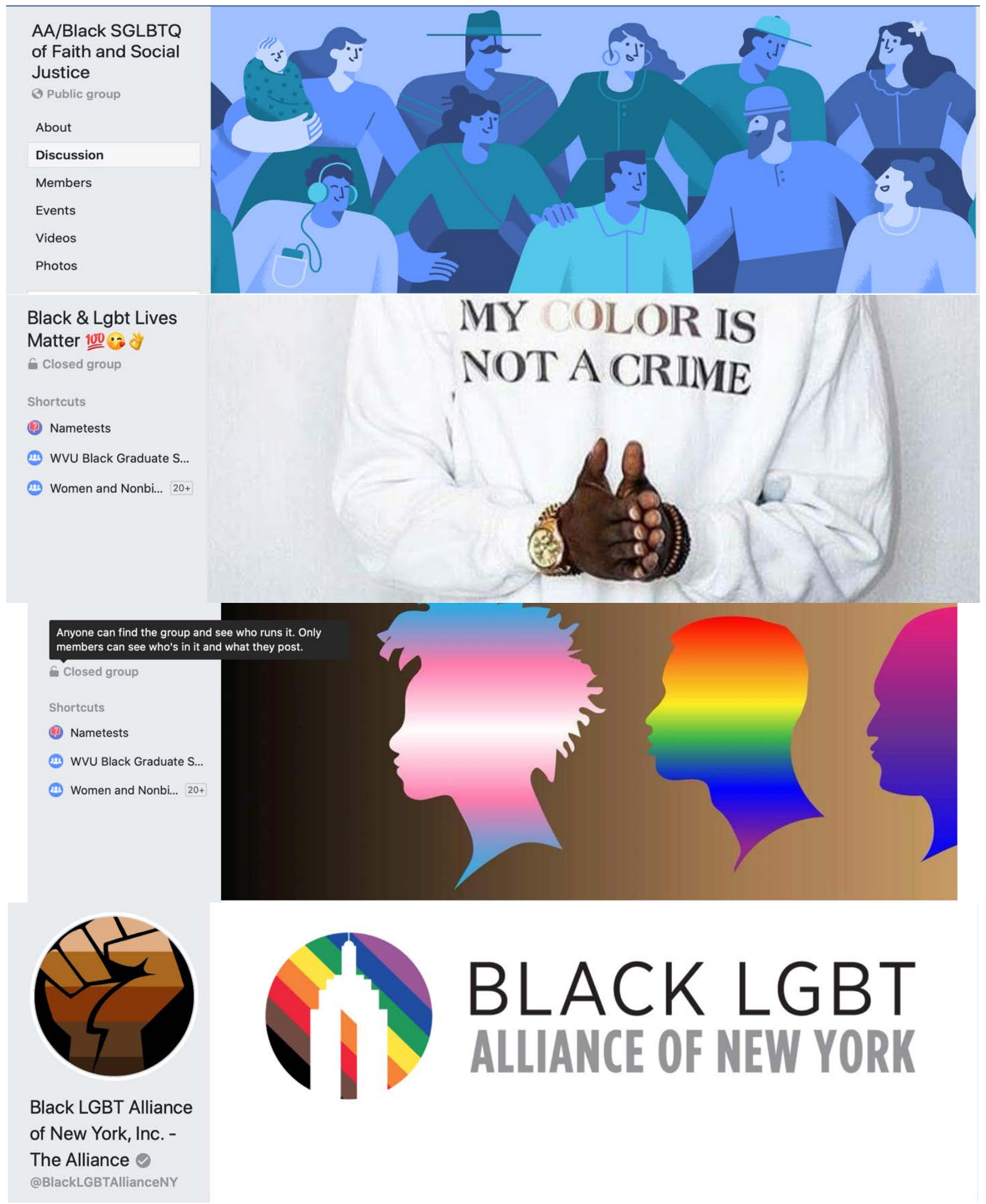




\section{APPENDIX I}

Facebook Advertisements

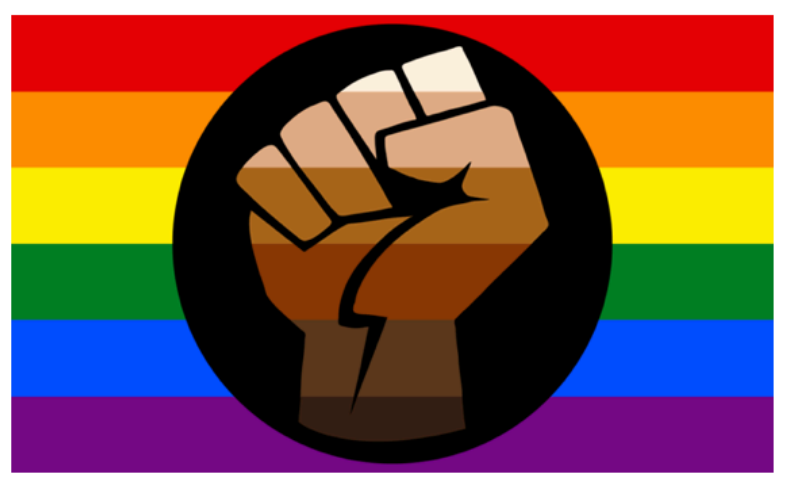

Participants need for a dissertation study assessing the relationship between faith, perceived discrimination, sexuality acceptance, and psychological well-being in Black sexual minorities. All participants who complete will be compensated with a \$5 Amazon gift card. Please the link below for more details.

[Insert Qualtrics link here]

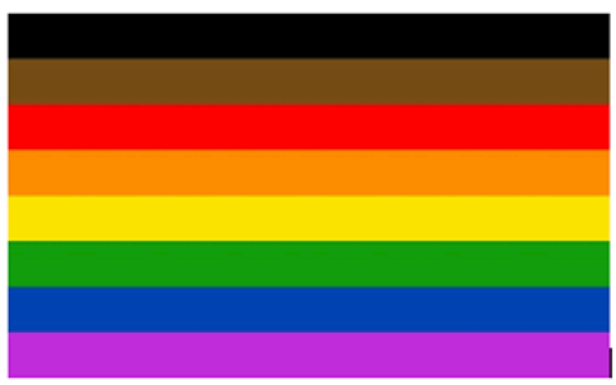

Participants need for a dissertation study assessing the relationship between faith, perceived discrimination, sexuality acceptance, and psychological well-being in Black sexual minorities. All participants who complete will be compensated with a \$5 Amazon gift card. Please the link below for more details.

[Insert Qualtrics link here]

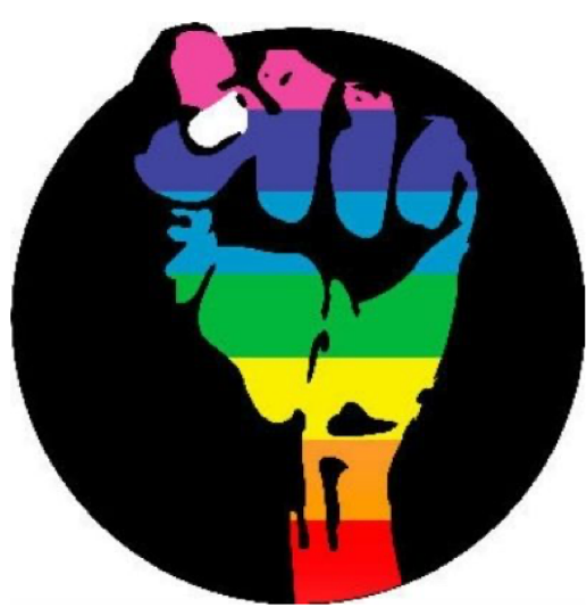

Participants need for a dissertation study assessing the relationship between faith, perceived discrimination, sexuality acceptance, and psychological well-being in Black sexual minorities. All participants who complete will be compensated with a \$5 Amazon gift card. Please the link below for more details.

[Insert Qualtrics link here] 